\title{
SULFATO DE CÁlCIO, FOSFOGESSO E CARBONATO DE CÁLCIO NA MELHORIA DO AMBIENTE RADICULAR DE SUBSOLOS ÁCIDOS
}

\author{
MARIA DA CONCEIÇÃO SANTANA CARVALHO \\ Engenheiro Agrônomo
}

Orientador: Dr. BERNARDO VAN RAIJ

Dissertação apresentada à Escola Superior de Agricultura "Luiz de Queiroz" da Universidade de São Paulo, para obtenção do título de Mestre em Agronomia, Área de Concentração: Solos e Nutrição de Plantas.

PIR A C I C A B A

Estado de São Paulo - Brasil

Novembro - 1994 
Ficha catalogràfica preparada pela Seção de Livros da Divis o de Biblioteca e Documentaçâo - PCLQ/USP

Carvalho, Maria da Conceif o Santana
c331s
na melhoria do ambiente radicular de subsolos ácidos.
Piracicaba, 1994 . $84 p$.

Diss. (Mestre) - ESALQ

Bibliografia.

1. Calagem 2. Carbonato de càlcio em solo 3. Fosfg gesso em solo 4. Milho - Crescimento .5. Milho - NutrL o 6. Solo - Acidez 7. Sulfato de cálcio am solo I. Escola Superior de Agricultura Luiz de Queiroz, Pirac caba 


\title{
SULFATO DE CÁlCIO, FOSFOGESSO E CARBONATO \\ DE CÁLCIO NA IIffiLHORIA DO AMBIENTE \\ RADICULAR DE SUBSOLOS ÁCIDOS
}

\author{
MARIA DA CONCEIÇÃO SANTANA CARVALHO
}

Aprovada em: 20.12.1994

Comissão julgadora:

Dr. Bernardo van Raij

IAC

Dr. Heitor Cantarella

IAC

Prof. Dr. Jorge de Castro Kiehl

ESALQ/USP

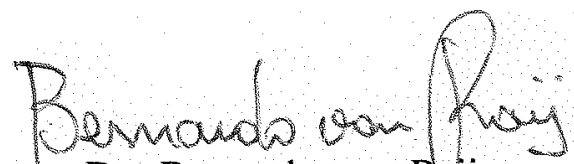

Dr. Bernardo van Raij

Orientador 
Aos meus pais, Antônio e Benedita;

aos meus irmãos, em especial a Gilberto;

aos meus tios e aos meus amigos,

Dário e Nildes

\section{OFEREÇO}

Ao Prof. Dr. Jorge A.G. Santos, meu

orientador no curso de graduação

DEDICO 


\section{AGRADECIMENTOS}

Ao Dr. Bernardo van Raij, por ter-me concedido o privilégio de sua segura orientação, pelo tempo a mim dedicado, pelo estímulo, crédito e pelo exemplo de profissional;

À CAPES, pela concessão da bolsa de estudos;

À Escola Superior de Agricultura "Luiz de Queiroz", em especial ao Prof. Dr. Geraldo Victorino de França, pela oportunidade oferecida;

À Seção de Fertilidade do Solo e Nutrição de Plantas do Instituto Agronômico de Campinas, nas pessoas dos pesquisadores científicos: Dr. Heitor Cantarella, pela cessão dos laboratórios para a realização das análises; Dr. Pedro R. Furlani, pelo fornecimento das sementes e da metodologia para a determinação do comprimento de raízes; Dr. Ronaldo S. Berton, pelas instruções sobre o uso do programa GEOCHEM; Dra. Mônica F. de Abreu e da técnica de apoio Irani F.F. Zanini, pelo valioso auxílio nas análises de laboratório; dos demais pesquisadores, agentes, técnicos e oficiais de apoio, pela simpática acolhida e inúmeras colaborações;

Aos oficiais de apoio do IAC, José A. Nogueira, José L.C. Domingues e José da S. Pinto Filho, pela ajuda na coleta das amostras dos solos;

À Professora Dra. Elke J.B.N. Cardoso e aos técnicos do laboratório de Microbiologia do Solo da ESALQ, Denise e Fernando, pelo apoio logístico durante a condução do experimento em casa de vegetação;

Ao colega Antonio Saraiva Moniz, pelo auxílio ma colheita do experimento;

Aos colegas do curso e aos amigos que encontrei, em especial à Simone, Maria do Rosário, Marcos Cabral, Monalisa, Regina, Sílvia e Giovana por terem tornado mais agradável a minha estada em Piracicaba;

À Clotilde Maria B. Cunha, pela digitação de parte desse trabalho;

À comissão julgadora, pelas correções e sugestões. 


\section{SUMÁRIO}

Página

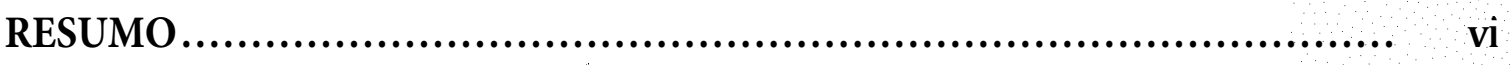

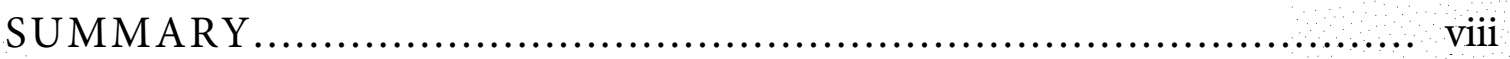

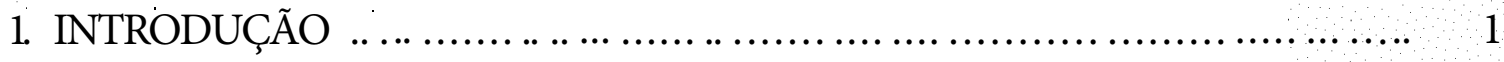

2. REVISÃO DE LITERATURA ............................................. 3

2.1. Acidez do solo e desenvolvimento radicular ............................. 3

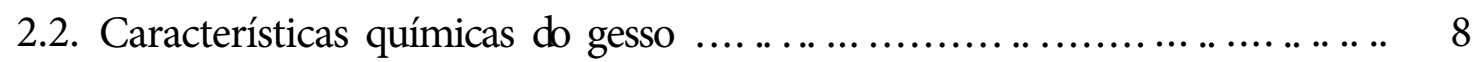

2.3. Efeito da calagem na melhoria do ambiente radicular de subsolos.

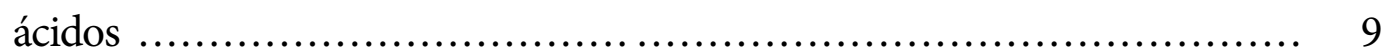

2.4. Efeitos do gesso e do fosfogesso na melhoria do ambiente radicular de subsolos ácidos............, ........................................... 11

2.5. Reações do gesso e do fosfogesso em solos ácidos ........................... 16

2.6. Respostas de culturas à aplicação de gesso e fosfogesso em solos ácidos .......................................................... 19

3. MATERIAL E MÉTODOS …............................................... 22

3. 1. Solos utilizados ..................................................... 22

3.2. Instalação e condução do experimento em casa de vegetação .............. 26

3.3. Determinação do consumo de água pelas plantas ......................... 29

3.4. Determinação do teor de água no subsolo .............................. 29

3.5. Estimativa do comprimento radicular .................................. 29

3.6. Análise química do solo ............................................ 30

3.7. Obtenção e análise do extrato de saturação ............................... 32

3.8. Especiação química da solução do solo (extrato de saturação) ............ 34

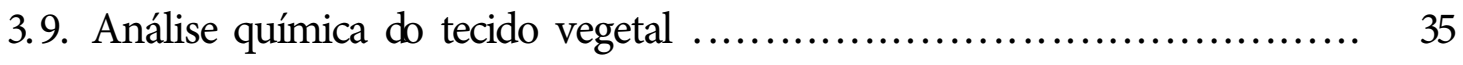

3.10. Análise estatística dos resultados .................................... 35 
4. RESULTADOS E DISCUSSÃO .............................................. 36

4. 1. Efeito dos tratamentos sobre as propriedades dos solos .................. 36

4.1.1. Teor de água nos subsolos no dia da colheita do milho .............. 36

4. 1.2. $\mathrm{pH}, \mathrm{Al}^{3+}$ trocável, $\mathrm{H}^{+}+\mathrm{Al}^{3}+\mathrm{e}$ porcentagem de saturação por $\mathrm{Al}^{3+}, 37$

4.1.3. Cálcio, magnésio e potássio trocáveis, $\mathrm{S}-\mathrm{SO} / \cdot$ e $\mathrm{N}$ mineral ......... 42

4.1.4. Composição química da solução do solo ............................ 47

4.1.5. Especiação química de alumínio e cálcio ma solução do solo ......... 51

4.2. Efeito dos tratamentos no crescimento e absorção de água e nutrientes pelo milho.............................................................. 56

4.2.1. Comprimento radicular ......................................... 56

4.2.2. Consumo de água e produção de matéria seca ....................... 60

4.2.3. Absorção de nutrientes .............................................. 63

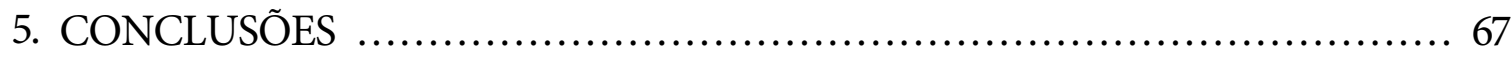

REFERÊNCIAS BIBLIOGRÁFICAS ....................................... 68 


\title{
SULFATO DE CÁLCIO, FOSFOGESSO E CARBONATO \\ DE CÁLCIO NA :MELHORIA DO AIIIBIENTE \\ RADICULAR DE SUBSOLOS ÁCIDOS
}

\author{
Autora: MARIA DA CONCEIÇÃO SANTANA CARVALHO \\ Orientador: Dr. BERNARDO VAN RAU
}

\section{RESUMO}

Um experimento foi conduzido em casa de vegetação, objetivando comparar os efeitos da aplicação de sulfato de cálcio, fosfogesso e carbonato de cálcio sobre a alteração das propriedades das fases sólida e líquida de amostras de subsolo de dois latossolos vermelho-amarelos álicos, dois latossolos roxos ácricos e um latossolo vermelho escuro álico do estado de São Paulo. Avaliaram-se os efeitos dessas alterações sobre o crescimento e a absorção de água e nutrientes pelo milho (Zea mays L.).

Utilizou-se uma técnica de raiz bipartida vertical, en que quatro plantas de milho foram cultivadas inicialmente em um recipiente contendo $130 \mathrm{~g}$ de uma amostra de solo fértil. Quinze dias após a germinação, removeu-se o recipiente e o bloco de terra com as plantas foi introduzido em um vaso preenchido com $2 \mathrm{dm}^{3}$ de amostra de subsolo, que recebeu um dos seguinte tratamentos: sem corretivo, sulfato de cálcio, fosfogesso e carbonato de cálcio, aplicados na dose de $10 \mathrm{mmo} . \mathrm{dm}-{ }^{3}$ de terra, além de $56 \mathrm{mg}$ de N e $78 \mathrm{mg}$ de K Passados mais dezenove dias, as plantas foram colhidas e o subsolo contido nos vasos foi amostrado para determinações do teor de água e do comprimento radicular e para a realização de análise química. 
O sulfato de cálcio e o fosfogesso aumentaram o $\mathrm{pH}$ em cloreto de cálcio e o teor de $\mathrm{Ca}^{2+}$ trocável e reduziram o $\mathrm{Al}^{3+}$ trocável e $\mathrm{o} \mathrm{H}^{+}+\mathrm{Al}^{3+}$, mas em menor proporção que o carbonato de cálcio. Não houve diferença significativa entre o sulfato de cálcio e o fosfogesso quanto a esses efeitos. Os valores de $\mathrm{pH}$ em água diminuíram devido ao efeito do sal na medida do $\mathrm{pH}$.

As amostras de subsolo utilizadas apresentaram severas restrições ao desenvolvimento do sistema radicular do milho. Com a adição dos corretivos o comprimento de raízes aumentou em até $194 \%$ devido à correção da deficiência de cálcio e/ou redução da toxicidade do alumínio. O carbonato de cálcio reduziu a atividade do $\mathrm{Al}^{3+}$ pelo aumento do $\mathrm{pH}$. Nos latossolos ácricos e no latossolo vermelho escuro álico, o sulfato de cálcio e o fosfogesso também provocaram a redução da atividade de $\mathrm{Al}^{3}+$ como resultado do aumento da força iônica da solução e formação do par iônico $\mathrm{AlSO}_{4}+$. No caso do fosfogesso, a formação de complexos de $\mathrm{Al}$ com $\mathrm{F}\left(\mathrm{AlF}^{2+}\right.$ e $\left.\mathrm{AlF}_{2}+\right)$ foi a principal causa da redução da atividade do $\mathrm{Al}^{3}+$. Já nos latossolos vermelhoamarelos álicos, o aumento do comprimento de raízes nos tratamentos com sulfato de cálcio e fosfogesso deveu-se, provavelmente, ao efeito do cálcio em reduzir a toxicidade do alumínio, uma vez que a atividade do $\mathrm{Al}^{3+}$ foi aumentada.

A produção de matéria seca do milho aumentou com a aplicação dos corretivos em todos os solos. Nos latossolos ácricos e no latossolo vermelho escuro, o efeito do calcário foi inferior ao efeito do sulfato de cálcio e do fosfogesso devido à menor _concentração de nutrientes na solução. Nos latossolos vermelho-amarelos álicos não houve diferença entre os corretivos. $\mathrm{O}$ sulfato de cálcio e o fosfogesso foram tão eficazes quanto o carbonato de cálcio en favorecer a absorção de nitrogênio e potássio do subsolo. 


\title{
CALCIUM SULPHATE, PHOSPHOGYPSUM AND CALCIUM CARBONATE IN THE AMELIORATION OF ACID SUBSOILS FOR ROOT GROWTH
}

\author{
Author: MARIA DA CONCEIÇÃO SANTANA CARVALHO
}

Adviser: Dr. BERNARDO VAN RAU

\section{SUMMARY}

A greenhouse experiment was carried out in order to compare the effects of calcium sulphate, phosphogypsum and calcium carbonate on the properties of the solid and liquid phases of soil samples from two alie red-yellow latosols, two acric dusky red latosols and one alie dark red latosol from the state of São Paulo. The effects of change of soil properties on the growth and water and nutrients uptake by com (Zea mays L.) were evaluated.

A vertical split-root technique was used, with four com plants grown inicially in a container with $130 \mathrm{~g}$ of a fertile soil. Fifteen days after germination, the container was removed and the block of soil was introduced in a pot filled up with $2 \mathrm{dm}^{3}$ of the subsoil, which received one of the following treatments: without amendment, calcium sulphate, phosphogypsum and calcium carbonate, applied in a rate of $10 \mathrm{mmo} . \mathrm{dm}^{3}$ soil, as well as $56 \mathrm{mg}$ of $\mathrm{N}$ and $78 \mathrm{mg}$ of $\mathrm{K}$ After 19 days, the plants were harvested and samples taken from the subsoil for chemical analysis and for the determination of water content and root length.

Calcium sulphate and phosphogypsum increased the $\mathrm{pH}$ in calcium chloride and exchangeable $\mathrm{Ca}^{2+}$ and reduced $\mathrm{Al}^{3+}$ and $\mathrm{H}^{+}+\mathrm{Al}^{3+}$, but in smaller proportion when 
compared to calcium carbonate. There was no difference between calcium sulphate and phosphogypsum in that respect. The values of $\mathrm{pH}$ in water decreased due to the salt effect on the determination.

Subsoil samples presented severe restrictions to root development of com. With the additions of the amendments, root length increased up to $194 \%$ due to the correction of calcium deficiency and/or aluminum toxicity. Calcium carbonate reduced the activity of $\mathrm{Al}^{3}$ + due to the $\mathrm{pH}$ increase. In the acric latosols and in the alie dark red latosol calcium sulphate and phosphogypsum also promoted the reduction of the activity of $\mathrm{Al}^{\mathrm{H}}$ as result of the increase of ionic strength of the solution and formation of the ionic pair $\mathrm{AlSO}_{4}+$. In the case of phosphogypsum, the formation of complexes of $\mathrm{Al}$ with $\mathrm{F}\left(\mathrm{AlF}^{2}, \mathrm{AlF}_{2}{ }^{+}\right.$and $\left.\mathrm{AlF}_{3}{ }^{\circ}\right)$ was the main cause of the decrease in $\mathrm{Al}^{\mathrm{H}}$ activity. In the alie red-yellow latosols, the increase in root length observed for the treatments with calcium sulphate and phosphogypsum was due, problaby, to the effect of calcium in alleviating aluminum toxicity, since the activity of $\mathrm{Al}^{3+}$ was increased.

The yield of dry matter by the com plants increased with the application of the amendments to all soils. In the acric latosols and in the alie dark red latosol, the effect of calcium carbonate was inferior to the effect of calcium sulphate and of phosphogypsum due to lower concentration of nutrients in soil solution. In the alie redyellow latosols there was no difference between the amendments. Calcium sulphate and phosphogypsum were as effective as calcium carbonate in promotting the absorption of nitrogen and potassium from the subsoil. 


\section{INTRODUÇÃO}

Sabe-se que as raízes das plantas e, conseqüentemente, a produtividade das culturas, são negativamente afetadas quando a acidez do solo e a saturação por alumínio são muito altas e/ou os teores de cálcio muito baixos.

Com a calagem, resolve-se o problema da acidez na camada superficial. Mas no caso de subsolos ácidos, a calagem não apresenta benefício imediato devido à lentidão com que o calcário se movimenta no perfil.

O uso do gesso como uma possível prática para a melhoria do ambiente radicular das plantas em subsolos ácidos teve início a partir do trabalho publicado por RITCHEY et al. (1980). Foi observado, no Centro de Pesquisa Agropecuária dos Cerrados da EMBRAPA (CPAC), que a aplicação de superfosfato simples, que contém sulfato de cálcio, provocou melhor desenvolvimento do sistema radicular do milho do que a aplicação de superfosfato triplo. Desde então, inúmeros trabalhos têm sido conduzidos sobre esse tema, principalmente no Brasil, Estados Unidos e África do Sul. $\mathrm{O}$ interesse pelo assunto tem se acentuado pela existência de volumosos resíduos de gesso, também chamado de fosfogesso, como subproduto da fabricação de ácido fosfórico.

Embora na maior parte dos casos os resultados do uso do gesso em solos ácidos tenham sido positivos, alguns estudos têm mostrado ausência de resposta, ou mesmo respostas negativas (RAU, 1988; SHAINBERG et al., 1989; ALCORDO \& RECHCIGL, 1993). Esses resultados conflitantes sugerem que o efeito do gesso (ou fosfogesso) na melhoria do ambiente radicular de subsolos ácidos pode depender, dentre outros fatores, das propriedades dos solos em que são feitos os experimentos. Assim, as reações do gesso com diferentes solos necessitam ser melhor estudadas. 
Considerando-se que a ação benéfica do gesso ou do fosfogesso em subsolos ácidos é, em parte, devida ao aumento no teor de Ca, o efeito benéfico adicional na redução da toxicidade do alumínio poderá ser demonstrado comparando o efeito desses materiais com o do carbonato de cálcio, aplicados en doses equivalentes de Ca.

O presente trabalho teve como objetivos:

1) Comparar os efeitos da aplicação de sulfato de cálcio, fosfogesso e carbonato de cálcio sobre as mudanças das propriedades das fases sólida e líquida do solo de cinco amostras de subsolos ácidos do Estado de São Paulo;

2) Avaliar os efeitos dessas mudanças sobre o crescimento e a absorção de nutrientes pelo milho (Zea mays L.), cultivado em vasos. 


\section{REVISÃO DE LITERATURA}

\subsection{Acidez do solo e desenvolvimento radicular}

A acidez dos solos, acompanhada de elevados teores de alumínio e/ou baixos teores de cálcio, afeta negativamente o desenvolvimento radicular e o crescimento das plantas. Solos com elevada acidez, principalmente nas camadas subsuperficiais, são predominantes ma maioria das regiões brasileiras, com destaque para a região dos cerrados (OLMOS \& CAMARGO, 1976; DEMATIÊ, 1981; LOPES, 1983).

A toxicidade devida ao alumínio é o principal fator limitante ao crescimento de plantas em solos ácidos (FOY, 1984). O primeiro sintoma visível de toxicidade é a limitação do crescimento radicular, havendo engrossamento das raízes, inibição do crescimento das raízes laterais e desenvolvimento de coloração marrom (MENGEL \& KIRKBY, 1982; FOY, 1984). Como conseqüência da redução no desenvolvimento do sistema radicular, ocorrem diminuições significativas da absorção de água e nutrientes das camadas subsuperficiais do solo. Com isso, as plantas ficam mais suscetíveis à deficiência hídrica e mineral durante a ocorrência de "veranicos" (MENGEL \& KIRKBY, 1982; FOY, 1984), como os que freqüentemente ocorrem na região dos cerrados brasileiros (SOUZA \& RITCHEY, 1986).

Uma vez que a toxicidade do alumínio é manifestada primariamente por um retardamento no crescimento radicular, as raízes são materiais ideais para estudar o efeito do alumínio do solo sobre o crescimento de plantas. Isso tem sido feito por vários pesquisadores (RIOS \& PEARSON, 1964; ADAMS \& LUND, 1966; BRENES \& PEARSON, 1973; PAVAN et al., 1982; BLAMEY et al., 1983; ALVA et al., 1986a; 
HUE et al,, 1986). ADAMS \& LUND (1966), estudando os efeitos do pH do solo e do Al sobre a penetração de raízes de algodoeiro em três subsolos com características mineralógicas distintas, demonstraram que o desenvolvimento das raízes é limitado principalmente pelo Al.

Vários autores (MENGEL \& KIRKBY, 1982; FOY, 1984; CAMARGO \& FURLANI, 1989; FURLANI \& BERTON, 1992) têm relatado a dificuldade de se definir uma concentração crítica de Al. Essa dificuldade está relacionada com o fato de que, tanto os fatores do meio de crescimento das plantas (solução nutritiva ou solo), tais como $\mathrm{pH}$, força iônica da solução, formação de precipitados insolúveis, presença de quelatos ligantes, formação de pares iônicos, como espécie vegetal ou genótipos da planta, podem atuar na modificação da resposta da planta ao Al. ADAMS \& LUND (1966) mostraram que houve relações distintas entre penetração de raízes de algodoeiro e valores críticos de Al trocável ou saturação de Al de três solos diferentes.

Não é o $\mathrm{Al}^{3+}$ trocável que é tóxico para as plantas, e sim o alumínio na solução (ADAMS, 1984). Por isso, a atividade molar do $\mathrm{Al}^{3+}$ na solução do solo (ou solução nutritiva) tem sido melhor correlacionada com o desenvolvimento radicular de plantas (ADAMS \& LUND, 1966; PAVAN \& BINGHAM, 1982; PAVAN et al., 1982). BRENES \& PEARSON (1973), estudando o crescimento de raízes de três espécies de gramíneas em dois solos ácidos distintos, demonstraram que a atividade do $\mathrm{AI}^{3+}$ foi um bom índice da toxicidade de alumínio para milho e sorgo.

O surgimento dos modelos de especiação iônica via informática, baseados na termodinâmica de soluções, cujos cálculos se tornaram possíveis pelos modernos recursos da informática, a exemplo do GEOCHEM (SPOSITO \& MATTIGOD, 1980), estimulou o estudo da fitotoxicidade das várias espécies iônicas do alumínio.

PAVAN et al. (1982), trabalhando com amostras de seis solos ácidos do Paraná, em um experimento com vasos, demonstraram que a redução no crescimento das raízes do cafeeiro foi melhor correlacionada com a atividade molar do $\mathrm{Al}^{3+}$ $(\mathrm{r}=-0,97)$ do que com a porcentagem de saturação por $\mathrm{Al}(\mathrm{r}=-0.81)$, com a 
concentração do Al total $(\mathrm{r}=-0,82)$ e do $\mathrm{Al}^{3+}$ na solução $(\mathrm{r}=-0,92)$. Os autores demonstraram, também, que os níveis críticos para o $\mathrm{Al}^{3+}$ trocável, para a porcentagem de saturação por alumínio e para as concentrações de $\mathrm{Al}$ total e $\mathrm{AI}^{3+}$ na solução foram diferentes para cada solo estudado, enquanto que o nível crítico da atividade do $\mathrm{Al}^{3+}$ foi de aproximadamente $4 \times 10^{6}$ mol.L- ${ }^{1}$ para os seis solos estudados. Esses resultados confirmaram aqueles obtidos por ADAMS \& LUND (1966), e sugerem que os níveis de Al tóxico, expressos em mmol.dm- ${ }^{3}$ de terra, são diferentes para cada tipo de solo e espécie de planta.

Da mesma forma, PAVAN \& BINGHAM (1982) observaram que o crescimento da parte aérea e das raízes de plântulas de cafeeiro, em solução nutritiva, foi mais afetado com o aumento da atividade do $\mathrm{Al}^{3+}$ do que com o aumento da concentração do Al total na solução. Resultados semelhantes têm sido relatados para outras espécies, tanto em solo como em solução nutritiva (CAMERON et al., 1986; SHUMMAN et al., 1990).

Alguns autores (BLAMEY et al., 1983; ALVA et al., 1986b,c) mostraram que a redução do desenvolvimento radicular de soja foi melhor correlacionada com a soma das concentrações ou atividades das espécies monoméricas de $\mathrm{Al}\left[\mathrm{Al}^{3+}, \mathrm{Al}(\mathrm{OH}) 2^{+}\right.$, $\left.\mathrm{Al}(\mathrm{OH}) 2^{+}, \mathrm{Al}(\mathrm{OH}) 3^{\circ}\right]$ do que com cada espécie isolada. Entretanto, ALVA et al. (1986d) encontraram altas correlações entre o crescimento de raízes de alfafa, girassol e trevo e a atividade das espécies $\mathrm{Al}(\mathrm{OH})^{2+}$ ou $\mathrm{Al}(\mathrm{OH})$ /. Por outro lado, PARKER et al. (1988) demonstraram que não só as espécies monoméricas, mas também a espécie polimerizada de $\mathrm{Al}_{13}$ causou efeito fitotóxico no crescimento das raízes de trigo.

$\mathrm{O} \mathrm{Al}^{3+}$ na solução do solo em presença de SO/- forma a espécie iônica AlSO/ (PAVAN et al., 1982; KINRAIDE \& PARKER, 1987; NOBLE et al., 1988b; ALVA \& SUMNER, 1989). CAMERON et al. (1986) e NOBLE et al. (1988a,b) demonstraram que as raízes parecem não ser afetadas negativamente pelo complexo $\mathrm{AlSO4}_{4}$. Além disso, $\mathrm{o} \mathrm{AlSO}_{4}{ }^{+}$também contribui para a diminuição da atividade do $\mathrm{AB}^{+}$, conforme dados discutidos por FURLANI \& BERTON (1992). 
A importância da força iônica da solução do solo e/ou solução nutritiva em influenciar a fitotoxicidade do Al solúvel tem sido relatada em vários trabalhos. PAVAN \& BINGHAM (1982) verificaram que, para níveis constantes de Al total na solução, o aumento da força iônica provocou a diminuição da atividade do $\mathrm{Al}^{3+}$.

FURLANI \& BERTON (1992), analisando os resultados de vários trabalhos publicados, envolvendo diferentes espécies vegetais com tolerância diferencial ao $\mathrm{Al}$, concluíram que as alterações na força iônica podem dar resultados positivos quando a espécie ou cultivar apresenta relativa tolerância ao Al. Segundo os autores, no caso de plantas muito sensíveis ao $\mathrm{Al}$, as diminuições da atividade de $\mathrm{AB}^{+}$, induzidas pelo aumento da força iônica da solução, não são suficientes para reverter a ação fitotóxica do $\mathrm{Al}$, pois há necesssidade de reduzir a atividade do $\mathrm{Al}^{3+}$ para valores muito baixos.

Não só a elevada saturação de alumínio restringe o crescimento radicular, mas também a deficiência de Cana solução do solo. O Ca é de fundamental importância para a permeabilidade da membrana e para a manutenção da integridade da célula vegetal (MENGEL \& KIRKBY, 1982). O cálcio apresenta apenas movimento ascendente na planta, não sendo translocado da parte aérea para as extremidades das raízes. Sendo assim, a presença do Caem um meio é essencial para que as raízes se desenvolvam nele. RIOS \& PEARSON (1964), trabalhando com algodoeiro em solução nutritiva, em um sistema de raízes divididas, observaram que o desenvolvimento de raízes na porção da solução deficiente em Ca, foi prejudicado. Usando um sistema similar, Canal1, citado por RITCHEY et al. (1983), demonstrou que o crescimento de raízes de milho na solução pobre em Ca (0,2 mg.L-1), foi 2,6 vezes menor do que o observado na solução rica em Ca.

A deficiência de Ca é uma importante limitação nutricional nos solos brasileiros (MALAVOLTA et al., 1979; RITCHEY et al., 1982). RITCHEY et al.

1 CANAL, J. N. Parâmetros de absorção de potássio e translocação de cálcio em milho (Zea mays L.), afetados pela interação alumínio-cálcio. Porto Alegre, 1980. 85p. (Mestrado - Universidade Federal do Rio Grande do Sul). 
(1982) demonstraram que a penetração das raízes de trigo, soja e milho em subsolos ácidos altamente intemperizados do cerrado foi limitada mais pela deficiência de $\mathrm{Ca}$ do que pela toxicidade do $\mathrm{Al}$.

Usando um método biológico, visando estimar a relação entre o crescimento de raízes e o teor de cálcio trocável em solos, RITCHEY et al. (1983) consideraram que os teores de cálcio trocável no solo, abaixo da faixa de 0,2 a 0,5 $\mathrm{mmol}_{\mathrm{c}} \cdot \mathrm{kg}^{1}$ (4 a $10 \mathrm{mg} \cdot \mathrm{kg}^{-}{ }^{1}$ ) impediram o crescimento de raízes de trigo. Por outro lado, RITCHEY et al. (1982) demonstraram que a adição de apenas 1,0 a 1,5 mmol $_{c} \cdot \mathrm{kg}^{-1}(\mathrm{O}, 1$ a $\mathrm{O}, 15$ meq.100 $\mathrm{g}^{1}$ ) de $\mathrm{Ca}$ no solo na forma de cloreto, fosfato ou carbonato foram suficientes para normalizar o crescimento de raízes de plântulas de trigo, milho e soja em subsolos ácidos do cerrado.

Existem evidências do efeito do $\mathrm{Ca}$ na diminuição da toxicidade do $\mathrm{Al}$ (ALVAetal., 1986a,c; KINRAIDE\&PARKER, 1987; FURLANI\&BERTON, 1992). Esse efeito tem sido atribuído à redução na atividade de espécies fitotóxicas de Al através do aumento da força iônica da solução, ou efeito fisiológico direto do cálcio na superfície da raiz.

Visando estimar o efeito de Ca e Al conjuntamente sobre o crescimento radicular, NOBLE et al. (1988a) propuseram uma expressão chamada balanço Ca-Al $(\mathrm{CAB}): \mathrm{CAB}=\left[2 \log \mathrm{aCa}^{2+}\right]-\left[3 \log \mathrm{aAl}^{3+}+2 \log \mathrm{aAl}(\mathrm{OH})^{2+}+\log \mathrm{aAl}(\mathrm{OH})_{2}^{+}\right]$, onde $\mathrm{a}=$ atividade

O índice $\mathrm{CAB}$ teve uma boa correlação $(\mathrm{r}=0,88)$ com o crescimento de raízes de soja (NOBLE et al., 1988b).

SHAMSHUDDIN et al. (1991), em um experimento de campo, demonstraram que as produções relativas de milho e amendoim foram positivamente correlacionadas com a relação $\mathrm{Cal} \mathrm{Al}$ da solução do solo, na camada de $0-15 \mathrm{~cm}$. 
2.2. Características químicas do gesso

$\mathrm{O}$ sulfato de cálcio $\left(\mathrm{CaSO}_{4} \cdot 2 \mathrm{H}_{2} 0\right)$ está disponível para o uso na agricultura como produto obtido da mineração, conhecido como gesso, ou como subproduto de processos industriais, chamado fosfogesso (ALCORDO \& RECHCIGL, 1993).

O termo "fosfogesso" tem sido mundialmente aceito. Entretanto, no Brasil existe uma certa preferência pelo "gesso agrícola" que é ambíguo, pois tanto o gesso de mineração como o obtido como subproduto da indústria pode ser utilizado para fins agrícolas.

O fosfogesso é proveniente da reação de ácido sulfúrico sobre rocha fosfatada, para produzir ácido fosfórico (RAIJ, 1988; MALAVOLTA, 1992). A representação simplificada dessa reação é:

$\mathrm{Ca}_{10}\left(\mathrm{PO}_{4}\right)_{6} \mathrm{~F}_{2}+10 \mathrm{H}_{2} \mathrm{SO}_{4}+20 \mathrm{H}_{2} \mathrm{O} \ldots-\cdots 10 \mathrm{CaSO}_{4} .2 \mathrm{H}_{2} \mathrm{O}+6 \mathrm{H}_{3} \mathrm{PO}_{4}+2 \mathrm{HF}$

Trata-se, essencialmente, de fosfato de cálcio dihidratado $\left(\mathrm{CaSO}_{4} \cdot 2 \mathrm{H}_{2} \mathrm{O}\right)$ com pequenas proporções de $\mathrm{P}, \mathrm{F}, \mathrm{Si}, \mathrm{Fe}, \mathrm{Al}$ e outros elementos como impurezas (PAOLINELLI etal., 1986, MALAVOLTA, 1992; ALCORDO \& RECHCIGL, 1993; SHAINBERG et al., 1989).

Uma análise típica do fosfogesso foi apresentada por PAOLINELLI et al. (1986):

Umidade livre $15,5 \%$

$\mathrm{Ca} 0 \ldots \ldots \ldots \ldots \ldots \ldots \ldots \ldots \ldots . . . . . . . . . . . . . . . .30,9 \%$

S. $17,7 \%$

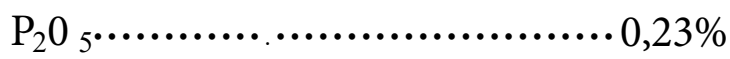

$\mathrm{Si}_{2}$ (resíduo insolúvel) ........... 3,20\%

F............................ 0,67\%

$\mathrm{R}_{2} \mathrm{O}_{3}\left(\mathrm{Al}_{2} \mathrm{O}_{3}+\mathrm{FeiO}_{3}\right) \ldots \ldots \ldots \ldots . . ., 39 \%$ 
A composição química teórica do $\mathrm{CaSO}_{4} \cdot 2 \mathrm{H}_{2} \mathrm{O}$ p.a. é de $32,5 \%$ de $\mathrm{CaO}$ e $18,9 \%$ de S. A solubilidade em água é de aproximadamente 2,5 g.L-1, a $25{ }^{\circ} \mathrm{C}$ (SHAINBERG et al., 1989). É um sal neutro e dissocia-se na solução conforme representado a seguir (DONNER \& LYNN, 1977):

$$
\mathrm{CaSO}_{4} \cdot 2 \mathrm{H}_{2} \mathrm{O}==^{\prime \prime} \mathrm{ca}^{+2}+\mathrm{XSO} /+(1-\mathrm{X}) \mathrm{CaSO} /+2 \mathrm{H}_{2} \mathrm{O}
$$

Existe um grande interesse em se utilizar o gesso obtido como subproduto da indústria do ácido fosfórico, tanto no Brasil (FREITAS, 1992) como em muitas outras regiões do mundo, por questões ambientais e econômicas (SHAINBERG et al., 1989; ALCORDO \& RECHCIGL, 1993; SUMNER, 1993). De acordo com PAOLINELLI et al. (1986), o fosfogesso é produzido na proporção de 4 a 5 toneladas para cada tonelada de $\mathrm{P}_{2} \mathrm{O}_{5}$ do ácido fosfórico. A produção média anual do fosfogesso, no Brasil, é de cerca de 2,4 milhões de toneladas (PAOLINELLI et al., 1986; FREITAS, 1992).

\subsection{Efeito da calagem na melhoria do ambiente radicular de subsolos ácidos}

A calagem é uma prática já consagrada para aumentar o $\mathrm{pH}$ e corrigir a acidez na camada arável do solo. No caso de subsolos ácidos, diversos autores demonstraram que a calagem em doses elevadas também pode reduzir a acidez nas camadas subsuperficiais (QUAGGIO, 1982, 1985, 1992; RAIJ et al., 1982; SOUZA \& RITCHEY, 1986). Entretanto, o efeito benéfico do calcário incorporado superficialmente pode ser demorado, o que é atribuído à baixa solubilidade e mobilidade do calcário no perfil (ALCORDO \& RECHCIGL, 1993). SOUZA \& RITCHEY (1986) demonstraram que foi possível reduzir a acidez de um latossolo vermelho escuro argiloso a uma profundidade de até $60 \mathrm{~cm}$ com calcário. Para tanto, porém, foram necessários oito anos e doses superiores a 7,5 tha- $^{1}$. Em solos de textura média e arenosa o tempo para esta correção é menor. 
De acordo com os resultados apresentados por QUAGGIO et al. $(1982,1985)$ e RAIJ et al. (1982), é possível que o tempo para que o efeito da calagem seja manifestado, em profundidade, não seja tão longo. QUAGGIO et al. (1982), em um experimento conduzido em latossolo roxo distrófico de cerrado, verificaram que a aplicação de 6 tha- ${ }^{1}$ de calcário elevou os teores de $\mathrm{Ca}+\mathrm{Mg}$ e o pH em água, a $50 \mathrm{~cm}$ de profundidade, após 30 meses. Em outro experimento, num Cambissolo álico, QUAGGIO et al. (1985) observaram que em 12 meses, 12 tha- ${ }^{-1}$ de calcário elevaram os teores de $\mathrm{Ca}+\mathrm{Mg}$ em cerca de 15,0 mmolc.dm- $\left(1,5\right.$ meq.100 $\left.\mathrm{cm}^{-3}\right)$ a uma profundidade de $50 \mathrm{~cm}$.

$\mathrm{O}$ efeito da calagem melhoria do ambiente radicular de subsolos ácidos nem sempre é constatado, mesmo com aplicação de doses elevadas. MESSICK et al. (1984) relataram que não houve efeito de até 13,4 tha- ${ }^{-1}$ de calcário na acidez do subsolo de sete solos da Virgínia (EUA). RAIJ et al. (1994) não verificaram efeito de 8, 1 tha- $^{1}$ de calcário na redução da acidez do subsolo de um latossolo roxo distrófico, acidificado por adubações, mesmo após 38 meses.

Deve-se ressaltar, entretanto, que calagens em doses muito altas, com o objetivo de promover a redução da acidez do subsolo, podem causar efeitos deletérios nas propriedades físico-químicos dos solos, como por exemplo, dispersão de argila (JUCKSCH, 1987). RAIJ (1991) registrou a preocupação existente com calagens mais elevadas, relacionadas com efeitos depressivos sobre as produções. Tais efeitos negativos são associados geralmente às deficiências de potássio, zinco, boro e manganês, quando as adubações não são adequadas.

Por outro lado, vários trabalhos têm demonstrado que a incorporação de calcário em profundidade aumenta a proliferação de raízes no subsolo, e, conseqüentemente, a produção das culturas (GONZALEZ-ERICO et al., 1979; SUMNER et al., 1986; FARINA \& CHANNON, 1988a). Contudo, a incorporação profunda de calcário é uma operação cara, e, portanto, inviável economicamente (RAIJ, 1988; SHAINBERG et al., 1989; SUMNER, 1992). 
Diante do exposto acima, o uso do gesso, principalmente aquele obtido como subproduto da indústria de ácido fosfórico (fosfogesso), aplicado na superfície ou incorporado superficialmente, para promover a melhoria do ambiente radicular de subsolos ácidos, é uma prática que tem recebido atenção em várias regiões do mundo (RAU, 1988; SHAINBERG etal., 1989; ALCORDO \& RECHCIGL, 1993; SUMNER, 1992; SUMNER, 1993).

\subsection{Efeitos do gesso e do fosfogesso na melhoria do ambiente radicular de subsolos ácidos}

Confome citam SHAINBERG et al. (1989), as primeiras pesqmisas envolvendo o uso do gesso, como melhorador do ambiente radicular do subsolo, foram realizadas no início da década de 70 ma África do Sul, destacando-se o trabalho de REEVE \& SUMNER (1972). Porém, só a partir do trabalho realizado no Brasil por RITCHEY et al. (1980), no Centro de Pesquisa Agropecuária dos Cerrados EMBRAPA - é que o interesse pelo gesso aumentou.

RITCHEY et al. (1980) observaram que os solos de vários experimentos de campo, conduzidos na região do cerrado, amostrados após 3 a 4 anos da aplicação de superfosfato simples, mostraram aumentos no $\mathrm{pH}$ e nos teores de $\mathrm{Ca}$ e $\mathrm{Mg}$ do subsolo e diminuição dos teores e das saturações por $\mathrm{Al}$ na profundidade de até $90 \mathrm{~cm}$. As raízes das plantas de milho cultivado na área que recebeu superfosfato simples aprofundaram-se até $120 \mathrm{~cm}$, e as plantas não apresentaram sintomas de murcha durante a ocorrência de um "veranico". Já na área fertilizada com superfosfato triplo as raízes se aprofundaram apenas até $45 \mathrm{~cm}$ e as plantas apresentaram sintomas de murcha. O efeito do superfosfato simples foi atribuído à presença do gesso $\left(\mathrm{CaSO}_{4} \cdot 2 \mathrm{H}_{2} 0\right)$. Desde então, inúmeras pesquisas têm sido conduzidas, principalmente no Brasil, Estados Unidos e África do Sul. 
Informações mais completas sobre o uso de gesso na agricultura encontram-se nas revisões feitas por RAIJ (1988), SHAINBERG et al. (1989), ALCORDO \& RECHCIGL (1993), SUMNER (1993), em SEMINÁRIO SOBRE O USO DE FOSFOGESSO NA AGRICULTURA (1986) e SEMINÁRIO SOBRE O USO DE GESSO NA AGRICULTURA (1992).

Os efeitos benéficos do gesso na melhoria do ambiente radicular de subsolos ácidos, permitindo maior absorção de água e nutrientes pelas raízes, têm sido demonstrados em diversos trabalhos (RAIJ, 1988; SHAINBERG et al., 1989; SUMNER, 1992; ALCORDO \& RECHCIGL, 1993; SUMNER, 1993). Tais efeitos são geralmente atribuídos ao aumento dos teores de Ca trocável e em solução e à diminuição da atividade do $\mathrm{Al}^{3+}$ na solução.

Os efeitos do gesso sobre o $\mathrm{pH}$ do solo têm sido contraditórios, tanto em condições de campo como em laboratório e casa de vegetação (SHAINBERG et al., 1989; ALCORDO \& RECHCIGL, 1993; SUMNER, 1993). Aumentos no pH do solo após a aplicação de gesso foram reportados por RITCHEY et al., (1980), SOUZA \& RITCHEY (1986), FARINA \& CHANNON (1988b), RAIJ et al. (1988), CHAVES et al. (1988), SILVA \& RAIJ (1992), PAVAN (1993), ISMAIL et al. (1993), RAIJ et al. (1994). Outros autores (BLACK \& CAMERON, 1984; PAVAN et al. 1982,1984; PAVAN, 1993) reportaram que houve decréscimo do $\mathrm{pH}$. Por outro lado, KIEHL \& FRANCO (1984), OATES \& CALDWELL (1985), SUMNER et al. (1986) e PAVAN (1993) ão observaram mudanças no $\mathrm{pH}$ de alguns solos tratados com gesso.

PAVAN (1993), trabalhando com amostras de vinte solos ácidos cujos teores de Al trocável variaram de $\mathrm{O}$ a $39,3 \mathrm{mmol}_{\mathrm{c}} \cdot \mathrm{kg}_{-}{ }^{1}$, observaram dois efeitos distintos do gesso sobre a reação dos solos: 1) um leve aumento no $\mathrm{pH}$, para solos sem ou com teores muito baixos de $\mathrm{Al}$ trocável $\left(<0,9 \mathrm{mmol}_{\mathrm{c}} \cdot \mathrm{kg}_{-}{ }^{1}\right)$; e 2) um pequeno decréscimo no $\mathrm{pH}$ de solos com teores maiores de Al trocável.

De maneira geral, a magnitude da mudança no $\mathrm{pH}$ do solo com a aplicação do gesso, quando ocorre, é da ordem de 0,2 a 0,3 unidade. Em alguns casos, porém, 
os aumentos são um pouco mais acentuados (RITCHEY et al., 1980; SILVA \& RAIJ, 1992). RITCHEY et al. (1980) observaram aumentos no pH.de um latossolo vermelho escuro de até 0,8 unidades após o tratamento com gesso tanto em colunas de solo como em condições de campo. SILVA \& RAIJ (1992) compararam os efeitos de continuadas aplicações de superfosfato triplo e de superfosfato simples em um latossolo roxo distrófico, por um período de 17 anos, e verificaram aumentos de até 0,9 unidades no $\mathrm{pH}$ do subsolo devido ao gesso contido no superfosfato simples.

RAIJ et al. (1988) avaliaram o efeito na reação do solo, da absorção de amónio e nitrato pelo sorgo, na presença e na ausência de gesso. Os autores concluíram que o gesso reduziu a acidez do solo tanto na presença como na ausência das formas de nitrogênio. A absorção de nitrogênio pelo sorgo também ocasionou alteração na reação do solo, ocorrendo aumento na acidez pela absorção de amónio e diminuição pela absorção de nitrato, o que torna evidente a importância de se considerar a influência do nitrogênio na alteração da acidez dos solos em estudos envolvendo gesso.

A redução da toxicidade do $\mathrm{Al}$ em subsolos através do uso de gesso é resultado de um ou mais dos seguintes mecanismos: 1) ação de "autocalagem", que envolve a polimerização ou precipitação do alumínio como resultado da liberação de Off, devido à troca de ligantes entre $\mathrm{SO} / \mathrm{e} \mathrm{Of}^{\mathrm{f}}$ (REEVE \& SUMNER, 1972; SUMNER et al., 1986; ALVA et al., 1991); 2) reações de precipitação com formação de sulfatos básicos de Al (HUE et al., 1985; ALVA et al., 1990, 1991; PAVAN, 1993;

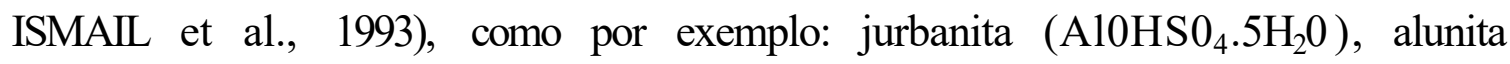
[KAliOH)iSO $\left.{ }_{4}\right)_{2}$ e basaluminita [AliOH) ${ }_{10} \mathrm{SO}_{4} .5 \mathrm{H}_{2} \mathrm{O}$ ]; 3) formação de pares iônicos, como $\mathrm{AlSO}_{4}+$ (PAVAN et al., 1982; SINGH, 1982; CAMERON et al., 1986; NOBLE et al., 1988a; McLAY \& RITCHIE, 1993), e $\mathrm{AF}^{2+}$ (no caso do fosfogesso), que são menos tóxicas do que outras espécies não complexadas de $\mathrm{Al}$ (CAMERON et al., 1986; ALVA et al., 1988; ALVA \& SUMNER, 1989); 4) redução na atividade do $\mathrm{Al}^{3+} \mathrm{em}$ solução, devido ao aumento da força iônica da solução do solo (ADAMS \& LUND, 1966; PAVAN et al., 1987; FURLANI \& BERTON, 1992); e 5) adsorção de $\mathrm{Al}^{1+}$ e 
$\mathrm{H}^{+}$, preferencialmente ao $\mathrm{Ca}^{2+}$, nas cargas negativas criadas pela adsorção específica de SO/ (SUMNER, 1993).

Muitos trabalhos têm sido conduzidos com o objetivo de avaliar o efeito da aplicação de gesso ou fosfogesso sobre a composição química da solução do solo (PAVAN et al., 1982, 1984; RAIJ, 1988; SHAINBERG et al., 1989; CHAVES et al., 1991; FURLANI \& BERTON, 1992; SUMNER, 1993; ISMAIL et al., 1993, entre outros). Em resumo, os resultados têm demonstrado que: 1) algumas vezes, mas nem sempre, ocorre um pequeno aumento do pH (SHAMSHUDDIN et al., 1991; CHAVES, 1991; ISMAIL et al., 1993); 2) a concentração de Al total geralmente é aumentada, na forma do complexo solúvel $\mathrm{AlSO}^{+}$e/ou Al-F (no caso do fosfogesso); 3) a concentração e a atividade do $\mathrm{Al}^{3+}$ sempre diminuem; 4) em todos os casos, a concentração e a atividade de $\mathrm{Ca}^{2+}$ aumenta marcadamente; e 5) a força iônica aumenta, invariavelmente.

PAVAN et al. (1987) mostraram que o gesso agrícola aumentou a força iônica do extrato de saturação e diminuiu a atividade do $\mathrm{Al}^{3+}$ de um Cambissolo, resultando em maior proliferação de raízes de macieira.

ISMAIL et al. (1993), trabalhando com amostras de um ultisol e de um oxisol da Malásia, em experimento com vasos, observaram que o gesso aumentou o $\mathrm{pH}$ da solução do solo no oxisol, o que foi atribuído à liberação de $\mathrm{OH}$ como resultado da troca de ligantes entre $\mathrm{SO} / \cdot$ e OH . nas superfícies dos óxidos de Fe e/ou Al. Reportaram também que houve redução do $\mathrm{Al}$ trocável em ambos os solos estudados, devido à formação de alunita. Os resultados da especiação química da solução do solo, em ambos os solos, mostraram que, no tratamento com gesso, houve predominância das espécies $\mathrm{AP}^{+}$e $\mathrm{AlSO4}+$, sendo que a espécie $\mathrm{AlSO}_{4}^{+}$aumentou com a elevação das quantidades de gesso aplicadas.

Em experimentos conduzidos em laboratório, PAVAN (1993) avaliou a influência do sulfato de cálcio e outros sulfatos sobre as características químicas de um grupo de solos brasileiros altamente intemperizados. Os resultados mostraram que o 
sulfato de cálcio causou diminuições no $\mathrm{Al}^{3+}$ trocável em todos os solos, o que foi atribuído à formação de sulfatos básicos de alumínio, insolúveis em extratos de $\mathrm{KCl}$ 1 mol.L-1 - Houve aumento na concentração de Al total na solução do solo, mas a concentração de $\mathrm{Al}^{3+}$ diminuiu devido à formação do complexo AlSO4+. A indução do SO / na redução do Al trocável ocorre no máximo em 24 horas, permanecendo inalterada por um período de pelo menos 360 dias.

$\mathrm{O}$ fosfogesso parece ser mais efetivo em reduzir a toxicidade do Al do que o sulfato de cálcio puro devido à presença do $\mathrm{F}$, que forma complexos mais estáveis com o Al do que o SO/- (OATES \& CALDWELL, 1985; CAMERON et al., 1986). OATES \& CALDWELL (1985), em experimento conduzido em casa de vegetação, demonstraram que plantas de soja se desenvolveram melhor nos tratamentos com fosfogesso em comparação com o sulfato de cálcio puro.

MOORE \& RITCHIE (1988) demonstraram que o fluoreto de potássio adicionado a uma amostra de solo ácido, causou significativa redução da concentração de $\mathrm{Al}^{3+}$ em solução devido à formação de complexo com F. ALVA et al. (1988) verificaram que, em uma amostra solo tratado com fosfogesso, aproximadamente $90 \%$ do Al estavam complexados com F, embora tenha havido aumento na concentração de Al total na solução.

Com relação aos cátions básicos $(\mathrm{Ca}, \mathrm{Mg}$ e $\mathrm{K})$, tem sido observado que o $\mathrm{Ca}$ trocável aumenta de modo praticamente uniforme no perfil, enquanto que $\mathrm{Mg}$ e $\mathrm{K}$, em muitos casos, são deslocados da camada arável para o subsolo (SOUZA \& RITCHEY, 1986; SHAINBERG et al., 1989; FARINA \& CHANNON, 1988b; QUAGGIO, 1992; VITTI et al., 1992).

$\mathrm{O}$ movimento de $\mathrm{Mg}$ e $\mathrm{K}$ para as camadas subsuperficiais do solo é devido à substituição destes cátions pelo $\mathrm{Ca}$ nos sítios de troca, sendo o $S O t$ o ânion acompanhante nessa movimentação. Contudo, deve-se considerar que a aplicação de gesso cria condições favoráveis para que as raízes penetrem no subsolo e absorvam esses elementos nas camadas mais profundas do solo, não constituindo, assim, em perdas. 
SOUZA et al. (1992) reportaram que a aplicação de 6 tha- ${ }^{-1}$ de gesso em um latossolo vermelho escuro argiloso não provocou a alteração nos teores de $\mathrm{K}^{+}$, a uma profundidade de até $120 \mathrm{~cm}$, após cinco cultivos. Maiores cuidados, contudo, são necessários quando se trata de solos muito arenosos, onde a velocidade de movimentação é maior que nos solos argilosos (SOUZA \& RITCHEY, 1986; QUAGGIO, 1992).

$\mathrm{O} \mathrm{SO} /$ é removido da camada arável e se acumula nas camadas subsuperficiais (SOUZA \& RITCHEY, 1986; SHAINBERG et al., 1989; SOUZA et al., 1992). A quantidade adsorvida depende das características mineralógicas do solo e do pH (COUTO et al., 1979; HUE et al., 1985; CAMARGO \& RAIJ, 1989).

\subsection{Reações do gesso e do fosfogesso em solos ácidos}

Após a aplicação de gesso em solos ácidos, ocorrem diversas reações de adsorção, troca de cátions, precipitação e dissolução, resultando em mudanças no pH, CTC, atividade de íons livres em solução e formação de pares iônicos de metais com SO/- e p-, no caso de fosfogesso (SINGH, 1982; PAVAN \& VOLKWEISS, 1986; SHAINBERG et al., 1989; ALVA \& SUMNER, 1990; ALVA et al., 1990; RAIJ, 1992; ALCORDO \& RECHICGL, 1993; SUMNER, 1993). Por outro lado, as alterações nas características químicas do subsolo e as respostas de culturas em função da aplicação de gesso e fosfogesso têm sido altamente variáveis em diferentes solos. Isso sugere que as propriedades dos solos influenciam os mecanismos de reação desses produtos. Nesse aspecto, a propriedade de troca de íons, resultante da existência de cargas elétricas no solo, tem um papel fundamental, pois o efeito desses produtos depende primariamente das reações na superfície das partículas do solo (ALVA \& SUMNER, 1990).

Com relação à propriedade de troca de íons, os solos de cargas variáveis têm importância especial para o uso de gesso, principalmente no que se refere à adsorção de $\mathrm{S}_{4} 4^{2}$. A expressão "solos de cargas variáveis" é usada para representar os solos cujos componentes posssuem cargas dependentes do $\mathrm{pH}$ (caulinita, óxidos de Fe e Ale matéria 
orgânica). Destes componentes, os mais importantes, em se tratando do uso de gesso, são os óxidos de Fe e Al, por terem comportamento anfótero, isto é, podem desenvolver cargas negativas e positivas em suas superfícies, dependendo do $\mathrm{pH}$ do meio (UEHARA \& GILLMAN, 1981; RAIJ, 1986). O desenvolvimento de cargas elétricas na superfície desses materiais é consequência do mecanismo de protonação e desprotonação (UEHARA \& GILLMAN, 1981): com o aumento do pH do meio ocorre a dissociação de $\mathrm{H}^{+}$da superfície, gerando cargas negativas, e com a diminuição do $\mathrm{pH}$ o $\mathrm{H}^{+}$é adsorvido à superfície, produzindo cargas positivas. RAIJ \& PEECH (1972) demonstraram que as cargas elétricas negativas e positivas podem variar em função da concentração de eletrólitos e da valência dos íons trocáveis, além de poderem coexistir simultaneamente.

Dois mecanismos têm sido descritos para explicar a adsorção de SO/- em solos com predominância de cargas variáveis (GILLMAN, 1991; RAIJ, 1992): 1) adsorção eletrostática à superfície carregada positivamente; e, 2) adsorção específica, ou troca de ligantes, pela substituição de $\mathrm{OH}$ - da superfície dos óxidos de $\mathrm{Fe}$ e/ou $\mathrm{Al}$ por So/-. No segundo caso, a liberação do O R causaria um aumento no $\mathrm{pH}$ do meio. Entretanto, segundo RAIJ (1992), as hidroxilas formadas podem reagir com $\mathrm{H}^{+}$ dissociado e também liberar cargas negativas, ocorrendo a formação de cargas positivas e negativas ao mesmo tempo.

Assim, reações de solos em resposta à aplicação de gesso são diferentes, dependendo da magnitude dos componentes de carga variável e da mineralogia do solo, conforme tem sido verificado por vários autores (YAMADA, 1988; ALVA \& SUMNER, 1990; NOGUEIRA \& MOZETO, 1990; ALVA et al., 1991).

CAMARGO \& RAIJ (1989) realizaram estudo com colunas de terra procurando avaliar a influência das cargas elétricas líquidas de um latossolo roxo ácrico e de um latossolo vermelho-amarelo sobre a lixiviação dos íons $\mathrm{Ca}^{2+}$ e $\mathrm{SO} /$. Observaram que o $\mathrm{Ca}^{2+}$ era mais retido em solos com $\mathrm{pH}$ mais alto e que com o $\mathrm{SO} /$ acontecia o contrário, indicando que a adsorção de $\mathrm{SO} /$ deve estar ligada também à formação de carga positiva nos colóides do solo. 
A possibilidade de cargas negativas e positivas ocorrerem simultaneamente no subsolo, conforme foi demonstrado por RAU \& PEECH (1972), é particularmente importante no caso do uso de gesso, podendo ocorrer adsorção simultânea de $\mathrm{Ca}^{2}+\mathrm{e}$ SO/-. ALVA et al. (1990) não observaram mudança no $\mathrm{pH}$ da solução do solo tratado com sulfato de cálcio e fosfogesso. Para explicar o fato, os autores sugeriram a existência de um balanço entre: (1) efeito do sal, em que a adição de um cátion $\left(\mathrm{Ca}^{2+}\right.$ no caso) induz à dissociação de próton e AI trocável do complexo de troca, causando decréscimo no $\mathrm{pH}$; e, (2) liberação de $\mathrm{OH}$ - como resultado das reações de troca de ligantes entre $\mathrm{Off}$ e SO/-. Segundo os autores, o efeito da liberação de $\mathrm{OH}$ devido à troca de ligantes foi anulado pelo efeito do sal, resultando em nenhum aumento líquido do $\mathrm{pH}$ da solução do solo deslocada pelas soluções de sulfato de cálcio e fosfogesso. Mais tarde, ALVA et al. (1991) relataram a ocorrência de adsorção de $\mathrm{Ca}^{2+}$ e SO/- sem ter ocorrido liberação líquida de cátions e ânions para a solução dos solos tratados com sulfato de cálcio e fosfogesso, evidenciando a adsorção do sal $\left(\mathrm{CaSO}_{4}\right)$.

ALVA \& SUMNER (1990) avaliaram o efeito da aplicação de fosfogesso sobre as características químicas de três solos da Georgia (EUA) com diferentes características mineralógicas. Os autores observaram que os efeitos de "autocalagem" do fosfogesso foram mais acentuados nos solos com características de carga variável do que naqueles com predominância de esmectita (minerais de argila do tipo 2: 1, que apresentam cargas elétricas negativas permanentes, resultantes da substituição isomórfica de $\mathrm{Si}^{4+}$ por $\mathrm{Al}^{3+}$ na camada tetraédrica ou de $\mathrm{Al}^{3+}$ por $\mathrm{Mg}^{2+}$ na camada octaédrica), com elevado teor de $\mathrm{Al}^{3+}$ trocável $\left(76,2 \mathrm{mmol}_{\mathrm{c}} \cdot \mathrm{kg}^{-}{ }^{-}\right)$

YAMADA (1988), em trabalho sobre adsorção máxima de sulfato pelo solo, estudou os efeitos de doses de gesso aplicado a amostras de diferentes solos no comprimento de raízes de plântulas de trigo. Foi observado que nos solos podzolizados, com elevados teores de $\mathrm{Al}^{3+}$, o gesso não favoreceu o desenvolvimento das raízes. Já nos latossolos com menores teores de $\mathrm{Al}^{3+}\left(1,0\right.$ a $\left.13,9 \mathrm{mmol}_{\mathrm{c}} \cdot \mathrm{dm}^{-}\right)$e/ou deficiência de Ca houve efeitos positivos. Uma possível explicação para a falta de resposta nos solos 
podzolizados, segundo o autor, estaria nos elevados teores de $\mathrm{Al}^{3+}$ apresentados pelas

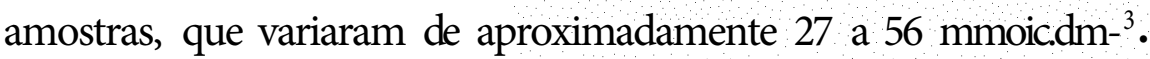

Uma outra reação possível de ocorrer nos solos tratados com gesso, que leva à redução do Al trocável, é a precipitação de fases sólidas, devido à formação de sulfatos básicos de alumínio (SUMNER, 1993; PAVAN, 1993; ISMAIL et al., 1993), que são estáveis quando o $\mathrm{pH}$ do meio é menor que 4,5 (SHAINBERG et al., 1989; SUMNER, 1993).

\subsection{Respostas de culturas à aplicação de gesso e fosfogesso em solos ácidos}

Aumentos de produção de diversas culturas (café, cana-de-açúcar, milho, trigo, feijão etc) em resposta à aplicação de gesso e fosfogesso em solos ácidos do Brasil, África do Sul e Estados Unidos foram reportados por SHAINBERG et al. (1989), SUMNER (1992), SUMNER (1993), ALCORDO \& RECHCIGL (1993), e em

SEMINÁRIO SOBRE O USO DE GESSO NA AGRICULTURA (1992). De uma maneira geral, as respostas positivas são relacionadas ao aumento no teor de Ca e/ou redução da toxicidade do $\mathrm{Al}$ no subsolo. Por outro lado, em alguns casos, os aumentos de produções têm sido atribuídos ao efeito nutritivo do Ca e do S (VITTI et al., 1992; SOUZA et al., 1992).

É possível que a resposta de culturas à aplicação de gesso em solos com acidez subsuperficial deva-se principalmente à maior absorção de $\mathrm{N}_{3^{-}}$do subsolo. SOUZA \& RITCHEY (1986) reportaram que, em um experimento com milho irrigado, a aplicação de 6 tha- $^{-1}$ de gesso favoreceu a distribuição do sistema radicular do milho, o que resultou em absorção de $44 \mathrm{~kg}_{\mathrm{h}} \mathrm{a}^{-1}{ }^{1}$ de $\mathrm{N}$ a mais do que no tratamento sem gesso. Essa quantidade era bem próxima daquela encontrada no perfil do solo na parcela que não foi tratada com gesso. Resultados semelhantes foram relatados por SOUZA et al. (1992) em experimento com trigo. 
Com relação ao sistema radicular, vários autores (RITCHEY et al., 1980; SOUZA \& RITCHEY, 1986; CARVALHO et al., 1986; PAVAN et al, 1987; ALVA \& SUMNER, 1990; CHAVES, 1991) têm demonstrado que o gesso tem promovido o aumento na proliferação de raízes de diferentes culturas em subsolos ácidos, em função da melhoria nas condições químicas. Como resultado do aumento no desenvolvimento do sistema radicular, a absorção de água e nutrientes do subsolo é significativamente aumentada, tornando as plantas menos suscetíveis à deficiência hídrica e mineral durante a ocorrência de períodos curtos de estiagem, como os que ocorrem, por exemplo, na região do cerrado brasileiro.

Em experimento com milho, conduzido em um latossolo vermelho escuro com saturação por $\mathrm{Al}$ de $70 \%$ e saturação por $\mathrm{Ca}$ de $12 \%$ na profundidade de 20 a 60 $\mathrm{cm}$, SOUZA et al. (1992) observaram que o efeito do gesso sobre a produtividade foi mais pronunciado quando se induziu o déficit hídrico. Os efeitos no aumento da produção, em condições de déficit hídrico, foram associados a um maior aprofundamento das raízes e maior absorção de água e nutrientes. Os teores de $\mathrm{N}, \mathrm{P}$, $\mathrm{Ca}, \mathrm{Gu}$ e Mn no tecido foliar aumentaram com as doses de gesso. Mesmo quando não houve déficit hídrico a produção nos tratamentos com gesso foi aumentada quando comparada ao solo sem tratamento.

Por outro lado, alguns trabalhos demonstraram a ausência de efeito ou mesmo efeito negativo do gesso sobre o crescimento radicular (SHAINBERG, 1989; ALCORDO \& RECHCIGL, 1993). WRIGHT et al. (1985) reportaram que a lixiviação de gesso para o subsolo não teve efeito no crescimento de raízes de cevada, embora o Al trocável tenha sido reduzido.

McLAY \& RITCHIE (1993), realizando experimento em vasos com amostras de subsolos ácidos, observaram que o gesso promoveu aumento de até $50 \%$ na produção de matéria seca da parte aérea de plantas de trigo, mas a matéria seca e o comprimento das raízes decresceram em comparação com o solo que não recebeu tratamento. 
Contudo, foram observados aumentos na concentração de $\mathrm{Ca}, \mathrm{Mg}, \mathrm{S}, \mathrm{P}$ e K no tecido vegetal, indicando que a medida do crescimento radicular, apenas, pode ser insuficiente para avaliar a resposta de culturas à aplicação de gesso em solos ácidos. 


\section{MATERIAL E MÉTODOS}

\section{1. Solos utilizados}

Amostras de solo foram coletadas do horizonte B de cinco latossolos ácidos do Estado de Sao Paulo, sendo retiradas próximo dos perfis utilizados para a classificação dos solos nos levantamentos pedológicos semidetalhados do Estado de São Paulo, realizados por OLIVEIRA et al. (1979) e OLIVEIRA \& PRADO (1987). Optouse por subsolos que continham acima de 300 g.kg- ${ }^{1}$ de argila, baixos teores de $\mathrm{Ca}^{2+}$ ( $\left.3,0 \mathrm{mmol}_{\mathrm{c}} \cdot \mathrm{dm}^{-}{ }^{3}\right)$ contendo ou não $\mathrm{Al}^{3+}$ trocável. A classificação dos solos e o número dos perfis, próximo dos quais as amostras de terra foram coletadas, encontram-se na Tabela 1. Na Tabela 2 são apresentados a composição granulométrica e os valores dos índices $\mathrm{Ki}$ e $\mathrm{Kr}$ nos horizontes em que as amostras foram coletadas.

Após a coleta, as amostras foram secas ao ar e peneiradas (malha de $2 \mathrm{~mm}$ ). Subamostras foram tomadas para caracterização química $\left(\mathrm{pH} \mathrm{em} \mathrm{H}_{2} 0\right.$, em $\mathrm{CaCl}_{2}$ e em $\mathrm{KCl} 1$ mol.L- ${ }^{1} ; \mathrm{Ca}^{2+}, \mathrm{Mg}^{2+}, \mathrm{K}^{+}, \mathrm{Al}^{3}+, \mathrm{H}^{+}+\mathrm{Al}^{3+}, \mathrm{S}-\mathrm{SO} /-,{\mathrm{N}-\mathrm{NH}_{4}{ }^{+} \text {e } \mathrm{N}-\mathrm{NO}_{3}-\text {. }}^{-} \mathrm{Os}$ resultados dessas análises encontram-se na Tabela 3, e os métodos analíticos utilizados serão descritos no ítem 3.6. 
Tabela 1 - Classificação dos solos utilizados e número dos perfis, próximo dos quais as amostras de subsolo foram coletadas.

\begin{tabular}{llll}
\hline Solo & \multicolumn{1}{c}{ Classificação - Município } & Perfil & Fonte \\
\hline LVál-1 & $\begin{array}{l}\text { Latossolo vermelho-amarelo álico, textura } \\
\text { argilosa - Campinas, SP }\end{array}$ & 1392 & Oliveira et al. (s.d.) \\
\hline LRác-1 & $\begin{array}{l}\text { Latossolo roxo ácrico, textura muito argilosa, } \\
\text { unidade Capão da Cruz - Ribeirão Preto, SP }\end{array}$ & 1348 & OLIVEIRA \& PRADO (1987) \\
LRác-2 & $\begin{array}{l}\text { Latossolo roxo ácrico, textura argilosa, unidade } \\
\text { Jardinópolis - Jardinópolis, SP }\end{array}$ & 1350 & OLIVEIRA \& PRADO (1987) \\
& $\begin{array}{l}\text { Latossolo vermelho escuro álico, textura argilosa, } \\
\text { unidade Santo Antônio - Cosmópolis, SP }\end{array}$ & 1173 & OLIVEIRA et ai. (1979) \\
LVál-2 & $\begin{array}{l}\text { Latossolo vermelho-amarelo álico, textura } \\
\text { argilosa, unidade Mato Dentro - Cosmópolis, SP }\end{array}$ & 1193 & OLIVEIRA et ai. (1979) \\
\hline \hline
\end{tabular}

${ }^{1}$ OLIVEIRA, J.B.; MENK, J.R.F.; NIESTEN, B; JONG VAN LIER, Q. Levantamento pedológico detalhado do Centro Experimental de Campinas. Campinas, IAC, s.d. (não publicado). 
Tabela 2 - Composição granulométrica e valores dos índices $\mathrm{Ki}$ e $\mathrm{Kr}$ dos solos, nos horizontes em que as amostras foram coletadas (retirados de OLIVEIRA et al., 1979; OLIVEIRA \& PRADO, 1987 e Oliveira et al., s.d. ${ }^{1}$.

\begin{tabular}{|c|c|c|c|c|c|}
\hline \multirow{2}{*}{ Parâmetros } & \multicolumn{5}{|c|}{ Solos } \\
\hline & LVál-1 & LRác-1 & LRác-2 & LEál & LVál-2 \\
\hline Horizonte & $\mathbf{B W}_{1}$ & B 1 & B 21 & B 21 & B 1 \\
\hline Profundidade $(\mathrm{cm})$ & $50-93$ & $55-85$ & $58-100$ & $50-97$ & $52-102$ \\
\hline \multicolumn{6}{|c|}{ Composição granulométrica (g.kg- ${ }^{1}$ ) } \\
\hline Areia & 540 & 110 & 300 & 360 & 570 \\
\hline Silte & 130 & 210 & 180 & 60 & 30 \\
\hline Argila & 330 & 680 & 520 & 580 & 400 \\
\hline Índice $\mathrm{Ki}$ & 2,3 & 0,9 & 0,3 & 1,6 & 1,5 \\
\hline Índice $\mathrm{Kr}$ & 2,0 & 0,5 & 0,1 & 1,2 & 1,2 \\
\hline
\end{tabular}

${ }^{1}$ OLIVEIRA, J.B.; MENK, J.R.F.; NIESTEN, B.; JONG VAN LIER, Q. Levantamento pedológico detalhado do Centro Experimental de Campinas. Campinas, IAC, s.d. (não publicado). 
Tabela 3 - Resultados da análise das amostras dos subsolos utilizados no experimento.

\begin{tabular}{|c|c|c|c|c|c|}
\hline \multirow[b]{2}{*}{ Parâmetros } & \multicolumn{5}{|c|}{ Solos } \\
\hline & LVál-1 & LRác-1 & LRác-2 & LEál & LVál-2 \\
\hline $\mathrm{pH} \mathrm{em} \mathrm{CaCl}_{2} 0,01$ mol.L- -1 & 4,03 & 4,40 & 5,53 & 4,32 & 4,10 \\
\hline \multicolumn{6}{|l|}{ Cátions trocáveis $\left(\mathrm{mmol}_{\mathrm{c} \cdot} \mathrm{dm}^{3}\right)$} \\
\hline $\mathrm{Ca}^{2+}$ & 0,9 & 0,7 & 0,6 & 3,0 & 0,7 \\
\hline $\mathrm{Mg}^{2+}$ & 0,6 & 0,4 & 0,2 & 1,1 & 0,8 \\
\hline $\mathrm{K}^{+}$ & 0,5 & 0,2 & 0,2 & 0,4 & 0,3 \\
\hline $\mathrm{Al}^{3+}$ & 13,8 & 2,4 & 0,0 & 7,2 & 8,7 \\
\hline CTCe & 15,8 & 3,7 & 1,0 & 11,7 & 10,5 \\
\hline $\mathrm{H}^{+}+\mathrm{Al}^{3+}\left(\mathrm{mmol}_{\mathrm{c}} \cdot \mathrm{dm}^{-}\right)$ & 55,0 & 43,7 & 25,0 & 48,5 & 50,6 \\
\hline $\mathrm{SB}\left(\mathrm{mmol} \cdot \mathrm{dm}^{-}{ }^{3}\right)$ & 2,0 & 1,3 & 1,0 & 4,5 & 1,8 \\
\hline CTC (mmol.dm- $\left.{ }^{3}\right)$ & 57,0 & 45,0 & 26,0 & 53,0 & 52,4 \\
\hline Valor $\mathrm{m}(\%)$ & 87,3 & 64,9 & 0,0 & 61,5 & 82,9 \\
\hline Valor V(\%) & 3,5 & 2,9 & 3,8 & 8,5 & 3,4 \\
\hline $\mathrm{S}-\mathrm{SO} /\left(\mathrm{mmol}_{\mathrm{c}} \cdot \mathrm{dm}^{3}\right)$ & 2,0 & 0,3 & 0,3 & 0,4 & 1,1 \\
\hline $\mathrm{N}-\mathrm{NH}_{4}++\mathrm{N}-\mathrm{NO}_{3^{-}}\left(\mathrm{mg} \cdot \mathrm{dm}^{-}{ }^{3}\right)$ & 6,2 & 4,2 & 5,3 & 4,8 & 6,2 \\
\hline $\mathrm{ApH}\left(\mathrm{pH}_{\mathrm{KCI}}-\mathrm{pH}_{\mathrm{H} 20}\right)$ & $-0,6$ & $-0,4$ & 0,3 & $-0,8$ & $-0,7$ \\
\hline
\end{tabular}




\subsection{Instalação e condução do experimento em casa de vegetação}

Um experimento com vasos foi conduzido em casa de vegetação, no período de 28 de setembro a 5 de novembro de 1993, no qual plantas de milho foram cultivadas, utilizando-se uma técnica de raiz bipartida vertical, com dois recipientes justapostos, semelhante à utilizada por ADAMS \& LUND (1966) e RAU et al. (1988). Essa técnica permitiu que as raízes se desenvolvessem em amostras de dois solos diferentes.

$\mathrm{O}$ experimento foi constituído de um esquema fatorial $5 \times 4$, sendo cinco solos (Tabela 1) e quatro tratamentos: sem tratamento (T), sulfato de cálcio p.a. (G), fosfogesso (FG) e carbonato de cálcio p.a. (C), aplicados às amostars de subsolo, usando-se um delineamento de blocos ao acaso com quatro repetições. Foram utilizadas sementes de milho (Zea mays L.), cultivar ICI-8568, híbrido simples, com média tolerância à acidez.

A amostra de solo da parte superior do vaso, onde as sementes de milho foram plantadas, foi proveniente da camada superficial $(\mathrm{O}-20 \mathrm{~cm})$ de um brunizen avermelhado, textura argilosa (Vidal-Torrado \& Sparovek, 1992)2, cujas características químicas são apresentadas na Tabela 4.

As amostras da parte inferior foram as cinco já mencionadas no ítem 3. 1, que receberam os tratamentos. Essas amostras serão doravante denominadas de subsolos para facilitar a descrição.

Como recipiente superior foi utilizado um copo plástico de formato do tipo tronco de cone ( $5 \mathrm{~cm}$ de base menor, $7 \mathrm{~cm}$ de base maior e $5 \mathrm{~cm}$ de altura), que foi preenchido com $130 \mathrm{~g}$ de terra. Foram adicionados a cada copo: $200 \mathrm{mg}$ de $\mathrm{P}$ misturados à terra na forma sólida; e $40 \mathrm{~mL}$ de uma solução contendo $\mathrm{KN}_{3}$, $\left(\mathrm{NH}_{4}\right)_{2} \mathrm{SO}_{4}, \mathrm{~N} \mathrm{N0}{ }_{3}$ e $\mathrm{ZnSO}_{4}$, parcelados em quatro vezes de $10 \mathrm{~mL}$ (aos 2, 6, 10 e 12 dias após a germinação), totalizando $40 \mathrm{mg}$ de $\mathrm{N}, 30 \mathrm{mg}$ de $\mathrm{K}, 12 \mathrm{mg}$ de Se 1,3 mg de Zn. Essa adubação foi feita com o objetivo de propiciar condições favoráveis para um bom desenvolvimento das plantas, antes de elas serem transferidas para os vasos contendo os subsolos. 
Tabela 4 - Resultados da análise química da amostra do brunizen avermelhado utilizado no experimento.

\begin{tabular}{|c|c|c|c|c|c|c|c|c|c|}
\hline 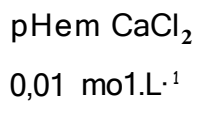 & $P$ resina & $\mathrm{Ca}^{2+}$ & $\mathrm{Mg}^{2+}$ & $\mathrm{K}^{+}$ & $\mathrm{H}^{+}+\mathrm{Al}^{3^{+}}$ & S-SO/- & SB & СтС & $\mathrm{V}$ \\
\hline & $\mathrm{mg} \cdot \mathrm{dm}^{3}$ & $\ldots \ldots$ & $\ldots \ldots$ & $\ldots \ldots$ & mmolc.dm & ......... & ......... & ........ & $\%$ \\
\hline 5,49 & 40,0 & 216,0 & 12,0 & 0,7 & 40,5 & 0,6 & 228,7 & 269,2 & 85 \\
\hline
\end{tabular}

Cada copo recebeu oito sementes e, quatro dias após a germinação, foi feito o desbaste, deixando-se quatro plantas por copo. A irrigação foi feita duas vezes por dia com água destilada, em quantidades determinadas mediante a pesagem dos copos, visando-se manter a umidade próxima de $80 \%$ de capacidade de campo, que foi determinada pelo método TSFM (Torrão Separado pela Frente de Molhamento), descrito por COSTA (1983).

Quinze dias após a germinação, o bloco de terra contendo as quatro plantas de milho foi retirado e colocado em vaso de cerâmica, usado como recipiente da parte inferior, preenchido com $2 \mathrm{dm}^{3}$ de subsolo. Nesse dia, cada subsolo recebeu um dos seguintes tratamentos: sem corretivo, $\mathrm{CaSO}_{4} \cdot 2 \mathrm{H}_{2} \mathrm{O}$ p.a., fosfogesso e $\mathrm{CaCO}_{3}$ p.a.. $\mathrm{Na}$ montagem dos vasos, esses materiais foram misturados à terra seca, na dose de 10 $\operatorname{mmol}_{0} \mathrm{dm}^{3}$ de Ca. Em seguida, adicionou-se água suficiente para atingir $40 \%$ da capacidade de campo. Ao mesmo tempo, foi adicionada uma solução de $\mathrm{KNO}_{3}$ e NH.tNO ${ }_{3}$, contendo $28 \mathrm{mg}$ de $\mathrm{N}^{-\mathrm{NH}_{4}}{ }^{+}, 28 \mathrm{mg}$ de N-N0 $3_{3}$ e $78 \mathrm{mg}$ de $\mathrm{K}$ A terra umedecida foi então acondicionada nos vasos em camadas sucessivas, as quais foram ligeiramente compactadas com um soquete e cortadas com espátula por várias vezes em sentido transversal, visando obter-se um substrato melhor estruturado. No final desse processo, antes que o vaso fosse completamente preenchido, foi introduzido um copo plástico vazio, igual àquele onde o milho foi plantado, com o objetivo de deixar o espaço, onde o bloco de terra com as plantas seria introduzido. A partir daí, as plantas passaram a se desenvolver em dois substratos diferentes. 
A massa de todos os vasos foi anotada diariamente e a irrigação foi feita adicionando-se água destilada, até ser atingida a massa final prevista para cada vaso, que foi calculada incluindo a quantidade de água necessária para se atingir $80 \%$ da capacidade de campo de cada subsolo, somada à massa do bloco de terra com as plantas. Passados quinze dias, foi induzido um déficit hídrico, interrompendo-se o fornecimento de água, mas as massas dos vasos continuaram a ser anotadas. Quatro dias depois, quando cerca de metade da água contida nos vasos havia sido consumida, o milho foi colhido. No total, o experimento foi conduzido por 34 dias após a germinação.

A parte aérea das plantas de milho foi colhida, cortando-se rente à terra, lavada com água destilada, seca em estufa com circulação forçada de ar a $70^{\circ} \mathrm{C}$, pesada, moída e armazenada em frascos de vidro com tampa, para posterior análise química.

Logo após a colheita, a camada de terra superficial dos vasos (aproximadamente $7 \mathrm{~cm}$ ), incluindo o bloco de terra que tinha sido introduzido com as plantas, foi retirada, restando apenas o subsolo.

Em seguida, retirou-se uma amostra do subsolo no centro de cada vaso, para determinação do teor de água no dia da colheita. Utilizou-se, para isso, uma sonda de aço inoxidável, com diâmetro interno de $2,5 \mathrm{~cm}$.

Amostras com $100 \mathrm{~cm}^{3}$ de subsolo foram, também, coletadas para estimar o comprimento radicular. A amostragem foi feita simulando-se a divisão do vaso em quadrantes, tomando-se uma subamostra de $25 \mathrm{~cm}^{3}$ de cada quadrante. O volume foi determinado utilizando-se a fórmula para o cálculo do volume do cilindro ( $\mathrm{V}=11$ "'2h), considerando-se o diâmetro interno da sonda e a altura do cilindro de terra retirado $(5,1 \mathrm{~cm})$. As amostras foram colocadas em sacos plásticos e guardadas em geladeira.

Finalmente, os vasos foram desmontados e o restante do subsolo foi seco ao ar, peneirado (malha de $2 \mathrm{~mm}$ ) e armazenado em sacos plásticos para posterior análise química. 


\subsection{Determinação do consumo de água pelas plantas}

A quantidade de água perdida por evapotranspiração, após a transferência das plantas para o vaso contendo os subsolos, e determinada através de pesagem diária dos vasos, foi considerada como "consumo de água pelas plantas".

\subsection{Determinação do teor de água no subsolo}

As amostras coletadas foram colocadas em latas de alumínio com tampa. Estas foram pesadas (lata + terra úmida) e imediatamente transferidas para uma estufa com circulação forçada de ar a $105^{\circ} \mathrm{C}$. Quarenta e oito horas depois, as latas foram retiradas da estufa e pesadas novamente (lata + terra seca). O teor de água foi determinado por diferença [(lata + terra úmida) - (lata + terra seca a $\left.\left.105^{\circ} \mathrm{C}\right)\right] \mathrm{e}$ expresso com base na massa do solo, conhecendo-se a massa da lata vazia.

\subsection{Estimativa do comprimento radicular}

As raízes foram separadas da terra através de lavagem sob torneira, em uma peneira de $25 \mathrm{~mm}$ de malha (ABNT $=60$ ). Em seguida, as raízes foram acondicionadas em frascos de vidro, contendo uma solução AFA (ácido acético, formol e álcool, na proporção 1:5:20).

A estimativa do comprimento das raízes no volume de $100 \mathrm{~cm}^{3}$ de terra, foi feita segundo TENNANT (1975), com modificações. Uma placa de Petri foi colocada sobre um quadriculado ("grid") de 0,5 x 0,5 cm. As raízes foram distribuídas aleatoriamente no interior da placa, contando-se as interceptações entre elas e as linhas horizontais e verticais do quadriculado. As contagens foram acumuladas em um contador manual. O total de interceptações, para cada amostra, foi convertido em comprimento pela seguinte fórmula: 
$\mathrm{R}=\mathrm{N} \times \mathrm{f}$, onde:

$\mathrm{R}=$ comprimento das raízes $(\mathrm{cm})$

$\mathrm{N}=$ número de interceptações

$\mathrm{f}=$ fator de conversão relacionado com o tamanho dos quadrados do quadriculado. Neste trabalho, usou-se o fator 0,3928 (para quadriculado de 0,5 x 0,5 cm).

\subsection{Análise química do solo}

A metodologia utilizada foi descrita por RAIJ et al. (1987), exceto para N mineral e S-SOi-.

Foram feitas as seguintes determinações:

a) pH em $\mathrm{H}_{2} \mathbf{O}$ e pH em solução de $\mathrm{CaCl}_{2} \mathbf{0 , 0 1}$ mot.L. ${ }^{1}$ : o pH em $\mathrm{H}_{2} \mathrm{O}$ e em $\mathrm{CaCl}_{2}$ 0,01 mol.L- ${ }^{1}$ foi determinado numa suspensão de solo:solução de 1:2,5, que foi agitada por 15 minutos. A leitura do $\mathrm{pH}$ foi feita em potenciômetro após um período de 30 minutos, sem agitação, com um eletrodo de vidro, cujo bulbo foi encostado no sedimento, em combinação com um eletrodo calomelano de referência mergulhado no sobrenadante.

b) Cátions básicos trocáveis $\left(\mathrm{Ca}^{2+}, \mathbf{M g}^{+}\right.$e $\left.\mathbf{K}^{+}\right)$: os cátions básicos foram extraídos com uma solução de $\mathrm{CH}_{3} \mathrm{COONH}_{4} 1 \mathrm{moLL}^{-1}$ a pH 7,0. O extrato foi obtido por agitação de $5 \mathrm{~cm}^{3}$ de terra com $50 \mathrm{~mL}$ da solução por um período de 15 minutos. A suspensão foi deixada decantar por uma noite. No dia seguinte, transferiram-se $2 \mathrm{~mL}$ do extrato sobrenadante para um tubo de ensaio e acrescentaram-se $10 \mathrm{~mL}$ de uma solução de óxido de lantânio a $\mathrm{O}, 1 \%$. O mesmo procedimento foi usado para o preparo de padrões mistos de $\mathrm{Ca}, \mathrm{Mg}$ e $\mathrm{K}$. Cálcio $\left(\mathrm{Ca}^{2+}\right)$ e $\mathrm{Mg}^{2+}$ foram determinados em espectrofotômetro de absorção atômica e $\mathrm{K}+$ em fotômetro de chama. 
c) $\mathbf{A I}^{3+}$ trocável: o $\mathrm{Al}$ trocável foi extraído com $\mathrm{KCl} 1 \mathrm{~mol} . \mathrm{L}-{ }^{1}$, agitando-se $5 \mathrm{~cm}^{3}$ de terra com $50 \mathrm{~mL}$ da solução por 15 minutos. O extrato obtido foi decantado por uma noite. Uma alíquota de $25 \mathrm{~mL}$ do líquido sobrenadante foi usada para determinação do $\mathrm{Al}$ por titulometria com uma solução de $\mathrm{NaOH}$ 0,025 mol.L- ${ }^{1}$ padronizada, usando azul de bromotimol como indicador.

d) Acidez potencial $\left(\mathrm{H}^{+}+\mathbf{A l}^{3}+\right)$ : a acidez potencial foi determinada potenciometricamente pela solução tampão SMP. Cinco mililitros $(5 \mathrm{~mL})$ de solução tampão SMP foram adicionados à mesma suspensão em que foi determinado o $\mathrm{pH}$ em $\mathrm{CaCl}_{2}$ 0,01 mol.L- ${ }^{1}$. Esta nova suspensão foi agitada por 15 minutos e deixada em repouso por mais 60 minutos, após os quais o $\mathrm{pH}$ de equilíbrio (PHsMP) foi lido. Os teores de $\mathrm{H}^{+}+\mathrm{Al}^{3+}$ foram obtidos através da equação de regressão (RAIJ et al., 1987):

$\ln \mathrm{y}=7,76-1,053 \mathrm{x}$, onde $\mathrm{y}=\mathrm{H}^{+}+\mathrm{Al}^{3+}\left(\mathrm{mmol}_{\mathrm{c}} \cdot \mathrm{dm}^{-}{ }^{3}\right)$ e $\mathrm{x}=\mathrm{pHsMP}$.

\section{e) $\mathbf{N}$ mineral $\left(\mathbf{N}-\mathbf{N H}_{4}+\right.$ e $\left.\mathbf{N}-\mathbf{N O}_{3^{\prime}}\right)$}

O $\mathrm{N}$ mineral foi determinado segundo BREMNER \& KEENEY (1966). Agitaram-se $5 \mathrm{~cm}^{3}$ de terra com $50 \mathrm{~mL}$ de uma solução de $\mathrm{KCl} 2$ mol.L- $^{1}$ por 60 minutos. O extrato obtido foi deixado em repouso por mais 30 minutos para decantar e uma alíquota de $25 \mathrm{~mL}$ do líquido sobrenadante foi submetida à destilação a vapor, após a adição de 0,2 g de $\mathrm{MgO}$. Aproximadamente $30 \mathrm{~mL}$ do destilado foram recolhidos em béquer de $50 \mathrm{~mL}$, contendo $5 \mathrm{~mL}$ de solução de $\mathrm{H}_{3} \mathrm{BO}_{3}$ a $2 \%$ mais uma mistura de indicadores, para determinação do $\mathrm{N}_{-} \mathrm{NH}_{4}{ }^{+}$. Acrescentou-se ao mesmo extrato, 0,2 $\mathrm{g}$ de liga de Devarda. Prosseguiu-se a destilação, coletando-se aproximadamente $30 \mathrm{~mL}$ do destilado em outro béquer contendo $5 \mathrm{~mL}$ de $\mathrm{H}_{3} \mathrm{BO}_{3}+$ indicadores, para determinação

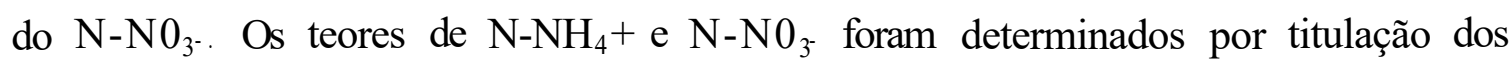
destilados com solução de $\mathrm{H}_{2} \mathrm{~S}_{4}$ 0,0025 mol.L1, descontando-se o valor da prova em branco. 
f) $\mathrm{S}-\mathrm{SO} /$

O S-So/- disponível foi extraído de acordo com a metodologia descrita por ANDRADE et al. (1990): $10 \mathrm{~cm}^{3}$ de terra foram agitados com $25 \mathrm{~mL}$ de uma solução de $\mathrm{Ca}\left(\mathrm{H}_{2} \mathrm{P} 04\right) \mathrm{z}$ 0,01 moLL- ${ }^{-}$e $0,25 \mathrm{~g}$ de carvão ativado por um período de 30 minutos e filtrados em papel de filtro quantitativo. O extrato obtido foi analisado pelo método turbidimétrico (TABATABAI \& BREMNER, 1970), descrito por MALAVOLTA et al. (1989), que consiste na determinação do sulfato, medindo-se a turbidez formada pela precipitação do enxofre na forma de $\mathrm{BaSO}_{4}$, após reagir com $\mathrm{BaCl}_{2}$. Assim, transferiu-se uma alíquota de $10 \mathrm{~mL}$ do extrato para um tubo de ensaio e acrescentou-se $1 \mathrm{~mL}$ de solução de $\mathrm{HCl}$, contendo $60 \mu \mathrm{g} \cdot \mathrm{mL}-1$ de $\mathrm{SO} /$ e $0,5 \mathrm{~g}$ de cristais de $\mathrm{BaCl}_{2}$ (que passaram na peneira de 20 mesh e ficaram retidos na de 60 mesh). Passado um minuto, agitou-se o tubo manualmente e leu-se a absorbância, após 2 a 8 minutos da dissolução dos cristais, em espectrofotômetro a $420 \mathrm{~nm}$. O cálculo dos teores de $\mathrm{S}$-So/- no solo foi realizado com base na equação de regressão obtida da leitura da absorbância de soluções padrões.

\section{7. Obtenção e análise do extrato de saturação}

\section{a) Obtenção}

O extrato de saturação foi obtido segundo RHOADS (1982). Pesaram-se $700 \mathrm{~g}$ de terra em um béquer de plástico de $1000 \mathrm{~mL}$ e adicionou-se água destilada paulatinamente, mexendo-se a mistura com uma espátula até a formação de uma pasta saturada. Na saturação, a pasta adquire as seguintes características: (1) reflete a luz incidente; (2) flui livremente quando o béquer é virado; e (3) escorrega livremente de uma espátula limpa, sem sujá-la (exceto para solos de textura muito argilosa). Em seguida, o béquer foi coberto e a pasta deixada em repouso por uma noite. Os critérios de saturação foram checados novamente no dia seguinte, observando-se se havia água livre na superfície (supersaturação) ou se a pasta havia perdido o seu brilho 
(subsaturação); quando isso aconteceu, acrescentou-se um pouco mais de terra ou de água, conforme o caso. Passadas outras duas horas de repouso, a pasta saturada foi transferida para um funil de Büchner forrado com papel de filtro resistente para filtração a vácuo. $\mathrm{O}$ filtrado foi coletado em um quitassato, transferido para um frasco plástico com tampa e guardado em geladeira (aproximadamente $5^{\circ} \mathrm{C}$ ). Uma gota de tolueno foi acrescentada a cada amostra com o objetivo de evitar o crescimento de microrganismos.

\section{b) Análise}

No extrato de saturação determinou-se: $\mathrm{pH}$, condutividade elétrica; $\mathrm{Ca}, \mathrm{Mg}$, $\mathrm{Mn}, \mathrm{S}$ e P por espectrometria de plasma; K por fotometria de chama; Ale F.

O Al foi determinado pelo método colorimétrico do alurninon (ácido aurintricarboxílico) descrito por RAU \& VALADARES (1974): tomou-se urna alíquota de $1 \mathrm{O} \mathrm{mL}$ do extrato à qual foram acrescentados $1 \mathrm{O} \mathrm{mL}$ de urna solução de $\mathrm{CaCl}_{2}$ 0,0003 mol.L- ${ }^{-1}$ e $\mathrm{HCl}$ 0,003 moLL- ${ }^{-1}, 1 \mathrm{~mL}$ de ácido tioglicólico a $1 \%$ e $5 \mathrm{~mL}$ da solução tampão de aluminon, lendo-se a absorbância após duas horas, em espectrofotômetro a $534 \mathrm{~nm}$.

O F foi determinado potenciometricamente (ADRIANO \& DONNER, 1982; MOORE \& RITCHEY, 1988). O método baseia-se na medida potenciornétrica do $\mathrm{F}$ através de um eletrodo seletivo de $\mathrm{F}$ mergulhado na solução, em combinação com um eletrodo de referência. Considerando que o eletrodo mede a atividade do íon F, quando se deseja determinar a concentração é necessário adicionar à amostra uma solução tampão de força iônica constante, que contenha agentes orgânicos cornplexantes de $\mathrm{Al}$ e Fe, para liberar o F complexado com esses metais. Tal solução é denominada TISAB ("Total Ionic Strength Adjustment Buffer"). Nesse trabalho, utilizou-se urna solução TISAB preparada com $84 \mathrm{~mL}$ de ácido clorídrico concentrado, $242 \mathrm{~g}$ de Tris (hidroximetil) aminometano e $230 \mathrm{~g}$ de tartarato de sódio, dissolvidos em um litro de água destilada (MOORE \& RITCHEY, 1988). Assim, uma alíquota de 1OrnL do extrato de saturação foi misturada com igual volume de TISAB, e leu-se o potencial elétrico, 
em $\mathrm{mV}$, com um eletrodo seletivo de fluoreto (Metrohm, modelo 6.052.150) mergulhado na solução juntamente com um eletrodo de referência $\mathrm{Ag} / \mathrm{AgCl}$ (Metrohm, modelo 6.072.100), conectados a um potenciómetro digital. Procedeu-se da mesma forma com as soluções padrões. A concentração de $\mathrm{F}$ foi determinada através da seguinte equação de regressão:

$$
\mathrm{y}=\mathrm{a}+\mathrm{b} \log \mathrm{x} \text {, onde: }
$$

$\mathrm{y}=$ potencial elétrico $(\mathrm{U})$ da solução padrão, em $\mathrm{mV}$; e $\mathrm{x}=$ concentração de $\mathrm{F}$, em mol.L- ${ }^{-1}$.

\subsection{Especiação química da solução do solo (extrato de saturação)}

$\mathrm{O}$ pH e as concentrações dos íons analisados no extrato de saturação (expressos em mol.L-1 ${ }^{1}$ ) foram submetidos ao programa de computação GEOCHEM (SPOSITO \& MATTIGOD, 1980), para o cálculo da força iônica e das concentrações das espécies químicas de Ale Cana solução. Os cálculos efetuados pelo programa são baseados nas constantes de estabilidade (LINDSAY, 1979) dos componentes da solução do solo. As atividades de $\mathrm{Al}^{3+} \mathrm{e} \mathrm{Ca}^{2+}$ foram, também, calculadas pelo GEOCHEM através dos respectivos coeficientes de atividade, calculados com o uso da equação de Davies (SPOSITO, 1981). Os resultados das concentrações das espécies iônicas de Al e Ca na solução foram expressos em porcentagem de $\mathrm{Al}$ e Ca total, respectivamente, para facilitar a interpretação.

\subsection{Análise química do tecido vegetal}

A análise química do tecido vegetal foi feita segundo BATAGUA et al. (1983): 
a) $\mathbf{N}$ total: digestão sulfúrica com sais catalizadores ( $\mathrm{Cu}$ e Se) e determinação do $\mathrm{N}$ amoniacal formado por destilação a vapor e posterior titulação com uma solução padronizada de $\mathrm{H}_{2} \mathrm{SO}_{4}$.

b) Ca, Mg, K, P e S: obtenção do extrato por via úmida (digestão nitroperclórica). Cálcio, $\mathrm{Mg}$, P e S foram determinados por espectrometria de plasma, e K por fotometria de chama.

\subsection{Análise estatística dos resultados}

Os resultados obtidos foram submetidos à análise de variância (teste F) e as comparações entre as médias dos tratamentos feitas pelo teste de Tukey a 5\% de probabilidade (GOMES, 1985). Para isso, utilizou-se o programa de computador SANEST. 


\section{RESULTADOS E DISCUSSÃO}

\subsection{Efeito dos tratamentos sobre as propriedades dos solos}

\subsubsection{Teor de água nos subsolos no dia da colheita do milho}

Os resultados do teor de água nos subsolos no dia da colheita do milho são apresentados na Tabela 5. Pode-se observar que, dentro de cada solo estudado, os teores de água nos subsolos tratados com G, FG e C foram menores do que aquele encontrado no subsolo que não recebeu tratamento. Considerando que as plantas de milho foram submetidas a um déficit hídrico antes da colheita, esses resultados evidenciam o efeito desses materiais em propiciar melhor desenvolvimento do sistema radicular do milho, que resultou em melhor aproveitamento da água contida no subsolo.

Resultados semelhantes aos obtidos no presente trabalho têm sido observados em ensaios de campo com gesso (RITCHEY et al., 1980; CARVALHO et al., 1986; SUMNER et al., 1986; SOUZA et al., 1992). Em um desses experimentos, CARVALHO et al. (1986) demonstraram que doses de gesso aplicadas a um LE do cerrado proporcionaram a exploração de um maior volume de solo pelas raízes de milho, permitindo que as plantas retirassem água das camadas mais profundas do solo, após serem submetidas a um déficit hídrico de 21 dias. As lâminas de água removidas no perfil $(\mathrm{Oa} 100 \mathrm{~cm})$ nas doses de $\mathrm{O}, 2$ e 6 tha- $^{-1}$ de gesso, foram de, respectivamente, $53,5,69,5$ e $74,8 \mathrm{~mm}$ 
Tabela 5 - Teor de água em amostras de subsolos, no dia da colheita de milho, em função dos tratamentos: sem tratamento $(\mathrm{T})$, sulfato cálcio $(\mathrm{G})$, fosfogesso (FG) e carbonato de cálcio (C). Ł

\begin{tabular}{|c|c|c|c|c|c|}
\hline \multirow{2}{*}{ Tratamentos } & \multicolumn{5}{|c|}{ Solos } \\
\hline & LVál-1 & LRác-1 & LRác-2 & LEál & LVál-2 \\
\hline & \multicolumn{5}{|c|}{$\ldots \ldots \ldots \ldots \ldots \ldots \ldots \ldots \ldots \ldots \ldots$ g g. kg-1 } \\
\hline $\mathrm{T}$ & $146,6 \mathrm{a}$ & $260,2 \mathrm{a}$ & 185,4 a & $190,0 \mathrm{a}$ & 135,9 a \\
\hline G & $135,3 \mathrm{~b}$ & $238,4 \mathrm{~b}$ & $173,2 \mathrm{~b}$ & $177,6 \mathrm{~b}$ & $120,7 \mathrm{~b}$ \\
\hline FG & $130,0 \mathrm{~b}$ & $241,6 \mathrm{~b}$ & $176,5 \mathrm{~b}$ & $176,0 \mathrm{~b}$ & $119,8 \mathrm{~b}$ \\
\hline e & $133,3 \mathrm{~b}$ & $238,1 \mathrm{~b}$ & $177,1 \mathrm{~b}$ & $176,5 \mathrm{~b}$ & $121,2 \mathrm{~b}$ \\
\hline C.V. \% & \multicolumn{5}{|c|}{2,41} \\
\hline
\end{tabular}

(1) Médias seguidas de mesma letra dentro de cada solo não diferem estatisticamente pelo teste de Tukey a $5 \% \bullet$

\subsection{2. $\mathbf{p H}, \mathbf{A l}^{3+}$ trocável, $\mathbf{H}^{+}+\mathbf{A l}^{3}+\mathbf{e}$ percentagem de saturação por $\mathbf{A l}^{3+}$}

Na tabela 6 encontram-se os valores de $\mathrm{pH}$ em $\mathrm{H}_{2} 0$ e em $\mathrm{CaCl}_{2} 0,01$ moLL- $^{1}$ medidos nos subsolos, após o cultivo do milho. Percebe-se que, independentemente dos tratamentos, os valores de $\mathrm{pH}$ medidos em $\mathrm{H}_{2} \mathrm{O}$ foram sempre maiores do que aqueles medidos em $\mathrm{CaCl}_{2}$. Essa diferença é explicada pelo chamado "efeito de sal" na medida do $\mathrm{pH}$. Quando uma solução salina é adicionada ao solo, a concentração eletrolítica da solução de equilíbrio é aumentada, provocando uma redução do pH por duas razões: (1) deslocamento dos íons $\mathrm{H}^{+}$e $\mathrm{Al}^{3+}$ da superfície das partículas pelo cátion adicionado (SUMNER, 1994); e (2) compressão da dupla camada elétrica difusa, fazendo com que 
o gradiente de concentração dos íons $\mathrm{H}^{+}$, entre a solução de equilíbrio e a superfície se reduza, de forma que o $\mathrm{pH}$ seja diminuído por se aproximar do $\mathrm{pH}$ da superfície das partículas (RAIJ, 1986). Por outro lado, quando o $\mathrm{pH}$ é determinado em água a concentração de eletrólitos, que deveria existir na solução do solo, é diluída, resultando em descompressão da dupla camada difusa, com conseqüente aumento no $\mathrm{pH}$.

O C teve o efeito previsto na acidez do subsolo, promovendo os maiores aumentos no $\mathrm{pH}$ e as maiores reduções nos teores de $\mathrm{Al}^{3+}$ trocável, $\mathrm{H}^{+}+\mathrm{AB}^{+}$e percentagem de saturação por alumínio (Tabela 7), nos cinco solos estudados. A neutralização total do $\mathrm{Al}^{3+}$ trocável ocorreu apenas no LRác-1, que continha originalmente o menor teor desse cátion (Tabela 3), em comparação com os latossolos álicos.

Os efeitos do $\mathrm{G}$ e do FG sobre a reação do solo foram semelhantes (Tabela 6). Ambos provocaram a redução significativa do $\mathrm{pH}$ em $\mathrm{H}_{2} \mathrm{O}$ nos três latossolos álicos, na ordem de 0,2 a 0,3 unidades, e praticamente não afetaram o $\mathrm{pH}$ em $\mathrm{H}_{2} \mathrm{O}$ nos latossolos ácricos. Diminuições dos valores do $\mathrm{pH}$ em $\mathrm{H}_{2} \mathrm{O}$ em solos tratados com gesso e fosfogesso têm sido reportados em vários trabalhos (BLACK \& CAMERON, 1984; PAV AN et al., 1984; ALVA et al., 1990) e são geralmente atribuídos ao efeito do sal sobre a hidrólise do AI, devido ao deslocamento do $\mathrm{AI}^{3+}$ pelo $\mathrm{Ca}^{2+}$ ma superfície das partículas. Segundo SHAINBERG et al. (1989), o efeito do gesso sobre a alteração do $\mathrm{pH}$ do solo é um resultado de duas reações de efeitos opostos que ocorrerem entre o gesso e a superfície das partículas dos solos, em que: (1) o $\mathrm{Ca}^{2+}$ desloca o $\mathrm{H}^{+}$e o $\mathrm{Al}^{3+}$ (que sofre hidrólise, liberando $\mathrm{H}^{+}$); e (2) o so $/{ }^{+}$desloca $\mathrm{OR}$, numa reação de troca de ligantes. É de se esperar, portanto, que o efeito dessas reações sobre o $\mathrm{pH}$ dependa da magnitude em que elas ocorrerem em cada caso particular. Assim, em latossolos álicos, altamente intemperizados, como os que foram utilizados neste estudo, $\mathrm{o} \mathrm{H}^{+}$ liberado pela hidrólise do $\mathrm{Al}^{3+}$ supera a liberação de $\mathrm{OR}$, resultando em decréscimo do pH, o que foi verificado também por ALVA et al. (1990), ALVA \& SUMNER (1990) e PAVAN (1993). Por outro lado, em solos altamente intemperizados, mas com baixos teores, ou mesmo ausência de Al trocável, o pH é aumentado (RITCHEY et al., 1980). 
Tabela 6 - Valores de $\mathrm{pH}$ em $\mathrm{H} 20$ e em $\mathrm{CaCl}_{2}$ 0,01 mol.L-1 em amostras de subsolos, após o cultivo com plntas de milho, em função dos tratamentos: sem tratamento $(\mathrm{T})$, sulfato de cálcio $(\mathrm{G})$, fosfogesso $(\mathrm{FG})$ e carbonato de cálcio (C). o)

\begin{tabular}{|c|c|c|c|c|c|}
\hline \multirow{2}{*}{ Tratamentos } & \multicolumn{5}{|c|}{ Solos } \\
\hline & LVál-1 & LRác-1 & LRác-2 & LEál & LVál-2 \\
\hline \multicolumn{6}{|l|}{ pHem $\mathrm{H}_{2} \mathrm{O}$} \\
\hline $\mathrm{T}$ & $4,82 \mathrm{~b}$ & $5,15 \mathrm{c}$ & $6,14 \mathrm{~b}$ & $5,28 \mathrm{~b}$ & $4,98 \mathrm{~b}$ \\
\hline G & $4,51 \mathrm{c}$ & $5,19 \mathrm{bc}$ & $6,18 \mathrm{~b}$ & $5,02 \mathrm{c}$ & $4,61 \mathrm{c}$ \\
\hline FG & $4,49 \mathrm{c}$ & $5,21 \mathrm{~b}$ & $6,18 \mathrm{~b}$ & $5,05 \mathrm{c}$ & $4,64 \mathrm{c}$ \\
\hline e & $5,08 \mathrm{a}$ & $5,50 \mathrm{a}$ & $6,55 \mathrm{a}$ & $5,51 \mathrm{a}$ & $5,30 \mathrm{a}$ \\
\hline C.V. (\%) & \multicolumn{5}{|c|}{0,57} \\
\hline \multicolumn{6}{|c|}{ pH em $\mathrm{CaCI}_{2}$ 0,01 mol.L- ${ }^{-1}$} \\
\hline $\mathrm{T}$ & $4,07 \mathrm{~d}$ & $4,42 \mathrm{c}$ & $5,57 \mathrm{c}$ & $4,34 \mathrm{c}$ & $4,09 \mathrm{c}$ \\
\hline G & $4,12 \mathrm{c}$ & $4,65 \mathrm{~b}$ & $5,80 \mathrm{~b}$ & $4,52 \mathrm{~b}$ & $4,28 \mathrm{~b}$ \\
\hline FG & $4,16 b$ & $4,65 \mathrm{~b}$ & $5,78 \mathrm{~b}$ & $4,53 \mathrm{~b}$ & $4,30 \mathrm{~b}$ \\
\hline $\mathrm{e}$ & $4,34 \mathrm{a}$ & $4,87 \mathrm{a}$ & $5,94 \mathrm{a}$ & $4,67 \mathrm{a}$ & $4,53 \mathrm{a}$ \\
\hline C.V. $(\%)$ & \multicolumn{5}{|c|}{0,36} \\
\hline
\end{tabular}

(I) Médias seguidas de mesma letra, dentro de cada $\mathrm{pH}$, dentro de cada solo, não diferem estatisticamente pelo teste de Tukey a $5 \%$ de significância. 
Quando o pH foi medido em solução de $\mathrm{CaCl}_{2}$ 0,01 mol.L-1 ${ }^{1}$, mantendo-se constante, portanto, o efeito do sal sobre a hidrólise do $\mathrm{Al}^{3+}$, foi observado um aumento efetivo no pH dos subsolos tratados com G ou FG, na ordem de 0,05 a 0,23 unidades. Estes resultados sugerem que os dados contraditórios sobre o efeito do gesso na reação do solo, mostrados em outros trabalhos (SHAINBERG et al., 1989; ALCORDO \& RECHICGL, 1993), podem estar relacionados com o efeito do sal na medida do $\mathrm{pH}$. Quando esse fator é controlado, por exemplo, medindo-se o $\mathrm{pH}$ em $\mathrm{CaCl}_{2}, o \mathrm{pH}$ do solo geralmente é aumentado após a aplicação de gesso, particularmente em solos altamente intemperizados, conforme foi observado por SUMNER et al. (1986), RAU et al. (1988), SILVA \& RAIJ (1992), entre outros. SINGH (1982), PAVAN \& VOLKWEISS (1986) e SUMNER et al. (1986) demonstraram que os valores de $\mathrm{pH}$ de suspensões de solos medidos em solução de $\mathrm{CaSO}_{4}$ foram sempre maiores do que os medidos em solução de $\mathrm{CaCl}_{2}$, a uma mesma molaridade, o que indica ter havido algum deslocamento de $\mathrm{OH}$ pelo $\mathrm{SO} /$-.

O G e o FG também afetaram significativamente a acidez trocável e a acidez potencial dos subsolos (Tabela 7). A redução média dos teores de $\mathrm{Al}^{+} \mathrm{e} \mathrm{H}^{+}+\mathrm{Al}^{3+}$ correspondeu a 1,5 e 3,0 $\mathrm{mmol}_{\mathrm{c}} \cdot \mathrm{dm}^{-}$de terra, no tratamento com $\mathrm{G}$, e 1,8 a 2,8, no tratamento com FG. Estes resultados confirmam aqueles obtidos por outros autores sobre a ação do gessso em reduzir a acidez do subsolo (RITCHEY et al., 1980; PAVAN et al., 1982, 1984, 1987; BLACK \& CAMERON, 1984; FARINA \& CHANNON, 1988b; RAIJ et al., 1988; ALVA et al., 1990; PAVAN, 1993; RAIJ et al., 1994). Sendo o $\mathrm{CaSO}_{4} \cdot 2 \mathrm{H}_{2} \mathrm{O}$ um sal neutro, o seu efeito na redução da acidez do solo pode ser explicado, em parte, pelo mecanismo de "autocalagem" proposto por REEVE \& SUMNER (1972), que envolve uma reação de troca de ligantes, onde o $\mathrm{OH}$ - é deslocado pelo SO/- na superfície dos óxidos e hidróxidos de $\mathrm{Fe}$ e $\mathrm{Al}$, seguida da precipitação do $\mathrm{AI}^{3+}$ como $\mathrm{Al}(\mathrm{OH})_{3}$. Por outro lado, alguns autores, a exemplo de PAVAN (1993) e ISMAIL et al. (1993), têm demonstrado que a redução do Al trocável em solos 
Tabela 7 - Teores de $\mathrm{Al}^{3+}$ trocável, $\mathrm{H}^{+}+\mathrm{Al}^{3+}$ e valores de porcentagem de saturação por $\mathrm{Al}^{3+}(\mathrm{m})$ em amostras de subsolos, após o cultivo com plantas de milho, em função dos tratamentos: sem tratamento $(\mathrm{T})$, sulfato de cálcio (G), fosfogesso (FG) e carbonato de cálcio (e). Ł>

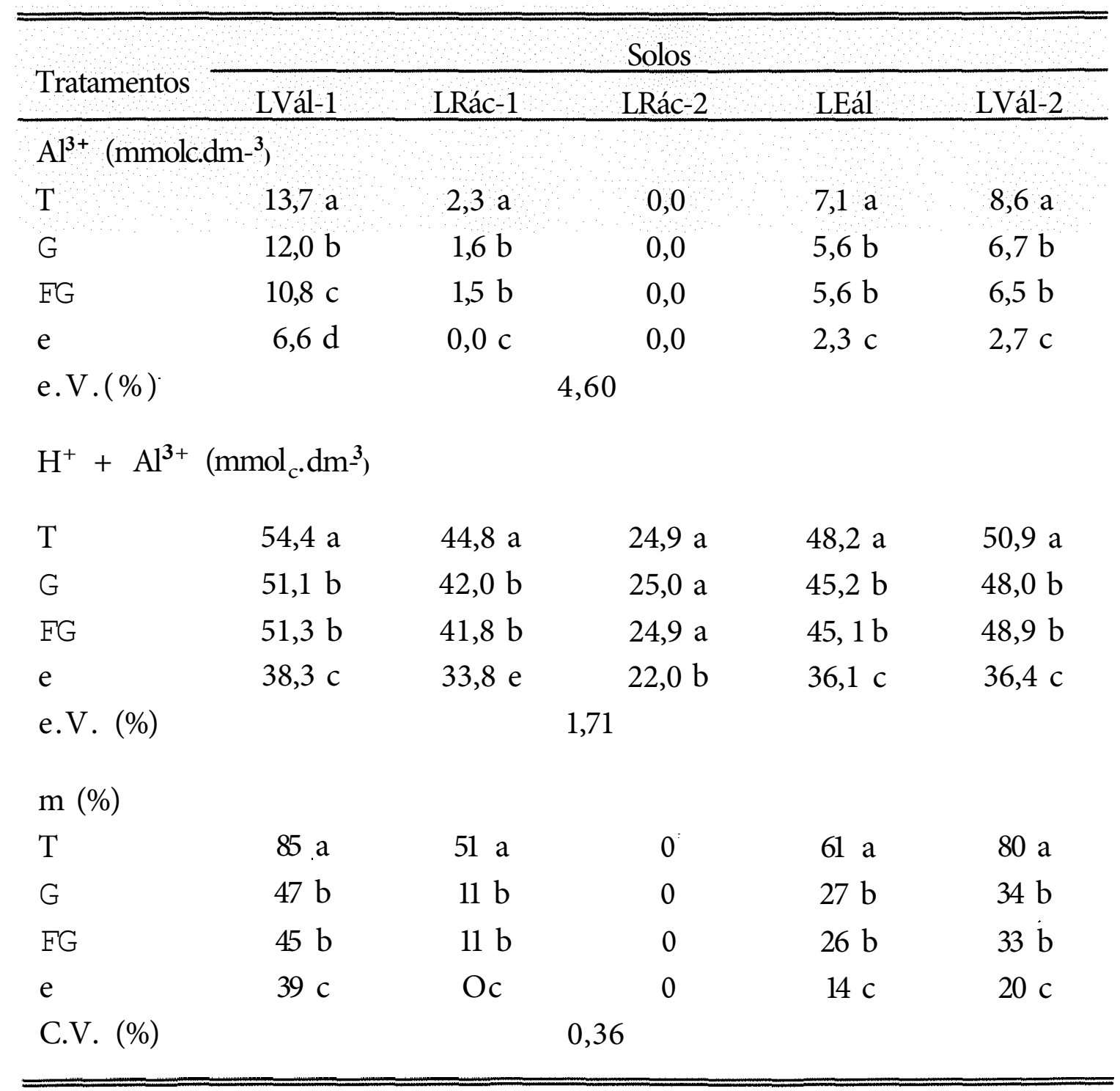

(I) Médias seguidas de mesma letra, dentro de cada parâmetro, dentro de cada solo, não diferem estatisticamente pelo teste de Tukey a $5 \%$. 
tratados com sulfato de cálcio foi devida à precipitação de fase sólida pela formação de sulfatos básicos de alumínio.

A redução da porcentagem de saturação por alumínio nos tratamentos com G e FG foi associada ao aumento nos teores de cálcio (Tabela 8) e diminuição do alumínio trocável.

\subsubsection{Cálcio, magnésio e potássio trocáveis, $\mathrm{S}-\mathrm{SO} /-$ e $\mathrm{N}$ mineral}

$\mathrm{Na}$ Tabela 8 são apresentados os resultados dos teores de $\mathrm{Ca}^{2+}, \mathrm{Mg}^{2+}$ e $\mathrm{K}^{+}$ e os valores de percentagem de saturação por bases nas amostras de subsolos, após o cultivo do milho. Os teores de $\mathrm{Ca}^{2+}$ trocáveis aumentaram em todas as amostras com a aplicação de G, FG e C. Porém, os acréscimos foram mais acentuados para o G e o FG do que no tratamento com $C$, o que não era esperado, uma vez que os corretivos foram aplicados em doses equivalentes de $\mathrm{Ca}^{2}+00 \mathrm{mmol}_{\mathrm{c}} \cdot \mathrm{dm}^{3}$ ). Uma possível explicação é que o $\mathrm{C}$ pode não ter reagido completamente no solo durante o período do experimento, pois a dissolução do $\mathrm{CaCO}_{3}$ é mais lenta do que a do $\mathrm{CaSO}_{4} \cdot 2 \mathrm{H}_{2} \mathrm{O}$ (PAVAN \& WOLKWEISS, 1986).

$\mathrm{O}$ teor de $\mathrm{K}^{+}$trocável foi significativamente maior nas amostras sem tratamento do que nas tratadas com G, FG e C, indicando que os corretivos proporcionaram maior esgotamento do potássio no subsolo. Vale recordar que a quantidade do potássio adicionada no subsolo, na montagem dos vasos, foi de $1, \mathrm{O}$ $\mathrm{mmol}_{\mathrm{c}} \cdot \mathrm{dm}^{3}$ (78 $\mathrm{mg}$ de $\mathrm{K}$ por vaso). Assim, percebe-se que muito pouco $\mathrm{K}$ foi absorvido dos subsolos que não receberam tratamento, com exceção para o LRác-2, devido, provavelmente, à ausência de Al trocável nesse solo. Assim, embora alguns autores (OATES \& CALDWELL, 1985; FARINA \& CHANNON, 1988b; QUAGGIO et al., 1982) tenham observado que o gesso promoveu o deslocamento de $\mathrm{Mg}$ e $\mathrm{K}$ da camada arável para o subsolo, os resultados obtidos no presente estudo permitem inferir que o gesso, ao reduzir a acidez do subsolo, favorece o aprofundamento do sistema radicular 
Tabela 8 - Teores de e $\mathrm{a}^{2+}, \mathrm{Mg}^{2+}, \mathrm{K}^{+}$e valores de saturação por bases (V) em amostras de subsolos, após o cultivo com plantas de milho, em função dos tratamentos: sem tratamento $(\mathrm{T})$, sulfato de cálcio $(\mathrm{G})$, fosfogesso (FG) e carbonato de cálcio (e). ব)

\begin{tabular}{|c|c|c|c|c|c|}
\hline \multirow{2}{*}{ Tratamentos } & \multicolumn{5}{|c|}{ Solos } \\
\hline & LVál-1 & LRác-1 & LRác-2 & LEál & LVál-2 \\
\hline \multicolumn{6}{|c|}{$\mathrm{ea}^{2+}\left(\mathrm{mmol}_{\mathrm{c}} \cdot \mathrm{dm}^{-}{ }^{3}\right)$} \\
\hline $\mathrm{T}$ & $0,62 c$ & $0,45 \mathrm{c}$ & $0,38 c$ & $2,50 \mathrm{c}$ & $0,45 c$ \\
\hline G & $12,15 \mathrm{a}$ & $11,20 \mathrm{a}$ & $9,30 a$ & $13,89 \mathrm{a}$ & $12,08 \mathrm{a}$ \\
\hline FG & $12,15 \mathrm{a}$ & $11,13 \mathrm{a}$ & $9,25 \mathrm{a}$ & $14,25 \mathrm{a}$ & $11,92 \mathrm{a}$ \\
\hline e & $9,22 \mathrm{~b}$ & $9,88 \mathrm{~b}$ & $7,78 \mathrm{~b}$ & $12,12 \mathrm{~b}$ & $9,88 \mathrm{~b}$ \\
\hline e.V.(\%) & \multicolumn{4}{|c|}{3,41} & \\
\hline \multicolumn{6}{|c|}{$\mathrm{Mg} 2+\left(\mathrm{mmol}_{\mathrm{c}} \cdot \mathrm{dm}^{-}\right)$} \\
\hline $\mathrm{T}$ & $0,52 \mathrm{a}$ & $0,38 \mathrm{a}$ & $0,10 \mathrm{a}$ & $1,08 \mathrm{a}$ & $0,75 \mathrm{a}$ \\
\hline G & $0,55 \mathrm{a}$ & $0,35 \mathrm{a}$ & $0,05 \mathrm{a}$ & $0,90 \mathrm{c}$ & $0,70 \mathrm{a}$ \\
\hline FG & $0,55 \mathrm{a}$ & $0,35 \mathrm{a}$ & $0,05 \mathrm{a}$ & $0,92 \mathrm{bc}$ & $0,70 \mathrm{a}$ \\
\hline e & $0,50 \mathrm{a}$ & $0,38 \mathrm{a}$ & $0,05 \mathrm{a}$ & $1,00 \mathrm{ab}$ & $0,68 \mathrm{a}$ \\
\hline e.V.(\%) & \multicolumn{4}{|c|}{8,12} & \\
\hline \multicolumn{6}{|c|}{$\left.\mathrm{K}^{+}\left(\mathrm{mmol}_{\mathrm{c} \cdot} \cdot \mathrm{dm}^{-}\right)^{3}\right)$} \\
\hline $\mathrm{T}$ & $1,20 \mathrm{a}$ & $1,10 \mathrm{a}$ & $0,50 \mathrm{a}$ & $0,95 \mathrm{a}$ & $0,95 \mathrm{a}$ \\
\hline $\mathrm{G}$ & $0,55 \mathrm{~b}$ & $0,48 \mathrm{c}$ & $0,25 \mathrm{~b}$ & $0,52 \mathrm{bc}$ & $0,42 \mathrm{~b}$ \\
\hline FG & $0,55 \mathrm{~b}$ & $0,48 c$ & $0,30 \mathrm{~b}$ & $0,48 \mathrm{c}$ & $0,42 \mathrm{~b}$ \\
\hline $\mathrm{e}$ & $0,55 \mathrm{~b}$ & $0,62 \mathrm{~b}$ & $0,35 \mathrm{~b}$ & $0,62 \mathrm{~b}$ & $0,45 \mathrm{~b}$ \\
\hline e.V.(\%) & \multicolumn{5}{|c|}{5,33} \\
\hline \multicolumn{6}{|c|}{ Saturação por bases (V\%) } \\
\hline $\mathrm{T}$ & $4 \mathrm{~b}$ & $4 \mathrm{~b}$ & $4 \mathrm{~b}$ & $9 b$ & $4 \mathrm{~b}$ \\
\hline $\mathrm{G}$ & $21 \mathrm{a}$ & $22 \mathrm{a}$ & $28 \mathrm{a}$ & $25 \mathrm{a}$ & $22 \mathrm{a}$ \\
\hline FG & $21 \mathrm{a}$ & $22 \mathrm{a}$ & $28 \mathrm{a}$ & $26 \mathrm{a}$ & $21 \mathrm{a}$ \\
\hline $\mathrm{e}$ & $21 \mathrm{a}$ & $24 \mathrm{a}$ & $28 \mathrm{a}$ & $28 \mathrm{a}$ & $23 \mathrm{a}$ \\
\hline e.V.(\%) & \multicolumn{5}{|c|}{2,80} \\
\hline
\end{tabular}

- Médias seguidas de mesma letra, dentro de cada parâmetro, dentro de cada solo, não diferem estatisticamente pelo teste de Tukey a $5 \%$. 
e a absorção desses nutrientes. Por outro lado, $\mathrm{o} \mathrm{Mg}^{2+}$ trocável foi alterado apenas no LEál, sendo reduzido com a aplicação de G ou FG.

A porcentagem de saturação por bases no subsolo aumentou significativamente nos cinco solos estudados, com a adição de G, FG e C, devido ao aumento do Ca trocável, não havendo diferença significativa entre os corretivos.

Na Tabela 9 encontram-se os resultados dos teores do $\mathrm{N}-\mathrm{NH}_{4}{ }^{+}, \mathrm{N}_{-}-\mathrm{No}_{3}$ e N mineral (N-NH4 $\left.{ }^{+}+\mathrm{N}-\mathrm{No3}-\right)$ nos subsolos, após o cultivo do milho. A quantidade de $\mathrm{N}$ aplicada correspondeu a $28 \mathrm{mg} \cdot \mathrm{dm}^{-}{ }^{3}$ de terra, sendo metade na forma de $\mathrm{NH}_{4}+\mathrm{e}$ metade na forma de $\mathrm{NO}_{3}$. Nota-se que, nos subsolos que receberam tratamento, foram encontrados os menores teores de $\mathrm{N}-\mathrm{N}+$, enquanto o N-No3- foi completamente exaurido. No LVál-1, que apresentava originalmente o maior teor de $\mathrm{Al}^{3+}$ trocável $(13,8$ $\mathrm{mmol}_{\mathrm{c}} \cdot \mathrm{dm}^{-}{ }^{3}$ ), uma quantidade igual a $91 \%$ do N-NH4 $4^{+}$aplicado permaneceram no subsolos sem tratamento. A maior absorção do $\mathrm{N}_{3}$ em relação ao $\mathrm{NH}_{4}^{+}$pode ser explicada pela elevada mobilidade do $\mathrm{NQ}_{3}$ - no solo e pelo processo de absorção dessas duas formas de $\mathrm{N}$ pelas raízes. $\mathrm{O} \mathrm{N0}_{3}$ - é absorvido por fluxo de massa, movimentandose junto com a água, enquanto que o $\mathrm{NH}_{4}+$ é absorvido por difusão, sendo este processo influenciado pelo volume de solo explorado pelas raízes. Comprovou-se, assim, nas condições deste experimento, as observações feitas por SOUZA \& RITCHEY (1986), RAU et al. (1988) e SOUZA et al. (1992) de que o gesso favorece a absorção de nutrientes, principalmente de $\mathrm{NO}_{3^{-}}$, do subsolo.

O teor de $\mathrm{S}-\mathrm{SO} /$ disponível nos subsolos, de acordo com as expectativas, foi afetado pelo G e pelo FG, aumentando significativamente em todos os solos (Tabela 10). 
Tabela 9 - Teores de N-NH.i+, N-N03 e $\mathrm{N}$ mineral $\left(\mathrm{N}_{-} \mathrm{NH}_{4+}+\mathrm{N}-\mathrm{NO}_{3}\right.$-) em amostras de subsolos, após o cultivo com plantas de milho, em função dos tratamentos: sem tratamento $(\mathrm{T})$, sulfato de cálcio $(\mathrm{G})$, fosfogesso (FG) e carbonato de cálcio (C). 4

\begin{tabular}{|c|c|c|c|c|c|}
\hline \multirow{2}{*}{ Tratamentos } & \multicolumn{5}{|c|}{ Solos } \\
\hline & LVál-1 & LRác-1 & LRác-2 & LEál & LVál-2 \\
\hline \multicolumn{6}{|c|}{$\mathrm{N}-\mathrm{NH}_{4}+\left(\mathrm{mg} \cdot \mathrm{dm}-{ }^{3}\right)$} \\
\hline $\mathrm{T}$ & $12,8 \mathrm{a}$ & $11,4 \mathrm{a}$ & 5,5 a & 10,2 a & $6,0 \mathrm{a}$ \\
\hline G & $5,8 \mathrm{~b}$ & $4,5 \mathrm{~b}$ & $2,3 \mathrm{~b}$ & $3,3 \mathrm{~b}$ & $3,1 \mathrm{~b}$ \\
\hline FG & $5,8 \mathrm{~b}$ & $5,1 \mathrm{~b}$ & $2,8 \mathrm{~b}$ & $3,5 \mathrm{~b}$ & $2,8 \mathrm{~b}$ \\
\hline e & $5,3 \mathrm{~b}$ & $5,1 \mathrm{~b}$ & $2,5 \mathrm{~b}$ & $3,4 \mathrm{~b}$ & $3,2 \mathrm{~b}$ \\
\hline C.V. (\%) & & & & & \\
\hline \multicolumn{6}{|c|}{$\mathrm{N}-\mathrm{No}_{3}-\left(\mathrm{mg} \cdot \mathrm{dm}-{ }^{3}\right)$} \\
\hline $\mathrm{T}$ & 5,5 & 6,2 & 2,7 & 1,6 & 1,9 \\
\hline G & 0,0 & 0,0 & 0,0 & 0,0 & 0,0 \\
\hline FG & 0,0 & 0,0 & 0,0 & 0,0 & 0,0 \\
\hline e & 0,0 & 0,0 & 0,0 & 0,0 & 0,0 \\
\hline \multicolumn{6}{|c|}{$\mathrm{N}$ mineral: $\mathrm{N}-\mathrm{NH} /+\mathrm{N}-\mathrm{NO}_{3}\left(\mathrm{mg}^{-\mathrm{dm}^{-}}{ }^{3}\right)$} \\
\hline $\mathrm{T}$ & 18,3 & 17,6 & 8,2 & 11,8 & 7,9 \\
\hline G & 5,8 & 4,5 & 2,3 & 3,3 & 3,1 \\
\hline $\mathrm{FG}$ & 5,8 & 5,1 & 2,8 & 3,5 & 2,8 \\
\hline e & 5,3 & 5,1 & 2,5 & 3,4 & 3,2 \\
\hline
\end{tabular}

(1) Médias seguidas de mesma letra, dentro de cada parâmetro, dentro de cada solo, não diferem estatisticamente pelo teste de Tukey $5 \%$. 
Tabela 10. Teores de S-So/-em amostras de subsolos, após o cultivo com plantas de milho, em função dos tratamentos: sem tratamento (T), sulfato de cálcio (G), fosfogesso (FG) e carbonato de cálcio (C) <1)

\begin{tabular}{|c|c|c|c|c|c|}
\hline \multirow{2}{*}{ Tratamentos } & \multicolumn{5}{|c|}{ Solos } \\
\hline & LVál-1 & LRác-1 & LRác-2 & LEál & LVál-2 \\
\hline & $\ldots \ldots$ & $\ldots \ldots$ & $\mathrm{mol}_{\mathrm{c}} \cdot \mathrm{dm}^{3}$. & ...... &,$\cdots \cdots \cdots \cdots$, \\
\hline $\mathrm{T}$ & $1,9 \mathrm{~b}$ & $0,1 \mathrm{~b}$ & $0,1 \mathrm{~b}$ & $3,6 \mathrm{~b}$ & $1,0 \mathrm{~b}$ \\
\hline $\mathrm{G}$ & $11,1 \mathrm{a}$ & $8,6 \mathrm{a}$ & $7,5 \mathrm{a}$ & $9,6 \mathrm{a}$ & $10,6 \mathrm{a}$ \\
\hline FG & $11,8 \mathrm{a}$ & $8,5 \mathrm{a}$ & $7,3 \mathrm{a}$ & $9,5 \mathrm{a}$ & $10,2 \mathrm{a}$ \\
\hline e & $2,0 \mathrm{~b}$ & $0,1 \mathrm{~b}$ & $0,2 \mathrm{~b}$ & $0,3 \mathrm{~b}$ & $1,1 \mathrm{~b}$ \\
\hline C.V. ( $(\%)$ & & & 4,86 & & \\
\hline
\end{tabular}

(I) Médias seguidas de mesma letra não diferem estatisticamente pelo teste de Tukey a $5 \%$ 


\subsubsection{Composição química da solução do solo}

Os valores de $\mathrm{pH}$, condutividade elétrica, força iônica e as concentrações totais de $\mathrm{Ca}, \mathrm{Mg}, \mathrm{K}, \mathrm{S}_{4}$ e $\mathrm{F}$ na solução dos subsolos, após o cultivo do milho, encontram-se na Tabela 11.

Nos cinco solos utilizados, o carbonato de cálcio (C) teve o efeito esperado, provocando o aumento do $\mathrm{pH}$ e a diminuição de $\mathrm{Al}$ e $\mathrm{K}$ solúveis. A concentração de $\mathrm{S}_{4}$ na solução também foi levemente aumentada em relação ao subsolo sem tratamento, enquanto a concentração de $\mathrm{Ca}$ foi inferior àquelas encontradas nos tratamentos com $\mathrm{G}$ ou FG. A explicação é a seguinte: com o aumento do $\mathrm{pH}$ houve precipitação de $\mathrm{Al}$ como $\mathrm{Al}(\mathrm{OH})_{3}$ e aumento das cargas elétricas negativas dependentes de $\mathrm{pH}$, que resultou em maior adsorção de $\mathrm{Ca}^{2+} \mathrm{e} \mathrm{K}^{+}$, e dessorção de $\mathrm{SO} /$. Por outro lado, nos tratamentos com G e FG observaram-se os menores valores de pH, exceto para o LRác1, onde foi verificado um ligeiro acréscimo no $\mathrm{pH}$. Decréscimos no $\mathrm{pH}$ da solução do solo em resposta à aplicação de G ou FG têm sido verificados por outros autores (ALVA \& SUMNER, 1990; NOGUEIRA \& MOZETO, 1990) e são devidos, provavelmente, ao efeito do sal, conforme foi discutido no ítem 4.1.2. Aumentos no $\mathrm{pH}$ da solução de solos tratados com G ou FG, quando ocorrem, são da ordem de O,1 a 0,3 unidades (SHAINBERG et al., 1989; McLA Y \& RITCHIE, 1993; ISMAIL et al., 1993) e são decorrentes da predominância do "efeito do sulfato" (reação de troca de ligantes entre o S O / e o OH-) sobre o "efeito do sal" (SHAINBERG et al., 1989).

A CE e a força iônica da solução nos subsolos tratados com G ou FG aumentaram com o aumento de $\mathrm{Ca}$ e $\mathrm{S}_{4}$ solúveis. Contudo, a magnitude desses acréscimos foi diferente para cada solo. Assim, as menores concentrações de $\mathrm{Ca}$ e $\mathrm{S}_{4}$ na solução foram encontradas nos solos LR ácricos e LE álico, indicando que esses solos possuem maior capacidade de adsorção desses íons, comparados aos LV álicos. Uma possível explicação para esse fato pode ser encontrada no maior teor de argila presente nos LR ácricos e no LE álico (superior a 500 g.kg- $^{1}$ ), associado a baixos 
índices $\mathrm{Ki}$ e $\mathrm{Kr}$ (Tabela 2), que indicam maior ocorrência de óxidos de $\mathrm{Fe}$ e $\mathrm{Al}$ ma fração argila. SHAINBERG et al. (1989) apresentaram os resultados da composição química da solução de dois solos argilosos e um arenoso, após o tratamento com $\mathrm{CaSO}_{4} \cdot 2 \mathrm{H}_{2} \mathrm{O}$, verificando que as concentrações de $\mathrm{Ca} \mathrm{e} \mathrm{S} 0_{4}$, bem como a concentração total de eletrólitos, foram menores nos solos argilosos. Os autores sugeriram, então, a ocorrência de uma adsorção do sal ( $\mathrm{CaS04})$ nesses solos. A adsorção de sal foi constatada também por MARCANO-MARTINEZ \& McBRIDE (1989), trabalhando com latossolos brasileiros, após equilíbrio com solução de $\mathrm{CaSO}_{4} \cdot 2 \mathrm{H}_{2} \mathrm{O}$ por 24 horas.

A "adsorção de sal" consiste, na verdade, ma adsorção simultânea de $\mathrm{Ca}^{2+} \mathrm{e}$ SO/- em função da ocorrência de cargas elétricas positivas e negativas coexistindo no subsolo, conforme foi demonstrado por RAIJ \& PEECH (1972). Esse fenômeno é possível pela presença de óxidos de Fe e AI no subsolo de solos altamente intemperizados, que possuem cargas elétricas dependentes do $\mathrm{pH}$ e da força iônica do meio (RAU \& PEECH, 1972; GILLMAN, 1991). Mais recentemente, ALLEONI (1992), estudando as propriedades eletroquímicas de solos ácricos, da mesma região que os utilizados no presente experimento, demonstrou que os citados solos apresentaram um balanço de cargas altamente dependente do $\mathrm{pH}$ e da força iônica do meio: a carga elétrica negativa aumentou e a positiva diminuiu com o aumento do $\mathrm{pH}$; enquanto que, para um mesmo valor de $\mathrm{pH}$, maiores valores de carga elétrica foram obtidos na maior concentração de $\mathrm{KCl}$ (maior força iônica).

No caso de solos tratados com gesso, um aumento na adsorção de $\mathrm{Ca}^{2+}$ (como de outros cátions) é possível pelo aumento das cargas negativas geradas com a adsorção específica de S O / (COUTO et al., 1979; ZHANG et al., 1987; HUE et al., 1985; MARCANO-MARTINEZ \& McBRIDE, 1989; CURTIN \& SYERS, 1990).

No presente estudo, a adsorção de $\mathrm{CaS0} 4$ nos tratamentos com G e FG foi particularmente evidente no LRác-1 (Tabela 11). Considerando-se que a quantidade de $\mathrm{CaSO}_{4}$ adicionada foi de $10 \mathrm{mmol}_{\mathrm{c} . \mathrm{dm}^{-}}{ }^{-}$de terra, e que a amostra de subsolo após a saturação continha, em média, 350 g.kg- ${ }^{1}$ de água, a concentração esperada de $\mathrm{Ca}$ e $\mathrm{S}_{4}$ 
Tabela 11 - Valores de pH, condutividade elétrica (CE), força iônica (1) e concentrações dos íons $\mathrm{Ca}, \mathrm{Mg}, \mathrm{K}, \mathrm{S}_{4}$ e F na solução de amostras de subsolos, após o cultivo com plantas de milho, em função dos tratamentos: sem tratamento (T), sulfato de cálcio (G), fosfogesso (FG) e carbonato de cálcio (C).

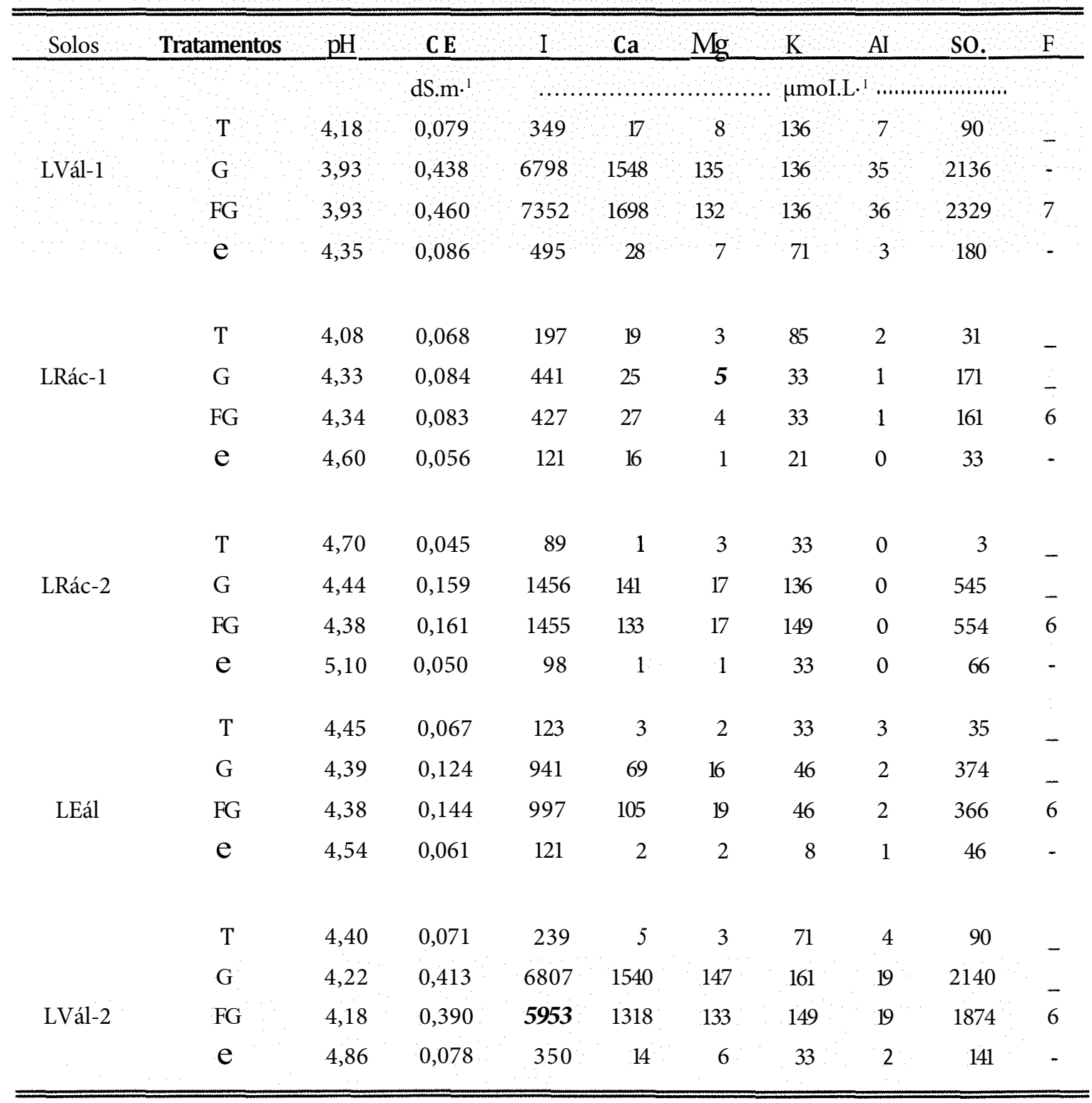


na solução, se não ocorresse adsorção, seria de, aproximadamente, $14500 \mu$ mol.1: $:^{1}$. Contudo, conforme pode-se observar na Tabela 11, os teores de Ca e $\mathrm{S}_{4} 4$ solúveis encontrados na solução do LRác-1 foram inferiores a $200 \mu$ mol.L-1 ${ }^{-1}$, indicando que mais de $99 \%$ do $\mathrm{CaS} 04$ adicionado foram adsorvidos. Outra evidência da adsorção do sal CaS04 no subsolo do LRác-1 foi a diminuição de K solúvel nos tratamentos com G ou FG, em comparação com o subsolo sem tratamento, mostrando que não houve deslocamento de $\mathrm{K}$ pelo Canos sítios de troca; ao contrário, parece ter havido uma coadsorção de $\mathrm{K}$ Isso pode ser explicado por um possível aumento das cargas negativas dependentes do $\mathrm{pH}$, geradas com a adsorção específica de So/-, resultando em maior adsorção de $\mathrm{Ca}, \mathrm{Mg}$ e $\mathrm{K}$.

$\mathrm{O}$ G e o FG causaram significativos aumentos na concentração total de $\mathrm{Al}$ na solução dos LV álicos (Tabela 11), sugerindo que, o "efeito do sal", com o Ca deslocando o Al para a solução, superou o efeito de "autocalagem", ou seja, as reações de troca sobrepujaram as reações de adsorção e precipitação. Por outro lado, no LRác-1 e no LEál, que apresentaram menores teores de $\mathrm{SO} /$ solúvel, o teor de $\mathrm{Al}$ na solução foi reduzido, tornando evidente a predominância do efeito de "autocalagem". SUMNER (1993) considerou que, em solos tratados com gesso, um dos mecanismos que leva à redução da toxicidade do $\mathrm{Al}^{3+}$ em solução é a sua adsorção nas cargas negativas criadas com a adsorção específica de SO/- (co-adsorção de SO/- e $\mathrm{Al}^{3}+$ ). No caso do presente experimento, é possível que alguma adsorção de $\mathrm{Al}^{3+}$ tenha ocorrido no LEál, no qual a concentração de Al solúvel diminuiu nos tratamentos com $\mathrm{G}$ ou $\mathrm{FG}$, a despeito da redução do pH (Tabela 11). SHAINBERG et al. (1989) mostraram resultados da composição química de dois solos argilosos tratados com gesso, em que a concentração de $\mathrm{Al}$ solúvel foi reduzida devido, segundo os autores, à co-adsorção de $\mathrm{SO} /-\mathrm{e} \mathrm{Al}^{3+}$.

Com excessão do LRác-1, observou-se aumento de Mg e $\mathrm{K}$ solúveis nos subsolos tratados com $\mathrm{G}$ ou FG, o que pode ser atribuído ao deslocamento desses cátions dos sítios de troca pelo Ca adicionado, confirmando os resultados obtidos por PA VAN et al. (1982), NOGUEIRA \& MOZETO (1990), ISMAIL et al, (1993). 


\subsubsection{Especiação química de alumínio e cálcio na solução do solo (extrato de saturação)}

As distribuições relativas das principais espécies químicas de alumínio e cálcio na solução dos subsolos (extrato de saturação) após o cultivo do milho, em função dos tratamentos, são apresentadas nas Tabelas 12 e 13. O LRác-2 foi excluído da Tabela 12, por não conter alumínio.

Os cálculos efetuados pelo programa de computador GEOCHEM (SPOSITO \& MATTIGOD, 1980) mostraram que as concentrações de $\mathrm{Al}^{3+} \mathrm{e} \mathrm{Ca}^{2+}$ livres foram sempre inferiores às de $\mathrm{A}$ e $\mathrm{C}$, devido à presença dos ligantes inorgânicos na solução, principalmente SO/-, $\mathrm{OH}$ - e P- (no tratamento com FG).

O tratamento com $\mathrm{C}$ alterou a distribuição das espécies de alumínio no extrato de saturação das amostras de subsolos, diminuindo a concentração e a atividade do $\mathrm{Al}^{3+}$ (Tabela 12) e elevando a proporção das espécies $\mathrm{AIOH}{ }^{2}+, \mathrm{Al}(\mathrm{OH})_{2}+\mathrm{e} \mathrm{Al}(\mathrm{OH})_{3}^{\circ}$ como resultado do aumento do $\mathrm{pH}$.

As proporções de $\mathrm{Al}^{3+}$ livre, em relação ao $\mathrm{Al}_{\mathfrak{t}}$, no extrato de saturação dos subsolos que receberam G ou FG como tratamento, foram invariavelmente menores do que aquelas encontradas nos subsolos sem tratamento (Tabela 12). Isso ocorreu pela associação iônica do $\mathrm{Al}^{3+}$ com SO/- e P- (FG), formando os pares iônicos $\mathrm{AlSO}_{4}{ }^{+}$, $\mathrm{AlF}^{2+}, \mathrm{AlF}_{2}{ }^{+}$e $\mathrm{AlF}_{3}{ }^{\circ}$. No tratamento com $\mathrm{G}$ a porcentagem de $\mathrm{AlSO}_{4}{ }^{+}$variou entre 12,5\% no LRác-1 a 50\%, no LVál-1, estando dentro da faixa obtida por outros autores (PAVAN et al., 1982; SUMNER et al., 1986; CHAVES et al., 1991). A maior proporção no LVál-1 deveu-se, provavelmente, à maior concentração de A (36,3 $\mu$ mol.L- $\left.{ }^{-}\right)$e ao $\mathrm{pH}$ mais baixo $(3,93)$ em relação aos demais solos. A concentração das espécies $\mathrm{AlOH}^{2+}, \mathrm{Al}(\mathrm{OH}) \mathrm{i}+\mathrm{e} \mathrm{Al}(\mathrm{OH}) /$ é aumentada com o aumento do $\mathrm{pH}$, resultando em um decréscimo na formação de $\mathrm{AlSO}_{4}{ }^{+}$.

A presença do $\mathrm{F}$ no extrato de saturação dos subsolos tratados com FG proporcionou a esse material um efeito superior ao do $G$ em reduzir a concentração e 
Tabela 12 - Distribuição relativa das principais espécies químicas de alumínio no extrato de saturação de amostras de subsolos, após o cultivo com plantas de milho, em função dos tratamentos: sem tratamento $(T)$, sulfato de cálcio $(G)$, fosfogesso (FG) e carbonato de cálcio (C).

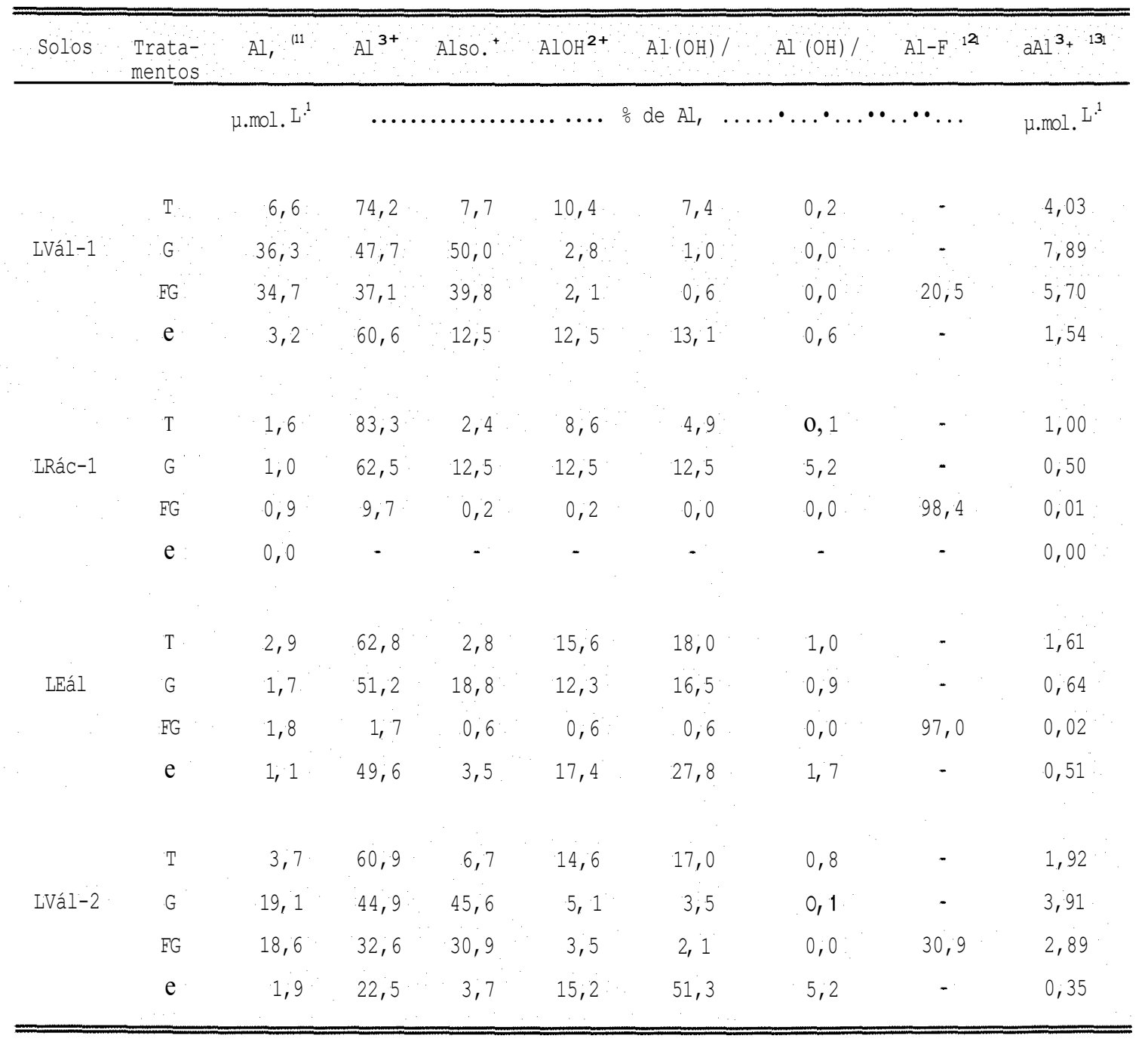

${ }^{111} \mathrm{Al}_{1}$ = concentração total de alumínio no extrato de saturação

${ }^{12} \mathrm{Al}-\mathrm{F}=\mathrm{AlF}^{2+}+\mathrm{AlF}_{2^{+}}+\mathrm{AlF} /$

${ }^{131} \mathrm{aAl}^{3+}=$ atividade de $\mathrm{Al}^{3+}$ no extrato de saturação 
a atividade do $\mathrm{Al}^{3+}$ (Tabela 12). Nos solos LRác-1 e LEál, nos quais a relação entre $\mathrm{Al}$ e $\mathrm{F}$ solúveis $(\mathrm{Al} / \mathrm{F})$ foi $<1$, a atividade do $\mathrm{Al}^{3+}$ foi completamente neutralizada, superando, inclusive, a ação do $\mathrm{C}$ no LEál. As porcentagens de $\mathrm{Al}_{\mathrm{t}}$ complexado com $\mathrm{F}$ foram de 20,5, 98,4, 97,0 e 30,9\% no LVál-1, LRác-1, LEál e LVál-2, respectivamente, embora a concentração de $\mathrm{F}$ tenha sido pelo menos 26 vezes inferior à do $\mathrm{S}_{4}$. Resultados semelhantes foram obtidos em outros trabalhos (MOORE \& RITCHIE, 1988; ALVA et al., 1988). ALVA et al. (1988) mostraram que, embora o $\mathrm{Al}_{\mathrm{t}}$ tenha aumentado na solução do solo após a aplicação de $\mathrm{FG}$, mais de $90 \%$ foram complexados pelo F. De maneira semelhante, MOORE \& RITCHIE (1988) observaram que a concentração de $\mathrm{Al}^{3+}$ na solução de um subsolo ácido da Austrália decresceu com o aumento da concentração de $\mathrm{AlF}^{2}+\mathrm{e} \mathrm{AlF}_{2}+$. Em um experimento com solução nutritiva, CAMERON et al. (1986) verificaram que mais de 90\% do F. presente na solução foram complexados com $\mathrm{Al}^{3+}$, enquanto menos de $0,5 \%$ de $\mathrm{SO} /$ total formou par iônico com esse cátion, em iguais concentrações dos dois ligantes.

Tais resultados revelam ter havido maior afinidade do $\mathrm{Al}^{3+}$ pelo $\mathrm{F}$ do que pelo $\mathrm{SO} /$. Esse fato pode ser explicado pelo princípio químico da teoria dos ácidos e bases descrito por PEARSON (1963), no qual os íns metálicos (ácidos de Lewis) e os ligantes (bases de Lewis), são classificados como duros, moles e intermediários, de acordo com a sua eletronegatividade, polarizibilidade e potencial de oxidação. Segundo essa teoria, os pares de íons formados em solução ocorrem preferencialmente entre ácidos duros com bases duras e ácidos moles com bases moles. No caso do presente trabalho, houve uma preferência do $\mathrm{Al}^{3+}$ em se associar com o $\mathrm{P}-$, que é uma base mais dura que o SO/ (o Fé o elemento mais eletronegativo da tabela periódica).

Verificou-se também, no presente experimento, que a espécie $\mathrm{AlF}^{2+}$ foi predominante nos LV álicos, nos quais a relação $\mathrm{Al} / \mathrm{F}$ foi $>1$. Quando essa relação foi $<1$, mais de $90 \%$ do $\mathrm{F}$ complexado apresentou-se na forma de $\mathrm{AlF}_{2^{+}}$, confirmando as observações de MOORE \& RITCHIE (1988). 
Tabela 13 - Distribuição relativa das principais espécies químicas de cálcio e relação entre as atividades de $\mathrm{Ca}^{2+}$ e $\mathrm{Al}^{3+}$ no extrato de saturação de amostras de subsolos, após o cultivo com plantas de milho, em função dos tratamentos: sem tratamento (T), sulfato de cálcio $(\mathrm{G})$, fosfogesso (FG) e carbonato de cálcio (C).

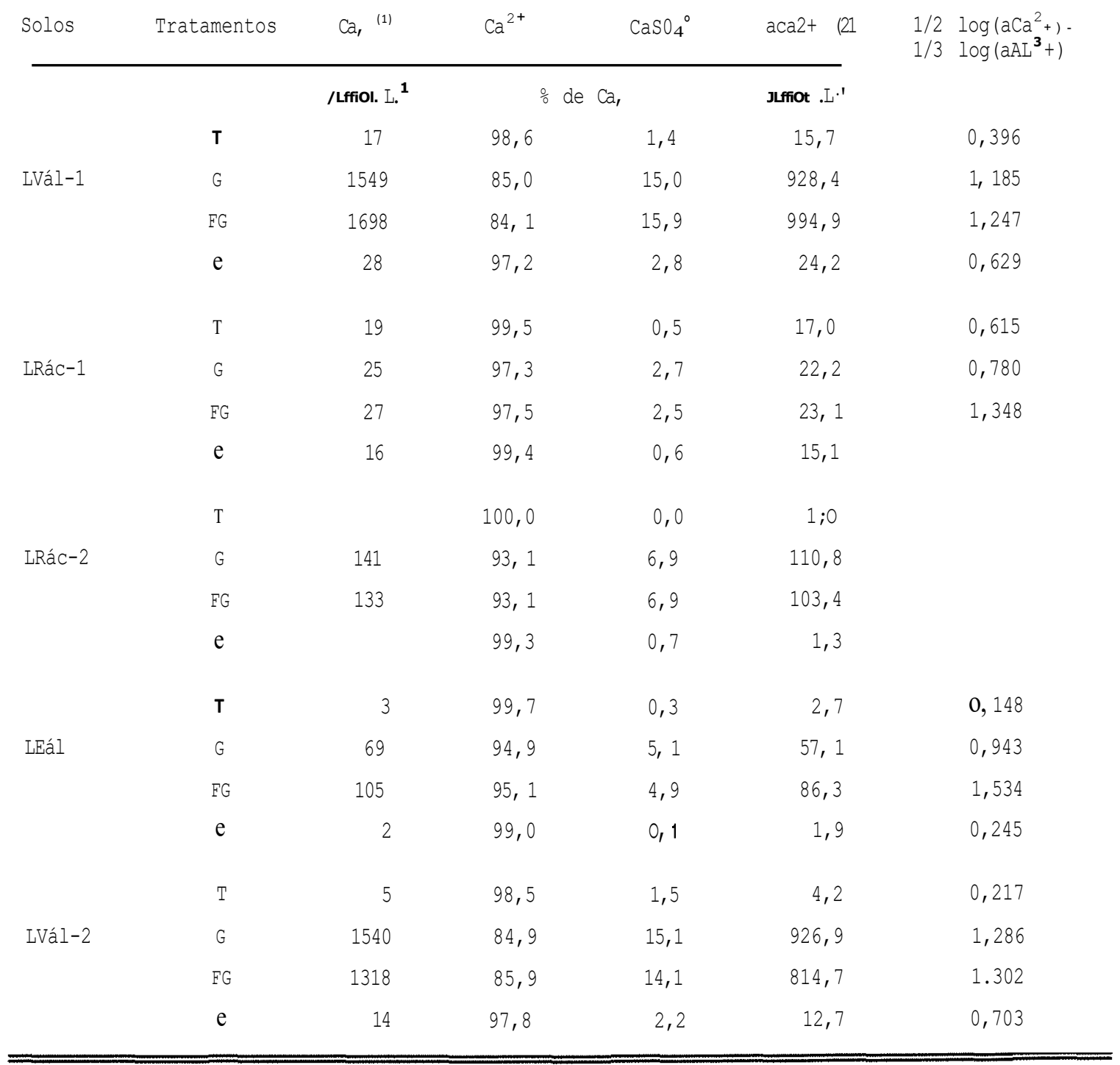

o) $\mathrm{Ca}$, = concentração total de cálcio no extrato de saturação

$\mathrm{t}_{\mathrm{i}} \mathrm{aCa}^{2+}=$ atividade de $\mathrm{Ca}^{2+}$ no extrato de saturação 
A quantidade de $\mathrm{CaSO}_{4}$ adicionada (equivalente a $10 \mathrm{mmol}_{\mathrm{c}} \cdot \mathrm{dm}^{3}$ ) parece ter sido insuficiente para reduzir a atividade de $\mathrm{Al}^{3+}$ nos $\mathrm{LV}$ álicos, que possuiam inicialmente os maiores teores de $\mathrm{Al}^{3+}$ trocável $\left(13,8\right.$ e $8,7 \mathrm{mmol}_{\mathrm{c}} \cdot \mathrm{dm}^{-}{ }^{3}$ de terra, respectivamente) e porcentagem de saturação por $\mathrm{Al}^{3+}$ acima de $82 \%$ (Tabela 3). Ao contrário, a atividade de $\mathrm{Al}^{3+}$ aumentou, passando de 4,03 para 7,89 e $5,70 \mu$ mol.L- ${ }^{1}$ no LVál-1, e de 1,92 para 3,91 e 2,89 $\mu$ mol.L-1 no LVál-2, nos tratamentos com G e FG, respectivamente (Tabela 12). Isso sugere que, nesse caso, a formação dos complexos $\mathrm{AlSO}_{4}+\mathrm{e} \mathrm{Al-F}\left(\mathrm{AlF}^{2+}, \mathrm{AlF} /, \mathrm{AlF}_{3}^{\circ}\right)$ não foi suficiente para amenizar o "efeito do sal" que causou uma significativa elevação do $\mathrm{Al}_{\mathrm{t}}$ solúvel nesses tratamentos (Tabela 12). Os cálculos realizados pelo GEOCHEM mostraram que mais de $11 \%$ do $\mathrm{SO} /$ - total solúvel foram complexados com $\mathrm{Ca}, \mathrm{Mg}$ e $\mathrm{Mn}$ (cujas concentrações aumentaram na solução dos LV álicos tratados com G ou FG), enquanto que apenas cerca de $0,5 \%$ do SO/- formou par iônico com $\mathrm{Al}^{3+}\left(\mathrm{AlSO}_{4}^{+}\right)$. Pode-se observar na Tabela 13 que as maiores proporções de $\mathrm{CaS}_{4}{ }^{\circ}$, em relação ao $\mathrm{Ca}_{1}$, foram encontradas nos LV álicos.

Esses resultados vão de encontro aos obtidos na maioria dos estudos sobre o efeito de G ou FG na composição química da solução do solo (SUMNER et al., 1986; SINGH, 1982; PAVAN et al., 1982, 1984; RAU et al., 1988; SHAINBERG et al., 1989), onde a atividade do $\mathrm{Al}^{3+}$ foi reduzida mesmo com o aumento da concentração de alumínio total. Entretanto, NOGUEIRA \& MOZETO (1990) demonstraram que, em três dos seis solos utilizados por aqueles autores, a espécie $\mathrm{Al}^{3}+$ foi predominante (> $70 \%$ do $\mathrm{Al}_{\mathrm{t}}$ ) após a aplicação de $\mathrm{CaSO}_{4} \cdot 2 \mathrm{H}_{2} \mathrm{O}$.

ISMAIL et al. (1983), trabalhando com amostras de dois solos ácidos da Malásia: um ultisol, com $72 \%$ de saturação por $\mathrm{Al}^{3}+$ e $25 \%$ de argila e um oxisol, com $74 \%$ de saturação por $\mathrm{Al}^{3+}$ e $54 \%$ de argila, verificaram que a atividade de $\mathrm{Al}^{3+}$ aumentou de 36 para $52 \mu$ mol.L' no primeiro solo pela aplicação de 2 tha- ${ }^{1}$ de gesso $\left(11,6 \mathrm{mmol}_{\mathrm{c}} \cdot \mathrm{dm}^{3}\right)$. Dobrando-se a dose aplicada (4 tha- ${ }^{1}$ ou $23,2 \mathrm{mmol}_{\mathrm{c}} \cdot \mathrm{dm}^{3}$ ) a atividade de $\mathrm{Al}^{\mathrm{H}}$ foi reduzida para $8 \mu$ moI.L- ${ }^{1}$, embora o $\mathrm{Al}_{\mathrm{t}}$ solúvel tenha aumentado 
de 73 para $231 \mu$ mol.L. ${ }^{1}$. Por outro lado, no oxisol, a atividade de $\mathrm{Al}^{\mathrm{H}}$ foi reduzida de 27 para 16 e $4 \mu \mathrm{mol} . L \cdot 1$, nas doses de 2 e 4 t.ha 1 , respectivamente.

A relação entre as atividades de $\mathrm{Ca}^{2}+\mathrm{e} \mathrm{Al}^{\mathrm{H}}$, representada nesse trabalho pela expressão: $1 / 2 \log \left(\mathrm{aCa}^{2+}\right)-1 / 3 \log \left(\mathrm{aAl}^{+}\right)$, foi aumentada com a adição dos corretivos nos cinco solos (Tabela 13). Assim, embora a atividade do Al tenha sido aumentada nas amostras dos LV álicos com a aplicação de sulfato de cálcio e fosfogesso, o aumento da atividade de $\mathrm{Ca}$ pode aliviar a toxicidade do $\mathrm{Al}$ para as raízes.

\subsection{Efeito dos tratamentos no crescimento e absorção de água e nutrientes pelo milho.}

\subsubsection{Comprimento radicular}

A análise de variância mostrou que o comprimento de raízes (Tabela 14) foi significativamente influenciado $(\mathrm{P}<0,01)$ pelos tratamentos, tipo de subsolo e pela interação solos $\mathrm{x}$ tratamentos.

De acordo com os resultados apresentados na Tabela 14, independentemente dos tratamentos, o maior e o menor comprimento radicular corresponderam, respectivamente, ao LRác-2 e ao LVál-1, o que está associado à ausência de alumínio no primeiro solo e à elevada saturação de alumínio $(87,3 \%)$ no segundo.

Nota-se que as condições químicas existentes originalmente nos subsolos causaram severas restrições ao aprofundamento do sistema radicular do milho, de maneira que em todos os solos estudados, os menores comprimentos de raízes foram observados nos subsolos sem tratamento (T). Tais restrições estão relacionadas, provavelmente, com elevadas saturações por $\mathrm{Al}^{3}$ ( $>61 \%$ ) e baixos teores de $\mathrm{Ca}^{2+}$ trocável (Tabela 3). 
Tabela 14 - Estimativa do comprimento de raízes de milho em amostras de subsolos, em função dos tratamentos: sem tratamento $(\mathrm{T})$, sulfato de cálcio $(\mathrm{G})$, fosfogesso (FG) e carbonato de cálcio (C). 女

\begin{tabular}{|c|c|c|c|c|c|c|}
\hline \multirow{2}{*}{ Tratamentos } & \multicolumn{5}{|c|}{ Solos } & \multirow[b]{2}{*}{ Médias } \\
\hline & LVál-1 & LRác-1 & LRác-2 & LEál & LVál-2 & \\
\hline & \multicolumn{6}{|c|}{ 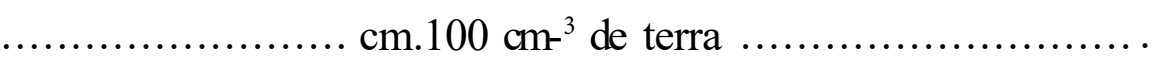 } \\
\hline $\mathrm{T}$ & $196 \mathrm{c}$ & $222 \mathrm{~b}$ & $390 \mathrm{~b}$ & $298 \mathrm{~b}$ & $283 \mathrm{~b}$ & $278 \mathrm{~b}$ \\
\hline G & $399 \mathrm{~b}$ & $630 \mathrm{a}$ & 658 a & $583 \mathrm{a}$ & $605 a$ & $575 \mathrm{a}$ \\
\hline FG & $438 \mathrm{~b}$ & $653 \mathrm{a}$ & $698 \mathrm{a}$ & $616 \mathrm{a}$ & $656 \mathrm{a}$ & $612 \mathrm{a}$ \\
\hline e & 549 a & 591 a & $642 \mathrm{a}$ & 536 a & $584 \mathrm{a}$ & $580 \mathrm{a}$ \\
\hline Médias & $396 \mathrm{e}$ & $524 \mathrm{~B}$ & $597 \mathrm{~A}$ & $508 \mathrm{~A}$ & $532 \mathrm{~B}$ & \\
\hline C.V. $(\%)$ & \multicolumn{5}{|c|}{8,64} & \\
\hline
\end{tabular}

(!) Médias seguidas de mesma letra minúscula, na vertical, e maiúscula, na horizontal, não diferem estatisticamente pelo teste de Tukey a $5 \%$

Assim, o comprimento de raízes aumentou marcadamente em resposta à aplicação tanto de C como de G ou FG. Os acréscimos variaram na faixa de 65 a 180\%, no tratamento com C; 69 a 184\% no tratamento com G; e 79 a 194\% no tratamento com FG (Tabela 14), sendo que as menores amplitudes ocorreram no LRác-2. A resposta positiva das raízes no LRác-2 resultou, provavelmente, da correção da deficiência de cálcio, uma vez que esse solo não continha alumínio.

RITCHEY et al. (1982) demonstraram que, em subsolos ácidos do cerrado, os teores de $\mathrm{Ca}^{2+}$ trocável abaixo da faixa de 0,2 a $0,5 \mathrm{mmol}_{\mathrm{c}} \cdot \mathrm{dm}^{-3}$ limitaram o desenvolvimento radicular de plantas de milho, soja e trigo. Porém, a adição de apenas 1,0 a 1,5 mmol $_{c} \cdot \mathrm{dm}^{-}{ }^{3}$ de $\mathrm{Ca}$ foi suficiente para que o crescimento fosse normalizado. 
O efeito positivo do $\mathrm{C}$ em favorecer o crescimento das raízes nos subsolos ácidos era previsível em decorrência do aumento do $\mathrm{pH}$ e do teor de $\mathrm{Ca}^{2+}$ trocável e redução do $\mathrm{Al}^{3+}$ trocável e do $\mathrm{Al}^{3+}$ em solução.

Considerando-se somente os parâmetros de acidez da fase sólida do solo $(\mathrm{pH}$, $\mathrm{Al}^{3+}$ trocável, $\mathrm{H}^{+}+\mathrm{Al}^{3+}$ e percentagem de saturação por $\mathrm{Al}^{\mathrm{H}}$, era de se esperar um efeito superior do $\mathrm{C}$ em promover o crescimento do sistema radicular, em relação ao G e ao FG. Entretanto, isso ocorreu apenas no LVál-1. Nos demais solos não houve diferença significativa entre os corretivos, embora o G e o FG tenham sido menos efetivos que o $\mathrm{C}$ em aumentar o $\mathrm{pH}\left(\mathrm{pH}\right.$ em $\left.\mathrm{CaCl}_{2} 0,01 \mathrm{ml}^{1} \mathrm{e}^{1}\right)$ e reduzir $\mathrm{AI}^{3+}$ trocável, $\mathrm{H}^{+}+\mathrm{Al}^{3+}$ e percentagem de $\mathrm{Al}^{3+}$, conforme foi discutido anteriormente (Tabelas $6 \mathrm{e}$ 7). Tal fato evidencia a importância de se considerar, também, as alterações na composição química e as interações entre os íons na solução de solos tratados com $G$ ou FG. Dessa forma, o efeito benéfico do G e do FG sobre as raízes do milho, nos subsolos com alumínio, pode ser explicado pela redução da atividade do $\mathrm{Al}^{3+}$ no LRác-1 e no LEál com o aumento na concentração dos complexos $\mathrm{AlS04}^{+}$e Al-F (no tratamento com FG). Vários autores têm demonstrado que a formação dos pares iônicos $\mathrm{AlS}_{4}{ }^{+}$, (PAVAN et al., 1982; 1984; 1987; SINGH, 1982; SUMNER et al., 1986), $\mathrm{AlF}_{2}{ }^{+} \mathrm{e}$ $\mathrm{AlF}^{2+}$ (OATES \& CALDWELL, 1985; CAMERON et al., 1986; ALVA et al., 1988) reduzem a toxicidade do $\mathrm{Al}$ para as raízes.

Já nos LV álicos, o efeito do G e do FG seria negativo, se apenas a atividade do $\mathrm{Al}^{\mathrm{H}}$ fosse considerada, visto que a mesma aumentou. No entanto, a atividade de $\mathrm{Ca}^{2+}$ foi elevada acima de $900 \mu$ mol.L- ${ }^{1}$ (Tabela 13). Assim, o balanço final foi positivo, considerando-se a interação entre Ca e Al. Tomando-se, como exemplo, o LVál-1, para o subsolo sem tratamento $(\mathrm{T})$ as atividades de $\mathrm{Ca}^{2+}$ e $\mathrm{Al}^{3+}$ foram, respectivamente, 15,7 e 4,0 $\mu_{\text {moLL- }}{ }^{1}$; a relação entre as atividades, representada pela expressão $1 / 2$ $\log \left(\mathrm{aCa}^{2+}\right)-1 / 3 \log \left(\mathrm{aAl}^{3+}\right)$, é igual a $0,396 \mu \mathrm{mol.L}^{-1}$, e o comprimento radicular igual a $196 \mathrm{~cm}$. No tratamento com G, os valores correspondentes de atividade foram de 928 e 7,89 $\mu$ moLL- ${ }^{-}$, a relação de 1,183 e o comprimento de raízes igual a $329 \mathrm{~cm}$. Para o FG, as atividades foram 928 e 5,70 $\mu \mathrm{mol}$. $\mathrm{L}^{-}{ }^{1}$, a relação 1,247 e o comprimento radicular $438 \mathrm{~cm}$. 
KHASAWNEH (1971) relatou que a absorção de um determinado ín pelas raízes depende não só da sua atividade na solução, mas também da atividade de outros íons e da relação que existe entre os íons em solução e na fase sólida do solo. Esse aspecto é de fundamental importância, em se tratando do uso de G (ou FG), pela possível alteração na relação de atividade de cátions. Algumas expressões têm sido

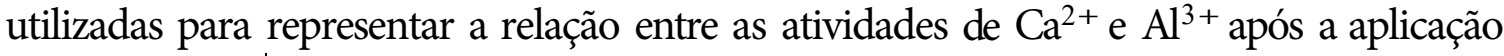
de G (SUMNER et al., 1986; NOBLE et al., 1988a,b), obtendo-se boas correlações com o crescimento radicular (NOBLE et al., 1988a,b; SHAMSHUDDIN et al., 1991).

Ainda com relação ao efeito do cálcio na diminuição da fitotoxicidade do alumínio, em alguns estudos com solução nutritiva foi observado que, para uma dada concentração de $\mathrm{AI}$, o aumento da concentração de $\mathrm{Ca}$, aplicado como $\mathrm{CaSO}_{4} \cdot 2 \mathrm{H}_{2} \mathrm{O}$ resultou em maior alongamento de raízes de algodoeiro (ADAMS \& LUND, 1966) e soja (BLAMEY et al., 1983; NOBLE et al., 1988a). Nesses casos, há dúvidas se houve realmente um efeito específico do $\mathrm{Ca}$, ou do aumento da força iônica, aliado à formação do complexo $\mathrm{AlSO}_{4}+$, em reduzir a atividade do $\mathrm{Al}^{3+}$. Por outro lado, ALVA et al. (1986c), usando a soma das atividades das espécies monoméricas de $\mathrm{Al}\left(\mathrm{Ea}_{\mathrm{A}}\right.$ i noro) para caracterizar o nível de AI no ambiente radicular (eliminando, portanto, o efeito da força iônica), mostraram que o aumento da concentração de Ca na faixa de 500 a 15.000 $\mu$ mol.L- ${ }^{-1}$ diminuiu substancialmente a toxicidade do AI para soja, alfafa, girassol e trevo, em $\mathrm{Ea}_{\mathrm{A}}$ inoro $\mp 18 \mu \mathrm{mol.L-}{ }^{-1}$. Em outro estudo, ALVA et al. (1986a) mostraram que, para uma solução com $\mathrm{Ea}_{\mathrm{Al}}$ monde $20 \mu$ mol.L- ${ }^{1}$, o comprimento radicular da soja aumentou de 85 para $209 \mathrm{~mm}$, e o do trevo de 56 para $85 \mathrm{~mm}$, com a adição de 500 e $5.000 \mu \mathrm{moLL} \cdot{ }^{1}$ de $\mathrm{Ca}$ ma forma de $\mathrm{Ca}\left(\mathrm{NO}_{3}\right)_{\mathrm{i}} .4 \mathrm{H}_{2} 0$. A resposta não foi devida à deficiência de $\mathrm{Ca}$ porque na ausência de $\mathrm{Al}$, o aumento na concentração de $\mathrm{Ca}$ de 500 até $15.000 \mu \mathrm{mol} . \mathrm{L}^{-1}$ não afetou o comprimento das raízes.

O menor efeito do G e do FG no LVál-1, comparado aos demais solos (Tabela 14), deveu-se, provavelmente, ao aumento do teor de alumínio em solução pelo aumento da força iônica, de modo que a formação dos complexos $\mathrm{AlSO}_{4}+\mathrm{e}$ Al-F (FG) 
não foi suficiente para reduzir a atividade do $\mathrm{Al}^{3+}$. Esse resultado parece confirmar uma tendência observada por outros autores (YAMADA, 1988; ALVA \& SUMNER, 1990; DEMATIÊ, 1992) de que, em solos com teores muito elevados de $\mathrm{Al}^{3+}$ trocável e com baixa capacidade de adsorção de SO/- o efeito do gesso (ou FG) em afetar positivamente o crescimento radicular e, conseqüentemente, a produção de culturas não é muito expressivo.

\subsubsection{Consumo de água e produção de matéria seca}

O consumo de água (Tabela 15) e o peso de matéria seca da parte aérea do milho (Tabela 16) foram influenciados significativamente $(\mathrm{P}<0,01)$ pelos tratamentos, tipo de solo e pela interação solos x tratamentos.

De maneira geral, a aplicação de G, FG e Caos subsolos ácidos e/ou pobres em bases resultou na melhoria das condições químicas previamente adversas, permitindo maior absorção de água pelas raízes (principalmente durante o período do déficit hídrico induzido) com conseqüente aumento no acúmulo de matéria seca. Analisando-se conjuntamente os resultados apresentados nas Tabelas 15 e 16, percebe-se que houve uma estreita relação entre consumo de água e produção de matéria seca. Isso não é surpresa, pois o papel da água no crescimento vegetal, através da fotossíntese e expansão celular é fato amplamente conhecido.

Considerando-se o efeito isolado do tipo de subsolo, verificou-se a mesma tendência observada no comprimento radicular, com o LVál-1 e o LRác-2 apresentando, respectivamente, o menores e os maiores valores de consumo de água (Tabela 15) e produção de matéria seca (Tabela 16).

Com relação ao efeito dos tratamentos, tanto o consumo de água quanto a produção de matéria seca aumentou significativamente em resposta à adição dos corretivos. Nos LR ácricos e no LE álico, a produção de matéria seca foi maior nos tratamentos com G e FG do que no tratamento com C. Essa diferença pode ser explicada pela maior disponibilidade de nutrientes ( $\mathrm{Ca}, \mathrm{Mg}, \mathrm{K}$ e S) ma solução dos subsolos tratados com G ou FG (Tabela 11). 
Tabela 15 - Consumo de água pelas plantas de milho, após a transferência para os vasos contendo as amostras de subsolos, em função dos tratamentos: sem tratamento (T), sulfato de cálcio $(\mathrm{G})$, fosfogesso (FG) e carbonato de cálcio (C).m

\begin{tabular}{|c|c|c|c|c|c|c|}
\hline \multirow{2}{*}{ Tratamentos } & \multicolumn{5}{|c|}{ Solos } & \multirow[b]{2}{*}{ Médias } \\
\hline & LVál-1 & LRác-1 & LRác-2 & LEál & LVál-2 & \\
\hline & \multicolumn{6}{|c|}{ 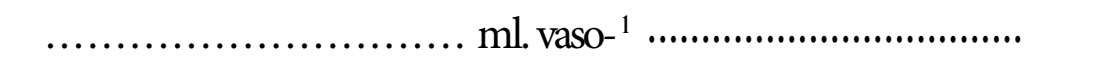 } \\
\hline $\mathrm{T}$ & $1472 \mathrm{~b}$ & 1538 c & $1712 \mathrm{~b}$ & $1548 \mathrm{c}$ & $1717 \mathrm{~b}$ & $1597 \mathrm{c}$ \\
\hline G & $1594 \mathrm{a}$ & $1885 \mathrm{a}$ & 2036 a & 1931 a & $2000 \mathrm{a}$ & $1889 \mathrm{a}$ \\
\hline FG & 1593 a & 1912 a & 2019 a & 1969 a & 2018 a & $1902 \mathrm{a}$ \\
\hline e & 1619 a & $1734 \mathrm{~b}$ & 1972 a & $1786 \mathrm{~b}$ & $1940 \mathrm{a}$ & $1810 \mathrm{~b}$ \\
\hline Médias & $1669 \mathrm{C}$ & $1768 \mathrm{~B}$ & $1935 \mathrm{~A}$ & $1808 \mathrm{~B}$ & 1919 A & \\
\hline C.V. (\%) & \multicolumn{6}{|c|}{2,75} \\
\hline
\end{tabular}

(1) Médias seguidas de mesma letra minúscula, na vertical, e maiúscula, na horizontal, não diferem estatisticamente pelo teste de Tukey a $5 \%$ •

A menor concentração de $\mathrm{Ca}$, Mg e $\mathrm{K}$ na solução dos subsolos tratados com C, em comparação com aqueles tratados com G ou FG (Tabela 11) deveu-se, provavelmente, à adsorção desses cátions nas cargas elétricas negativas criadas com o aumento do $\mathrm{pH}$. Assim, embora o $\mathrm{C}$ tenha sido mais efetivo em reduzir a toxicidade de alumínio para as raízes nos LV álicos (Tabela 14), a maior concentração de nutrientes na solução dos subsolos tratados com G ou FG contribuiu para que o acúmulo de 
matéria seca fosse semelhante nos três tratamentos. Outros autores também verificaram aumentos no peso de matéria seca de trigo (McLAY \& RITCHIE, 1993), cafeeiro (PAVAN et al., 1982; CHAVES et al., 1991), milho (ISMAIL et al., 1993), trevo (KEERTHSINGUE et al., 1991), soja e alfafa (ALVA \& SUMNER, 1990) em resposta à aplicação de gesso, em ensaios com vasos.

Tabela 16 - Produção de matéria seca da parte aérea de plantas de milho, em função dos tratamentos: sem tratamento $(\mathrm{T})$, sulfato de cálcio $(\mathrm{G})$, fosfogesso $(\mathrm{FG})$ e carbonato de cálcio $\{\mathrm{C}) . \nless$

\begin{tabular}{|c|c|c|c|c|c|c|}
\hline \multirow{2}{*}{ Tratamentos } & \multicolumn{5}{|c|}{ Solos } & \multirow[b]{2}{*}{ Médias } \\
\hline & LVál-1 & LRác-1 & LRác-2 & LEál & LVál-2 & \\
\hline & \multicolumn{5}{|c|}{ 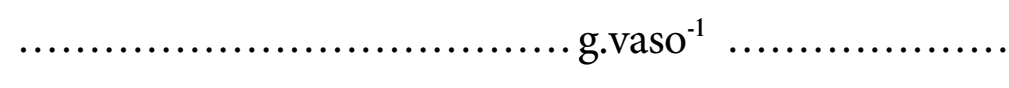 } & \\
\hline $\mathrm{T}$ & $4,85 \mathrm{~b}$ & $5,03 \mathrm{c}$ & $6,22 \mathrm{c}$ & 5,09 e & $6,12 b$ & $5,46 \mathrm{c}$ \\
\hline G & $5,81 \mathrm{a}$ & $6,99 a$ & $7,54 \mathrm{a}$ & $6,77 \mathrm{ab}$ & 7,27 a & $6,85 a$ \\
\hline FG & $5,99 \mathrm{a}$ & $6,84 \mathrm{a}$ & $7,50 \mathrm{a}$ & $6,97 \mathrm{a}$ & 7,51 a & $6,99 a$ \\
\hline e & $6,09 \mathrm{a}$ & $5,75 \mathrm{~b}$ & $6,91 \mathrm{~b}$ & $6,33 \mathrm{~b}$ & $6,97 \mathrm{a}$ & $6,41 \mathrm{~b}$ \\
\hline Médias & $5,68 \mathrm{e}$ & $6,15 \mathrm{~B}$ & $7,04 \mathrm{~A}$ & $6,29 \mathrm{~B}$ & $6,97 \mathrm{~A}$ & \\
\hline C.V. $\{\%)$ & \multicolumn{5}{|c|}{4,92} & \\
\hline
\end{tabular}

O) Médias segmdas de mesma letra rnmuscula, na vertical, e mañscula, na honzontal, nao diferern estatisticamente pelo teste de Tukey a $5 \%$. 


\section{2.3. Absorção de nutrientes}

Os teores totais de $\mathrm{P}, \mathrm{S}, \mathrm{Ca}$ e $\mathrm{Mg}$ na matéria seca da parte aérea das plantas de milho encontram-se na tabela 17. De acordo com as expectativas, o teor de $\mathrm{Ca}$ aumentou com a aplicação dos corretivos. Nos solos LRác-2, LEál e LVál-2, o menor conteúdo de Cano tratamento com $\mathrm{C}$, comparado aos tratamentos com G ou FG, pode ser explicado pela menor concentração de Ca na solução, conforme pode-se verificar na Tabela 11.

$\mathrm{O}$ teor de $\mathrm{S}$ não foi afetado pelo $\mathrm{C}$, mas aumentou pela adição de $\mathrm{G}$ ou $\mathrm{FG}$ nos LV álicos e, em menor magnitude, no LRác-1. A ausência do efeito do G e do FG nos demais solos resultou provavelmente da elevada adsorção de SO/- com consequente decréscimo na sua disponibilidade.

Os teores totais de $\mathrm{P}$ e $\mathrm{Mg}$ foram maiores na ausência dos corretivos, nos cinco solos estudados (Tabela 17). Isso, contudo, não significa um efeito negativo do G, FG ou C na absorção desses nutrientes, podendo ter ocorrido, outrossim, um efeito de diluição devido ao maior crescimento das plantas nos subsolos corrigidos.

Na tabela 18 são apresentados os resultados de $\mathrm{Ne} \mathrm{K}$ absorvidos pelas plantas de milho. Nota-se que a absorção de ambos foi aumentada com a adição dos corretivos, confirmando os resultados da análise de solo, em que os teores no subsolo foram diminuídos pela absorção (Tabelas 8 e 9). Vale recordar que as quantidades de $\mathrm{N}$ e $\mathrm{K}$ adicionadas na parte superior foram de 40 e $30 \mathrm{mg}$, respectivamente, de modo que uma absorção acima desses valores deve estar associada com a capacidade das raízes em penetrar e absorver esses nutrientes no subsolo. Resultados semelhantes foram obtidos por RAU et al. (1988) com sorgo, e por McLAY \& RITCHIE (1993) com trigo, em experimentos com vasos, mesmo sem ter havido aumentos significativos no peso de matéria seca de raízes. 
Tabela 17 - Teores totais de P, S, Ca e Mg na matéria seca da parte aérea das plantas de milho, em função dos tratamentos: sem tratamento (T), sulfato de cálcio (G), fosfogesso (FG) e carbonato de cálcio (C). oJ

\begin{tabular}{|c|c|c|c|c|c|}
\hline \multirow{2}{*}{ Tratamentos } & \multicolumn{5}{|c|}{ Solos } \\
\hline & LVá.J-1. & I,Rác-1 & LRác $=2$ & _LE.ál_ & LLYál=2 \\
\hline \multicolumn{6}{|l|}{ p (gkg-1) } \\
\hline $\mathrm{T}$ & $3,0 \mathrm{a}$ & $2,9 \mathrm{a}$ & $2,3 \mathrm{a}$ & $2,7 \mathrm{a}$ & $2,5 \mathrm{a}$ \\
\hline G & $2,5 \mathrm{~b}$ & $2,2 \mathrm{bc}$ & $2,0 \mathrm{ab}$ & $2,0 \mathrm{~b}$ & $1,9 \mathrm{~b}$ \\
\hline FG & $2,5 \mathrm{~b}$ & $1,9 \mathrm{e}$ & $2,1 \mathrm{ab}$ & $2,0 \mathrm{~b}$ & $2,0 \mathrm{~b}$ \\
\hline e & $2,3 \mathrm{~b}$ & $2,4 \mathrm{~b}$ & $1,8 \mathrm{~b}$ & $2,3 \mathrm{ab}$ & $1,8 \mathrm{~b}$ \\
\hline C.V. (\%) & \multicolumn{5}{|c|}{9,37} \\
\hline \multicolumn{6}{|l|}{$S$ (gkg-1) } \\
\hline $\mathrm{T}$ & $0,7 \mathrm{~b}$ & $0,7 \mathrm{a}$ & $0,5 \mathrm{e}$ & $0,7 \mathrm{a}$ & $0,7 \mathrm{~b}$ \\
\hline G & $1,6 \mathrm{a}$ & $0,8 \mathrm{a}$ & $0,8 \mathrm{a}$ & $0,8 \mathrm{a}$ & $1,6 \mathrm{a}$ \\
\hline FG & $1,6 \mathrm{a}$ & $0,8 \mathrm{a}$ & $0,8 \mathrm{a}$ & $0,8 \mathrm{a}$ & $1,6 \mathrm{a}$ \\
\hline e & $0,9 \mathrm{~b}$ & $0,7 \mathrm{a}$ & $0,6 \mathrm{~b}$ & $0,7 \mathrm{a}$ & $0,7 \mathrm{~b}$ \\
\hline C.V. $(\%)$ & \multicolumn{5}{|c|}{9,12} \\
\hline \multicolumn{6}{|l|}{ Ca (g.kg-1) } \\
\hline $\mathrm{T}$ & $2,9 \mathrm{~b}$ & $2,7 \mathrm{~b}$ & $2,1 \mathrm{e}$ & $3,6 \mathrm{c}$ & $2,4 \mathrm{e}$ \\
\hline G & $5,6 \mathrm{a}$ & $5,7 \mathrm{a}$ & $5,7 \mathrm{a}$ & $5,5 \mathrm{a}$ & $5,5 \mathrm{a}$ \\
\hline FG & $5,4 \mathrm{a}$ & $5,4 \mathrm{a}$ & $5,9 \mathrm{a}$ & $5,7 \mathrm{a}$ & $5,3 \mathrm{a}$ \\
\hline e & $5,3 \mathrm{a}$ & $5,3 \mathrm{a}$ & $3,8 \mathrm{~b}$ & $4,7 \mathrm{~b}$ & $4,5 \mathrm{~b}$ \\
\hline C.V. (\%) & \multicolumn{5}{|c|}{5,36} \\
\hline \multicolumn{6}{|l|}{ Mg (gkg-1) } \\
\hline $\mathrm{T}$ & $3,0 \mathrm{a}$ & $2,8 \mathrm{a}$ & $2,0 \mathrm{a}$ & $2,8 \mathrm{a}$ & $2,7 \mathrm{a}$ \\
\hline G & $2,3 \mathrm{~b}$ & $1,8 \mathrm{e}$ & $1,8 \mathrm{a}$ & $2,3 \mathrm{~b}$ & $2,0 \mathrm{~b}$ \\
\hline FG & $2,3 \mathrm{~b}$ & $2,0 \mathrm{bc}$ & $1,7 \mathrm{a}$ & $2,3 \mathrm{~b}$ & $2,0 \mathrm{~b}$ \\
\hline e & $2,2 \mathrm{~b}$ & $2,2 \mathrm{~b}$ & $1,8 \mathrm{a}$ & $2,5 \mathrm{ab}$ & $1,8 \mathrm{~b}$ \\
\hline C.V. (\%) & \multicolumn{5}{|c|}{8,95} \\
\hline
\end{tabular}

(i) Médias seguidas da mesma letra, dentro de cada nutriente, dentro de cada solo, não diferem estatisticamente pelo teste de Tukey a $5 \%$. 
Tabela 18 - Absorção de N e K pelas plantas de milho, em função dos tratamentos: sem tratamento $(\mathrm{T})$, sulfato de cálcio $(\mathrm{G})$, fosfogesso $(\mathrm{FG})$ e carbonato de cálcio $(\mathrm{e}) .0)$

\begin{tabular}{|c|c|c|c|c|c|}
\hline \multirow{2}{*}{ Tratamentos } & \multicolumn{5}{|c|}{ Solos } \\
\hline & LVál-1 & LRác-1 & LRác-2 & LEál & LVál-2 \\
\hline \multicolumn{6}{|c|}{ N absorvido (mg. vaso- ${ }^{1}$ ) } \\
\hline $\mathrm{T}$ & $57,9 \mathrm{~b}$ & $50,0 \mathrm{~b}$ & $63,7 \mathrm{~b}$ & $55,0 \mathrm{~b}$ & $63,3 \mathrm{~b}$ \\
\hline $\mathrm{G}$ & 77,6 a & 75,3 a & 73,6 a & 69,6 a & $73,0 \mathrm{a}$ \\
\hline FG & 78,1 a & 72,6 a & 77,2 a & $71,5 \mathrm{a}$ & 74,1 a \\
\hline $\mathrm{e}$ & $78,5 \mathrm{a}$ & 70,9 a & $75,5 \mathrm{a}$ & 70,9 a & $73,2 \mathrm{a}$ \\
\hline e.V.( $(\%)$ & & & 17 & & \\
\hline \multicolumn{6}{|c|}{ K absorvido (mg. vaso- ${ }^{1}$ ) } \\
\hline $\mathrm{T}$ & $34,0 \mathrm{~b}$ & $35,0 \mathrm{c}$ & $56,8 \mathrm{c}$ & $42,2 \mathrm{~b}$ & $49,5 \mathrm{~b}$ \\
\hline G & $60,5 \mathrm{a}$ & $65,0 \mathrm{a}$ & $68,7 \mathrm{a}$ & $65,5 \mathrm{a}$ & 69,1 a \\
\hline FG & $63,5 \mathrm{a}$ & $63,4 \mathrm{a}$ & $70,7 \mathrm{ab}$ & $65,4 \mathrm{a}$ & $68,9 \mathrm{a}$ \\
\hline e & $61,5 \mathrm{a}$ & $54,6 \mathrm{~b}$ & $63,4 \mathrm{~b}$ & $61,4 \mathrm{a}$ & $64,6 \mathrm{a}$ \\
\hline e.V. $(\%)$ & & & & & \\
\hline
\end{tabular}

(1) Médias seguidas da mesma letra, dentro de cada nutriente, dentro de cada solo, não diferem estatisticamente pelo teste de Tukey a $5 \%$. 
Embora nas condições do presente experimento o carbonato de cálcio tenha tido o mesmo efeito que o gesso em permitir maior absorção de $\mathrm{N}$ do subsolo pelas raízes, em condições de campo pode-se esperar um efeito superior do gesso, visto que o cálcio do calcário se move mais lentamente no perfil por perder o seu ânion acompanhante, na forma de $\mathrm{C}_{2}$. Assim, CARVALHO et al. (1986), SOUZA \& RITCHEY (1986) e SOUZA et al. (1992) mostraram os resultados de experimentos de campo em que a aplicação de gesso em solos do cerrado proporcionou melhor aprofundamento do sistema radicular de milho, trigo, soja, sorgo e leucena, resultando

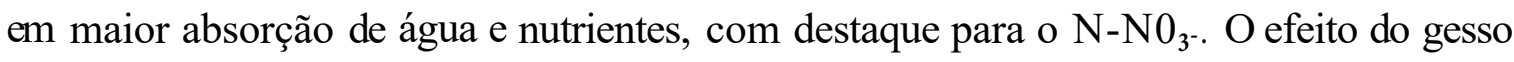
foi mais pronunciado quando as plantas eram submetidas a um determinado período de déficit hídrico. 


\section{CONCLUSÕES}

a) As amostras dos subsolos estudadas apresentaram severas restrições ao desenvolvimento radicular das plantas de milho devido à deficiência de cálcio e/ou toxicidade do alumínio.

b) O sulfato de cálcio e o fosfogesso alteraram de forma similar a reação do solo, aumentando o $\mathrm{pH}$ e reduzindo o alumínio trocável e a acidez potencial, embora em proporção menor do que o carbonato de cálcio.

c) O sulfato de cálcio e o fosfogesso proporcionaram condições adequadas ao desenvolvimento radicular nas amostras de subsolo dos cinco solos utilizados, propiciando maior absorção de água, nitrogênio e potássio e resultando em maior produção de matéria seca.

d) $\mathrm{O}$ fosfogesso mostrou ser um bom corretivo para solos que contém $\mathrm{Al}^{3+}$ trocável e/ou apresentam deficiência de cálcio na subsuperfície. 


\section{REFERÊNCIAS BIBLIOGRÁFICAS}

ADAMS, F. Crop response to lime in the Southem United States. In: ADAMS, F., ed. Soil acidity and liming. 2.ed. Madison, ASA, 1984. p. 212-66.

ADAMS, F. \& LUND, Z.F. Effect of chemical activity of soil solution aluminum on cotton root penetration of acid subsoils. Soil Science, Baltimore, 101(3): 193-8, 1966.

ADRIANO, D.C. \& DONNER, H.E. Bromine, chlorine, and fluorine. In: PAGE, A.L.; MILLER, R.H.; KEENEY, D.R. ed. Methods of soil analysis. 2.ed. Madison, ASA, 1982. p. 449-83. (Agronomy, 9).

ALCORDO, I.S. \& RECHCIGL, J.E. Phosphogypsum in agriculture: A review. Advances in Agronomy, New York, 49: 55-119, 1993.

ALLEONI, L.R.F. Atributos eletroquímicos de solos ácricos do norte paulista. Piracicaba, 1992. 123p. (M.S. - Escola Superior de Agricultura "Luiz de Queiroz"/USP).

ALVA, A.K. \& SUMNER, M.E. Alleviation of aluminum toxicity to soybeans by phosphogypsum or calcium sulfate in dilute nutrient solutions. Soil Science, Baltimore, 147(4): 278-85, 1989. 
ALVA, A.K. \& SUMNER, M.E. Amelioration of acid soil infertility by phosphogypsum. Plant and Soil, The Hague, 128(2): 127-34, 1990.

ALVA, A.K.; ASHER, C.J.; EDWARDS, D.G. The role of calcium in alleviating aluminium toxicity. AustralianJournal of Agricultural Researcb, East Melbourne, 37(4): 375-82, 1986a.

ALVA, A.K.; SUMNER, M.E.; MILLER, W.P. Reactions ofgypsum orphosphogypsum in highly weathered acid subsoils. Soil Science Society of America Journal, Madison, 54(4): 993-8, 1990.

ALVA, A.K.; SUMNER, M.E.; MILLER, W.P. Salt absorption in gypsum amended acid soils. In: WRIGHT, R.J.; BALIGAR, V.C.; MURRMAN, R.P., ed. Plant-soil interactions at low pH. Dordrecht, Kluwer Academic Publ., 1991. p. 93-7.

ALVA, A.K.; SUMNER, M.E.; NOBLE, A.D. Alleviation of aluminum toxicity by phosphogypsum. Communications in Soil Science and Plant Analysis, New York, 19(4): 385-403, 1988.

ALVA, A.K.; EDWARDS, D.G.; ASHER, C.J. BLAMEY, F.P. An evaluation of aluminum índices to predict aluminum toxicity to plant growth in nutrient solutions. Communications in Soil Science and Plant Analysis., New York, 17: 1271-80, 1986b.

ALVA, A.K.; EDWARDS, D.G.; ASHER, CJ.; BLAMEY, F.P.C. Effects of phosphorus/aluminum molar ratio and calcium concentration on plant response to aluminum toxicity. SoilScienceSociety of AmericaJournal, Madison, 50(1): 133-7, 1986c. 
ALVA, A.K.; EDWARDS, D.G.; ASHER, CJ.; BLAMEY, F.P.C. Relationships between root lenght of soybean and calculated activities of aluminum monomers in nutrient solution. Soil Science Society of America Journal, Madison, 50(4): 959-62, 1986d.

ANDRADE, J.C. de.; FRIGETTO; S.R.; BACCAN, N.; CANTARELLA, H.; BATAGLIA, O.e. Determinação turbidimétrica de sulfato em solos mediante análise por injeção em fluxo. Revista Brasileira de Ciência do Solo, Campinas, 14(1): 11924, 1990.

BATAGLIA, O.e.; FURLANI, A.M.C.; TEIXEIRA, J.P.F.; FURLANI, P.R.; GALLO, J.R. Métodos de análise química de plantas. Campinas, IAC, 1983. 48p. (Boletim Técnico, 78).

BLACK, A.S. \& CAMERON, K.C. Effect of leaching on soil properties and lucerne growth following lime and gypsum amendments to a soil with an acid subsoil. New ZealandJournal of Agricultural Research, Wellington, 27(2): 195-200, 1984.

BLAMEY, F.P.C.; EDWARDS, D.G.; ASHER, C.J. Effects of aluminum, OH:Al and $\mathrm{P}$ :Al molar ratios, and ionic strength on soybeans root elongation in solution culture. Soil Science, Baltimore, 136(4): 197-207, 1983.

BREMNER, J.M. \& KEENEY, D.A. Determination and isotope-ratio analysis of different forms of nitrogen in soils. 3. Exchangeable ammonium, nitrate and nitrite by extraction-destillation methods. Soil Science Society of America Proceedings, Madison, 30: 577-82, 1966. 
BRENES, E. \& PEARSON, R.W. Root response of three graminae species to soil acidity in an oxisol and ultisol. Soil Science, Baltimore, 116(4):295-302, 1973.

CAMARGO, O.A. \& FURLANI, P.R. Alumínio no solo: concentração, especiação e efeito no desenvolvimento radicular. In: SIMPÓSIO AVANÇADO DE SOLOS E NUTRIÇÃO DE PLANTAS, 2., Piracicaba, 1989. · Anais. Campinas, Fundação Cargill, 1989. p. 45-69.

CAMARGO, O.A. \& RAIJ, B. van. Movimento do gesso em amostras de latossolos com diferentes propriedades eletroquímicas. Revista Brasileira de Ciência do Solo, Campinas, 13(3): 275-80, 1989.

CAMERON, R.S.; RITCHIE, G.S.P.; ROBSON, A.D. Relative toxicities of inorganic aluminum complexes to barley. Soil Science Society of America Journal, Madison, 50(5): 1231-6, 1986.

CARVALHO, L.J.C.B.; GOMIDE, R.L.; RODRIGUES, G.C.; SOUZA, D.M.G.; FREITAS Jr, E. de. Resposta de milho à aplicação de gesso e déficit hídrico em solos de cerrado. In: SEMINÁRIO SOBRE O USO DO FOSFOGESSO NA AGRICULTURA, 1., Brasília, 1986. Anais. Brasília, EMBRAPA-DDT, 1986. p. 61-3.

CHAVES, J.C.D.; PAVAN, M.A.; MIYAZAWA, M. Redução da acidez subsuperficial em coluna de solo. Pesquisa Agropecuária Brasileira, Brasília, 46: 447-53, 1988.

CHAVES, J.C.D.; PAVAN, M.A.; MIYAZAWA, M. Especiação química da solução do solo para interpretação da absorção de cálcio e alumínio por raízes de cafeeiro. Pesquisa Agropecuária Brasileira, Brasília, 26(3): 447-53, 1991. 
COSTA, M.P. Efeitos da matéria orgânica em alguns atributos do solo. Piracicaba, 1983. 173p. (M.S. - Escola Superior de Agricultura "Luiz de Queiroz"/USP).

COUTO, W.; LATHWELL, D.J.; BOULDIN, D.R. Sulfate sorption by two oxisols and an alfisol of the tropics. Soil Science, Baltimore, 127(2): 108-16, 1979.

CURTINS, D. \& SYERS, J.K. Extractability and adsorption of sulphate in soils. Journal of Soil Science, Oxford, 41: 305-12, 1990.

DEMATTÊ, J.L.I. Characteristics of Brazilian soil related to root growth. $\ln$ : RUSSEL, R.S.; IGUE, K.; MEHTA, Y.R., ed. The soil root system in relation to Brazilian agriculture. Londrina, IAPAR, 1981. p. 21-41.

DEMATTÊ, J.L.I. Aptidão agrícola de solos e uso do gesso. ln: SEMINÁRIO SOBRE O USO DE GESSO NA AGRICULTURA, 2., Uberaba, 1992. Anais. Uberaba, IBRAFOS, 1992. p. 307-24.

DONNER, H.E. \& LYNN, W.C. Carbonate, halide, sulphte and sulfide minerais. In: DIXON, J.B.; WEED, S.B.; KITTRICK, J.A.; MILFORD, M.H.; WHITE, J.L., ed. Minerais in soil environment. Madison, ASA, 1977. p. 75-98.

FARINA, M.P.W. \& CHANNON, P. Acid-subsoil amelioration. I. A comparison of several mechanical procedures. Soil Science Society of America Journal, Madison, 52(1): 169-75, 1988a.

FARINA, M.P.W. \& CHANNON, P. Acid-subsoil amelioration. II. Gypsum effects on growth and subsoil chemical properties. Soil Science Society of America Journal, Madison, 52(1): 175-80, $1988 b$. 
FOY, C.D. Physiological effects of hidrogen, aluminum and manganese toxicities in acid soils. In: ADAMS, F., ed. Soil acidity and liming. 2.ed. Madison, ASA, 1984. p. $57-98$.

FREITAS, B.J. de. A disposição do fosfogesso e seus impactos ambientais. ln: SEMINÁRIO SOBRE O USO DE GESSO NA AGRICULTURA, 2., Uberaba, 1992. Anais. Uberaba, IBRAFOS, 1992. p. 325-39.

FURLANI, P.R. \& BERTON, R.S. Atividade de cálcio e alumínio e desenvolvimento radicular. ln: SEMINÁRIO SOBRE O USO DO GESSO NA AGRICULTURA, 2., Uberaba, 1992. Anais. Uberaba, IBRAFOS, 1992. p. 121-38.

GILLMAN, G.P. The chemical properties of acid soils with enphasis on soils of the humic tropics. In: WRIGHT, R.J.; BALIGAR, V.C.; MURRMAN, R.P., ed. Plant-soil interactions at low pH. Dordrecht, Kluwer Academic Publ., 1991. p. 509-17.

GOMES, F.P. A estatística moderna na agropecuária. 2.ed. Piracicaba, POTAFOS, 1985. 162p.

GONZALEZ-ERICO, E.; KAMPRATH, E.J.; NADERMAN, G.C.; SOARES, W.V. Effect of depth of lime incorporation on the growth of com on an Oxisol of Central Brazil. Soil Science Society of America Journal, Madison, 43(6): 1155-8, 1979.

HUE, N.V.; ADAMS, F.; EVANS, C.E. Sulfate retention by an acid BE horizon of an ultisol. Soil Science Society of America Journal, Madison, 49: 1196-1200, 1985. 
HUE, N.V.; CRADDOCK, G.A.; ADAMS, F. Effect of organic acids on aluminium toxicity in subsoils. Soil Science Society of America Journal, Madison, 50(1): 2834, 1986.

ISMAIL, H.; SHAMSHUDDIN, N.; SYED OMAR, S.R. Alleviation of soil acidity in Ultisol and Oxisol for com growth. Plant and Soil, The Hague, 151(1): 55-65, 1993.

JUCKSCH, I. Calagem e dispersão de argila em amostra de um latossolo vermelho escuro. Viçosa, 1987. 37p. (M.S. - Universidade Federal de Viçosa)

KHASAWNEH, F.E. Solution ion activity and plant growth. Soil Science Society of America Proceedings, Madison, 35: 426-36, 1971.

KEERTHISINGHE, G.; McLAUGHLIN, M.J.; FRENEY, J.R. Use of gypsum, phosphogypsum and fluoride to ameliorate subsurface acidity in a pasture soil. ln: WRIGHT, R.J.; BALIGAR, V.C.; MURRMAN, R.P., ed. Plant-soil interactions at low pH. Dordrecht, Kluwer Academic Publ., 1991. p. 509-17.

KIEHL, J.C. \& FRANCO, O. O efeito do gesso industrial sobre alguns componentes da fertilidade do solo. O Solo, Piracicaba, 76(1): 11-6, 1984.

KINRAIDE, T.B. \& PARKER, D.R. Non-phytotoxicity of the aluminum sulfate AlS04+. Physiologia Plantarum, Copenhagen, 71(2): 207-12, 1987.

LINDSAY, W. L. Chemical equilibria in soils. New York, John Wiley \& Sons, 1979. 449 . 
LOPES, A.S. Solos sob "cerrado"; características, propriedades e manejo. Piracicaba, POTAFOS, 1983. 162p.

MALAVOLTA, E. O gesso agrícola no ambiente e na nutrição da planta - perguntas e respostas. In: SEMINÁRIO SOBRE O USO DE GESSO NA AGRICULTURA, 2., Uberaba, 1992. Anais. Uberaba, IBRAFOS, 1992. p. 41-66.

MALAVOLTA, E.; DANTAS, J.P.; MORIAS, R.S.; NOGUEIRA, F.D. Calcium problem in Latin America. Communications in Soil Science and Plant Analysis, New York, 10(1): 29-40, 1979.

MALAVOLTA, E.; VITTI, G.C.; OLIVEIRA, S.A. de. Avaliação do estado nutricional das plantas; princípios e aplicações. Piracicaba, POTAFOS, 1989. 201p.

MARCANO-MARTINEZ, E. \& McBRIDE, M.B. Calcium and sulfate retention by two oxisols of the Brazilian cerrado. Soil Science Society of America Journal, Madison, 53(1): 63-9, 1989.

McLAY, C.D.A. \& RITCHIE, G.S.P. Effect of gypsum on wheat growth in pots containing an acidic subsoil. $\ln$ : INTERNATIONAL PLANT NUTRITION COLLOQIUM, 12., Perth, 1993. Plant nutrition: from genetic engineering to field practice. Dordrecht, Kluwer Academic Publ., 1993. p. 747-50.

MENGEL, K. \& KIRKBY, E.A. Principies of plant nutrition. 3.ed. Bem, Intemational Potash Institute, 1982. 655p. 
MESSICK, D.L.; ALLEY, M.M.; ZELAZNY, L.W. Movement of calcium and magnesium in ultissols from dolomitic limestone. Soil Science Society of America Journal, Madison, 48: 1096-101, 1984.

MOORE, C.S. \& RITCHIE, G.S.P. Aluminium speciation and $\mathrm{pH}$ of an acid soil in the presence of fluoride. Journal of Soil Science, Oxford, 39(1): 1-8, 1988.

NOBLE, A.D.; FEY, M.V.; SUMNER, M.E. Calcium-aluminum balance and growth of soybean roots in nutrient solutions. Soil Science Society of America Journal, Madison, 52(6): 1651-6, 1988a.

NOBLE, A.D.; SUMNER, M.E.; ALVA, A.K. The pH dependency of aluminum phytotoxicity alleviation by calcium sulfate. Soil Science Society of America Journal, Madison, 52(5): 1398-402, 1988 b.

NOGUEIRA, A.R.A. \& MOZETO, A.A. Interações químicas do sulfato e carbonato de cálcio em solos paulistas sob vegetação de cerrado. Revista Brasileira de Ciência do Solo, Campinas, 14(1): 1-6, 1990.

OATES, K.M. \& CALDWELL, A.G. Use of by product gypsum to alleviate soil acidity. Soil Science Society of Americn Journal, Madison, 49(4): 915-8, 1985.

OLIVEIRA, J.B. de \& PRADO, H. do. Levantamento pedológico semidetalhado solos do Estado de São Paulo; quadrícula de Ribeirão Preto. Campinas, IAC, 1987. 133p. (Boletim Científico, 7). 
OLIVEIRA, J.B. de; MENK, J.R.F.; ROTIA, C.L. Levantamento pedológico semidetalhado dos solos do Estado de São Paulo; quadrícula de Campinas. Rio de Janeiro, IBGE, 1979. 172p. (Recursos Naturais e Ambiente, 6).

OLMOS, J.L.J. \& CAMARGO, M.N. Ocorrência de alumínio tóxico nos solos do Brasil, sua caracterização e distribuição: Ciência e Cultura, Rio de Janeiro, 28(2): 171-80, 1976.

PAOLINELLI, N.T.; OLIVEIRA, P.M.; SANTOS, P.R.R.S.; LEANDRO, V.P.; MORAES, W.V. Aplicação direta do fosfogesso. ln: SEMINÁRIO SOBRE O USO DO FOSFOGESSO NA AGRICULTURA, 1., Brasília, 1986. Anais. Brasília, EMBRAPA-DDT, 1986. p. 197-217.

PARKER, D.R.; KINRAIDE, T.B.; ZELAZNY, L.W. Aluminum speciation and phytotoxicity in dilute hidroxy-aluminum solutions. Soil Science Society of America Journal, Madison, 52(2): 438-44, 1988.

PAVAN, M.A. Effect of so/--salts on exchangeable aluminum. Ciência e Cultura, Rio de Janeiro, 45(2): 123-26, 1993.

PAVAN, M.A. \& BINGHAM; F.T. Toxicity of aluminum to coffee seedlings grown in nutrient solution. Soil Science Socety of America Journal, Madison, 46(5): 993-7, 1982.

PAVAN, M.A. \& VOLKWEISS, S. Efeitos do gesso nas relações solo-planta: princípios. ln: SEMINÁRIO SOBRE O USO DO FOSFOGESSO NA AGRICULTURA, 1., Brasília, 1986. Anais. Brasília, EMBRAPA-DDT, 1986. p. 107-18. 
PAVAN, M.A.; BINGHAM, F.T.; PERYEA, F.J. Influence of calcium and magnesium salts and acid soil chemistry and calcium nutrition of apple. Soil Science Society of America Journal, Madison, 51(6): 1526-30, 1987.

PAVAN, M.A.; BINGHAM, F.T.; PRATT, P.F. Toxicity of aluminum to coffee in Ultisols and Oxisols amended with $\mathrm{CaCO}_{3}, \mathrm{MgCO}_{3}$ and $\mathrm{CaSO}_{4} \cdot 2 \mathrm{H}_{2} 0$. Soil Science Society of America Journal, Madison, 46(6): 1201-07, 1982.

PAVAN, M. A.; BINGHAM, F.T.; PRATT, P.F. Redistribution of exchangeable calcium, magnesium, and aluminum following lime or gypsum applications to a Brazilian Oxisol. Soil Science Society of America Journal, Madison, 48(1): 33-8, 1984.

PEARSON, R.G. Hard and soft acids and bases. Journal of the American Chemical Society, Washington, 85(22): 3533-9, 1963.

QUAGGIO, J.A. Resposta das culturas de milho e soja, à aplicação de calcário e gesso e movimento de íons em solos do Estado de São Paulo. In: SEMINÁRIO SOBRE O USO DE GESSO NA AGRICULTURA, 2., Uberaba, 1992. Anais. Uberaba, IBRAFOS, 1992. p. 341-62.

QUAGGIO, J.A.; MASCARENHAS, H.A.A.; BATAGLIA, 0.C. Respostas da soja à aplicação de doses crescentes de calcário em latossolo roxo distrófico do cerrado. IIEfeito residual. Revista Brasileira de Ciência do Solo, Campinas, 6(1): 113-8, 1982.

QUAGGIO, J.A.; RAMOS, V.J.; BATAGLIA, O.C.; RAIJ, Bvan.; SAKAI, M. Calagem para a sucessão batata-triticale-milho usando calcários com diferentes teores de magnésio. Revista Brasileira de Ciência do Solo, Campinas, 44(1):391-406, 1985. 
RAIJ, B. van. Propriedades eletroquímicas de solos. ln: SIMPÓSIO AVANÇADO DE QUÍMICA E FERTILIDADE DO SOLO, 1., Piracicaba, 1986. Anais Campinas, Fundação Cargill, 1986. p. 9-41.

RAU, B. van. Gesso agrícola na melhoria do ambiente radicular no subsolo. São Paulo, ANDA, 1988. 88p.

RAU, B. van. Fertilidade do solo e adubação. Piracicaba, POTAFOS, 1991. 343p.

RAIJ, B. van. Reações de gesso em solos ácidos. In: SEMINÁRIO SOBRE O USO DE GESSO NA AGRICULTURA, 2., Uberaba, 1992. Anais. Uberaba, IBRAFOS, 1992. p. 105-19.

RAIJ, B. van. \& PEECH, M. Eletrochemical properties of some oxisols and alfisols of the tropics. Soil Science Society of America Journal, Madison, 36(4): 587-97, 1972.

RAU, B. van. \& VALADARES, J.M.A.S. Análise dos elementos maiores de rochas, argilas e solos. Campinas, IAC, 1974. 23p. (Boletim Técnico, 16).

RAIJ, B. van; CANTARELLA, H.; FURLANI, P.R. Efeito na reação do solo, da absorção de amônio e nitrato pelo sorgo, ma presença e na ausência de gesso. Revista Brasileira de Ciência do Solo, Campinas, 12(2): 131-6, 1988.

RAIJ, B. van.; CANTARElla, H.; CAMARGO, A.P.; SOARES, E. Perdas de cálcio e magnésio durante cinco anos em ensaio de calagem. Revista Brasileira de Ciência do Solo, Campinas, 6(1): 33-7, 1982. 
RAIJ, B. van.; MASCARENHAS, H.A.A.; PEREIRA, J.C.V.N.A.; IGUE, T.; SORDI, G. de. Efeito de calcário e gesso para soja cultivada em latossolo roxo ácido saturado com sulfato. Revista Brasileira de Ciência do Solo, Campinas, 18: 305-12, 1994.

RAIJ, B. van.; QUAGGIO, J.A.; CANTARELLA, H.; FERREIRA, M.E.; LOPES, A.S.; BATAGLIA, O.C. Análise química do solo para fins de fertilidade. Campinas, Fundação Cargill, 1987. 170p.

REEVE, N.G. \& SUMNER, M.E. Amelioration of subsoils acidity in Natal Oxisols by leaching surface applied amendments. Agrochemophysica, Pretoria, 4(1): 1-6, 1972.

RHOADES, J.R. Soluble salts. In: PAGE, A.L.; MILLER, R.H.; KEENEY, D.R. ed. Methods of soil analysis. 2.ed. Madison, ASA, 1982. p. 167-79. (Agronomy, 9).

RIOS, M.A. \& PEARSON, R.W. The effect of some chemical environment factors on cotton root behavior. Soil Science Society of America Proceedings, Madison, 28(2): 232-5, 1964.

RITCHEY, K.D.; SILVA, J.E.; COSTA, U.F. Calcium deficiency in clayey B horizonts of savannah Oxisols. Soil Science, Baltimore, 133(6): 378-82, 1982.

RITCHEY, K.D; SILVA, J.E.; SOUSA, D.M.G. Relação entre teor de cálcio e desenvolvimento de raízes avaliado por um método biológico. Revista Brasileira de Ciência do Solo, Campinas, 7(3): 269-75, 1983.

RITCHEY, K.D.; SOUZA, D.H.G.; LOBATO, E.; CORREA, O. Calcium leaching to increase rooting depth in a Brazilian Savannah Oxisol. Agronomy Journal, Madison, 72(1): 40-4, 1980. 
SEMINÁRIO SOBRE O USO DO FOSFOGESSO NA AGRICULTURA, 1., Brasília, 1986. Anais. Brasília, EMBRAPA-DDT, 1986. 298p.

SEMINÁRIO SOBRE O USO DO GESSO NA AGRICULTURA, 2., Uberaba, 1992. Anais. Uberaba, IBRAFOS, 1992. 414p.

SHAINBERG, J.; SUMMER, M.E.; MILLER, W.P.; FARINA, M.P.W.; PAVAN, M.A.; FEY, M.V. Use of gypsum on soils: a review. Advances in Soil Science, New York, 9: 1-111, 1989.

SHAMSHUDDIN,J.; CHEFAUZIAH, J.; SHARIFUDDIN, H.A.H. Effectsoflimestone and gypsum application to a Malaysian ultisol on soil solution composition and yields of maizeand groundnut. In: WRIGHT, R.J.; BALIGAR, V.C.; MURRMAN, R.P., ed. Plant soil interaction at low pH. Dordrecht, Kluwer Academic Publ., 1991. p. 501-8.

SHUMMAN, L.M.; RAMSEUR, E.L.; DUNCAN, R.R. Soil aluminum effects on the growth and aluminium concentration of sorghum. Agronomy Journal, Madison, 82(2): 313-8, 1990.

SILVA, N.M. \& RAIJ, B. van. O uso do gesso e do superfosfato simples na cultura do algodoeiro. In: SEMINÁRIO SOBRE O USO DO FOSFOGESSO NA AGRICULTURA, 2., Uberaba, 1992. Anais. Uberaba, IBRAFOS, 1992. p. 159-74.

SINGH, S.J. Effect of chloride and sulfate anions on the chemical characteristics of some acid soils. Canadian Journal of Soil Science, Otawa, 62(4): 549-57, 1982. 
SOUZA, D.M.G. de. \& RITCHEY, K.D. Uso de gesso no solo de cerrado. ln: SEMINÁRIO SOBRE O USO DO FOSFOGESSO NA AGRICULTURA, 1., Brasília, 1986. Anais. Brasília, EMBRAPA-DDT, 1986. p. 119-44.

SOUZA, D.M.G.; LOBATO, E.; RITCHEY, K.D.; REIN, T.A. Respostas de culturas anuais e leucena a gesso no cerrado. ln: SEMINÁRIO SOBRE O USO DO FOSFOGESSO NA AGRICULTURA, 2., Uberaba, 1992. Anais. Uberaba, IBRAFOS, 1992. p. 277-306.

SPOSITO, G. The thennodinamic of soil solution. Oxford, Clarendon Press, 1981. $223 p$.

SPOSITO, G. \&MATTIGOD, S.V. GEOCHEM: acomputerprogram forthecalculation of chemical equilibria in soil solutions and other natural water systems. Riverside, University of California, Kearney Foundation of Soil Science, 1980. 82p.

SUMNER, M.E. Uso atual do gesso no mundo em solos ácidos. ln: SEMINÁRIO SOBRE O USO DO FOSFOGESSO NA AGRICULTURA, 2., Uberaba, 1992. Anais. Uberaba, IBRAFOS, 1992. p. 7-40.

SUMNER, M.E. Gypsum and acid soils: The world scene. Advances in Agronomy, New York, 51: 1-32, 1993.

SUMNER, M.E. Measurement of soil pH: problems and solutions. Communications in Soil Science and Plant Analysis, New York, 25(7/8): 859-79, 1994. 
SUMNER, M.E.; SHAHANDEH, H.; BOUTON, J.; HAMMEL, J. Amelioration on acid soil profile through deep liming and surface application of gypsum. Soil Science Society of America Journal, Madison, 50(5): 1254-78, 1986.

TABATABAI, M.A. \& BREMNER, J.M. A simple turbidimetric method of determining total sulfur in plant materials. Agronomy Journal, Madison, 62(6): 805-6, 1970.

TENNANT, D. A test of a modified line intersect method of estimating root lenght. Journal of Ecology, London, 63(3): 995-1001, 1975.

UEHARA, G. \& GILLMAN, G. The mineralogy, chemistry and physics properties of tropical soil with variable charge clay. Boulder, Westview Press, 1981. 170p.

VITTI, G.C.; MAZZA, J.A.; PEREIRA, H.S.; DEMATTÊ, J.L.I. Resultados experimentais do uso de gesso na agricultura - cana-de-açúcar. ln: SEMINÁRIO SOBRE O USO DO FOSFOGESSO NA AGRICULTURA, 2., Uberaba, 1992. Anais. Uberaba, IBRAFOS, 1992. p. 191-224.

WRIGHT, R.J.; HERN, J.L.; BALIGAR, V.C.; BENNET, 0.L. The effects of surface applied amendments on barley root growth in an acid subsoil. Communications in Soil Science and Plant Analysis, New York, 16(2): 179-92, 1985. 
YAMADA, T. Capacidade de adsorção máxima de sulfato do solo como parâmetro adicional na recomendação do gesso. Piracicaba, 1988. 73p. (Doutorado -Escola Superior de Agricultura "Luiz de Queiroz"/USP).

ZHANG, G. Y.; ZHANG, X.N.; YU, T.R. Adsorption of sulphate and fluoride by variable charge soils. Journal of Soil Science, Oxford, 38(1): 29-38, 1987. 